UNIVERSIDADE DE SÃO PAULO

ESCOLA DE ENGENHARIA DE SÃO CARLOS

INSTITUTO DE FÍSICA DE SÃO CARLOS

INSTITUTO DE QUÍMICA DE SÃo CARLOS

\title{
ESTUDO DO ADESIVO POLIURETANO À \\ BASE DE MAMONA EM MADEIRA \\ LAMINADA COLADA (MLC)
}

\section{JOSÉ MANOEL HENRIQUES DE JESUS}

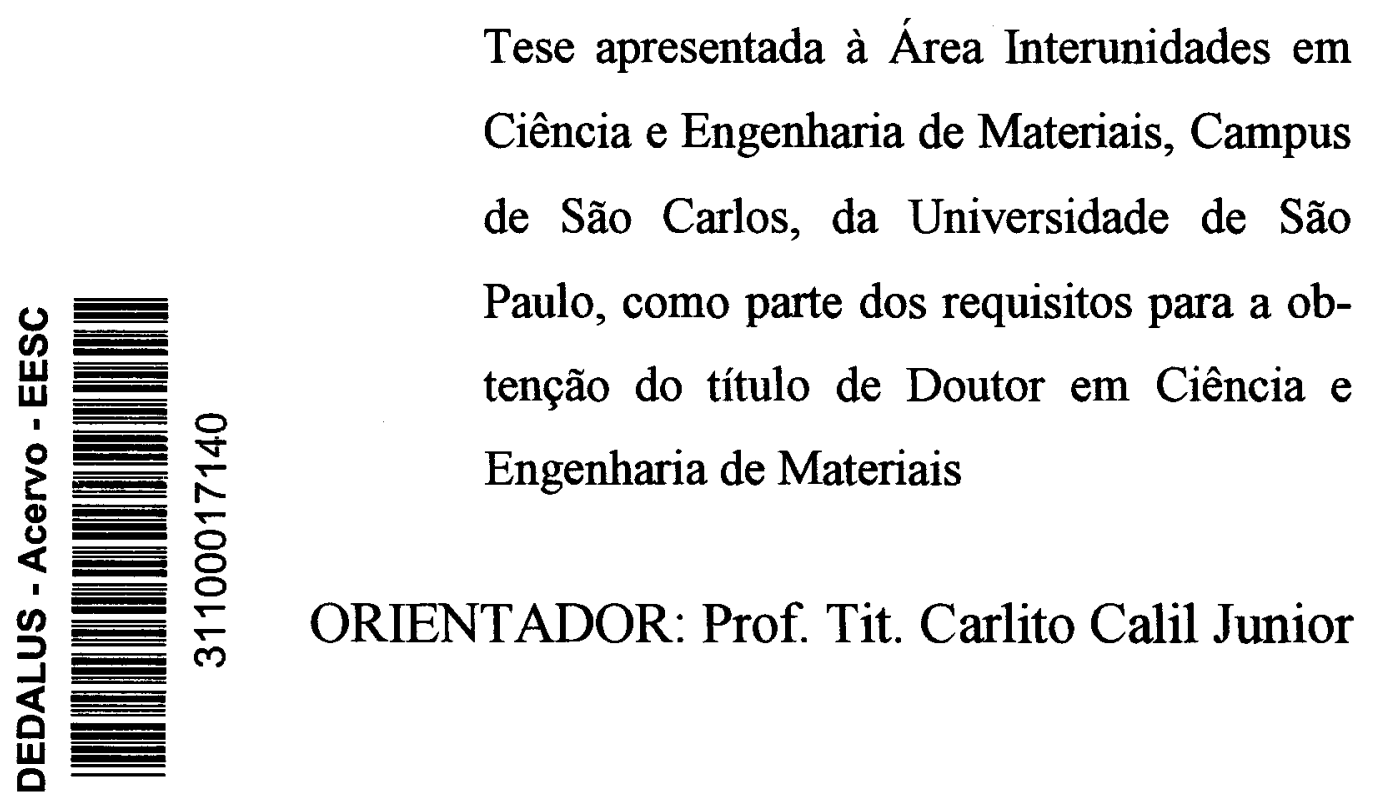

São Carlos

2000 
\begin{tabular}{|c|c|} 
Class. IES & EESC \\
Gutt. & 2631 \\
Tombo TO 20100
\end{tabular}

st $113 \% 20+$

Ficha catalográfica preparada pela Seçāo de Tratamento da Informação do Serviço de Biblioteca - EESC/USP

J58esus, José Manoel Henriques de

J58e Estudo do adesivo poliuretano à base de mamona em madeira laminada colada (MIC) / José Manoel Henriques de Jesus. -- Såo Carlos, 2000.

Tese (Doutorado) -- Escola de Engenharia de são Carlos/Instituto de Física de São Carlos/Instituto de Química de São Carlos-Universidade de São Paulo, 2000.

Área Interunidades: Ciência e Engenharia de Materiais.

orientador: Prof. Dr. Carlito Calil Junior.

1. Adesivo de mamona. 2. Parâmetros de colagem.

3. Madeira laminada colada. L. Título. 


\section{Ciência e Engenharia de Materiais}

MEMBROS DA COMISSÃO JULGADORA DA TESE DE DOUTORADO DE JOSÉ MANOEL HENRIQUES DE JESUS, APRESENTADA A ÁREA INTERUNIDADES EM CIÊNCIA E ENGENHARIA DE MATERIAIS, DA EESCIFSC-IQSC, UNIVERSIDADE DE SÃO PAULO, EM 03/05/2000.

COMISSÃO JULGADORA:

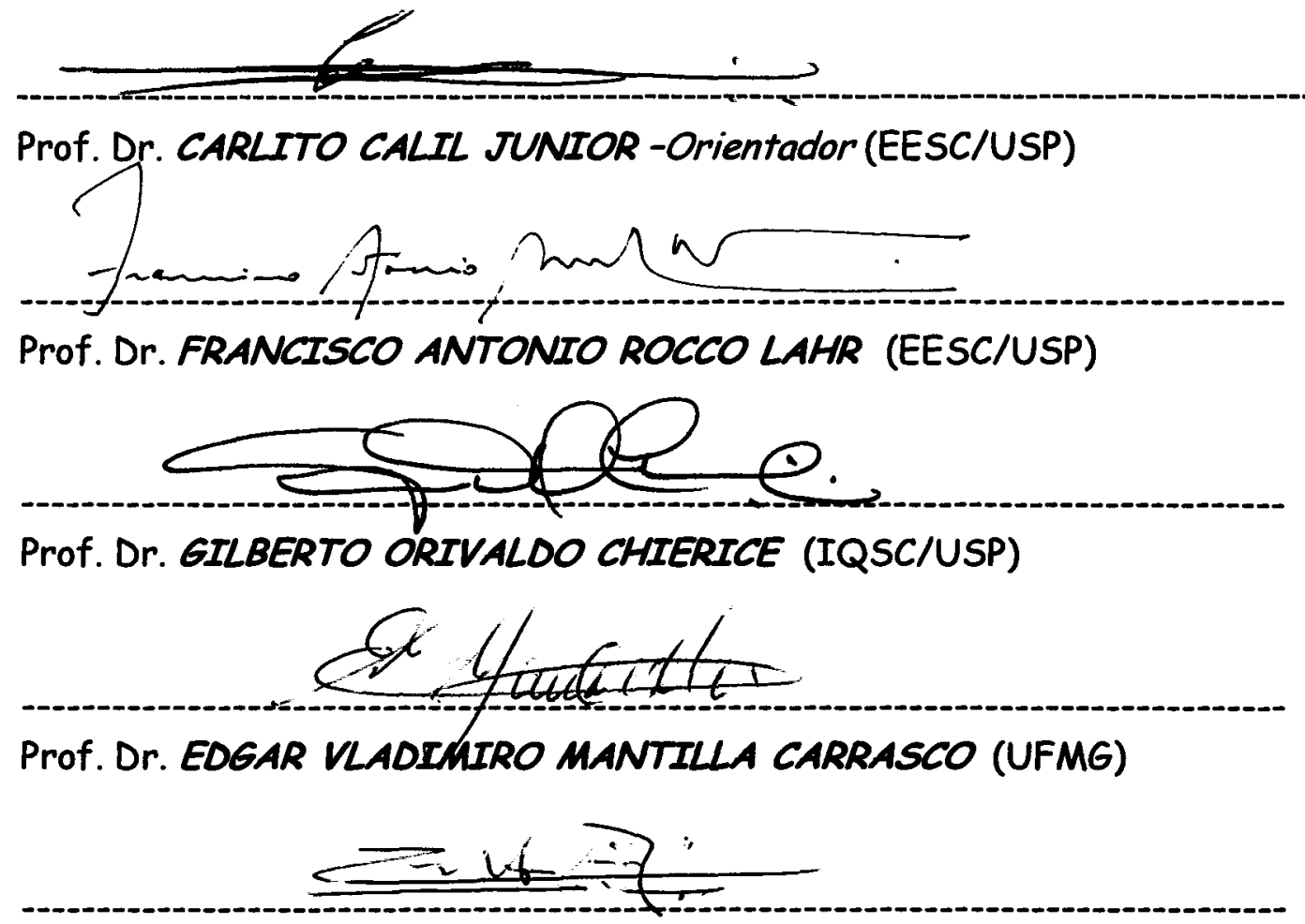

Prof. Dr. CARLOS ALBERTO SZÜCS (UFSC) 
À minha esposa Laerce e aos meus filhos Fábio, Bruna e Lucas perdão por todo o tempo que passamos afastados. Agradeço pelo enorme amor, paciência e compreensão. 


\section{AGRADECIMENTOS}

Um trabalho como este nunca é fruto de ação isolada e sim uma soma de esforços sinérgicos.

Ao professor Carlito Calil Júnior pela orientação segura e incansável durante a elaboração deste trabalho e pela sua amizade.

Aos professores Antonio Alves Dias, Francisco Antonio Rocco Lahr, Almir Sales, Gilberto Orivaldo Chierice, Salvador Claro Neto e Luiz Carlos pelo incentivo e amizade.

À Coordenadoria de Aperfeiçoamento de Pessoal de Nível Superior- Capes pela bolsa de estudos concedida.

Ao Horto Florestal de Itirapina, Instituto Florestal, Secretaria do Meio Ambiente do Estado de São Paulo, pela doação das espécies empregadas no trabalho.

À todos os funcionários e ex funcionários do LaMEM: Aparecido Galindo, Arnaldo, Roberto, Sílvio, Jaime, Tânia, Bragatto, Alemão e José Francisco pela apoio e agradável convívio durante o desenvolvimento dos trabalhos desta Tese.

À todos os funcionários do Laboratório de Química Analítica e Tecnologia de Polímeros do IQSC- USP pelo auxílio e preparação do poliol e do prepolímero empregados no trabalho.

À todos os colegas de pós graduação do LaMEM pelo auxílio, angústias e amizade compartilhados.

Aos amigos cuiabanos que juntos participamos deste curso e àqueles que deram apoio na condução do convênio, pela amizade e incentivo. 


\section{SUMÁRIO}

LISTA DE FIGURAS vii

LISTA DE TABELAS Cix

LISTA DE ABREVIATURAS E SIGLAS Xi

LISTA DE SÍMBOLOS Xii

RESUMO xiii

ABSTRACT Xiv

1 INTRODUÇÃO

2 ESTRUTURA DA MADEIRA 3

2.1 Aspectos da estrutura macroscópica da madeira 3

2.2 Aspectos da estrutura microscópica da madeira

2.3 Aspectos da estrutura molecular e ultraestrutura da madeira 9

2.3.1 Organização da parede celular 15

$\begin{array}{ll}2.3 .2 \text { Camadas da parede celular } & 18\end{array}$

2.4 Conclusões $\quad 21$

3 ADESIVOS E ADESÄO 22

3.1 Adesivos - Histórico 22 
3.2 Classificação dos adesivos

3.2.1 Adesivos inorgânicos 24

3.2.2 Adesivos orgânicos 24

3.2.2.1 Termofixos 25

$\begin{array}{ll}3.2 .2 .2 \text { Termoplásticos } & 27\end{array}$

3.3 Objeto do estudo - Adesivo poliuretano à base de mamona 30

$\begin{array}{ll}3.3 .1 \text { Obtenção do adesivo } & 30\end{array}$

3.4 Mecanismos de adesão $\quad 35$

$\begin{array}{ll}3.5 \text { Escolha do adesivo } & 37\end{array}$

3.6 Fatores que influenciam a ligação adesiva 40

3.7 Conclusões $\quad 41$

4 ENSAIOS PRELIMINARES

4.1 Espécies de madeira, adesivos, obtenção dos corpos-de-prova e condução dos ensaios $\quad 44$

$\begin{array}{ll}4.2 \text { Resultados } & 45\end{array}$

$\begin{array}{ll}4.3 \text { Conclusões preliminares } & 49\end{array}$

5 MATERLAIS E MÉTODOS

5.1 Materiais $\quad 51$

5.1.1 Essências florestais $\quad 51$

5.1.2 Adesivo $\quad 52$

5.1.3 Equipamentos

5.2 Métodos

5.2.1 Ensaios $\quad 53$

5.2.2 Dimensöes dos corpos-de-prova

5.2.2.1 Cisalhamento na lâmina de cola

5.2.2.2 Tração normal à lâmina de cola

5.2.2.3 Tração paralela de emendas dentadas coladas 56

5.2.3 Confecção dos corpos-de-prova $\quad 56$

5.2.3.1 Obtenção das peças para a confecção dos corpos-de-prova 56

5.2.3.2 Extração dos corpos-de-prova de cisalhamento

5.2.3.3 Extração dos corpos-de-prova de tração normal 58

5.2.3.4 Extração dos corpos-de-prova de tração paralela

$\begin{array}{lr}5.3 \text { Planejamento estatístico } & 59\end{array}$ 
6.1 Pinus caribea hondurensis

6.1.1 Resistência ao cisalhamento na lâmina de cola paralela às fibras $\left(f_{g v, d}\right)$

6.1.2 Resistência da lâmina de cola à tração normal $\left(f_{g t, 90}\right)$

6.1.3 Resistência da emenda dentada colada (finger joint) à tração paralela às fibras $\left(f_{g t, 0}\right)$

6.1.4 Tempo de Cura

6.2 Eucaliptus grandis

6.2.1 Resistência ao cisalhamento na lâmina de cola paralela às fibras $\left(f_{g v}, 0\right)$ 76

6.2.2 Resistência da lâmina de cola à tração normal $\left(f_{g t, 90}\right)$

6.2.3 Resistência da emenda dentada colada (finger joint) à tração paralela às fibras $\left(f_{g t, 0}\right)$

6.2.4 Tempo de Cura

6.3 Análise dos coeficientes de variação 


\section{LISTA DE FIGURAS}

FIGURA 1- Seção transversal de um tronco

FIGURA 2- Esquema de crescimento de uma árvore 5

$\begin{array}{lr}\text { FIGURA 3- Estrutura celular da madeira } & \mathbf{8}\end{array}$

FIGURA 4- Molécula de celulose 11

FIGURA 5- Ligações intramolecular e intermolecular 11

FIGURA 6- Cela unitária da celulose 12

FIGURA 7- Açúcares que compõem as hemiceluloses (polioses) 13

FIGURA 8- Modelo para a lignina de uma conífera e de uma folhosa, respectivamente $\quad 14$

FIGURA 9- Localização dos elementos que compõem a parede celular 16

FIGURA 10- Seção longitudinal hipotética de uma fibrila elementar 16

FIGURA 11- Modelo da seção transversal de uma microfibrila 17

$\begin{array}{ll}\text { FIGURA 12- Estrutura da parede celular } & 18\end{array}$

FIGURA 13- Disposição e ângulo das microfibrilas nas paredes celulares 19

FIGURA 14- Distribuição dos componentes químicos em uma parede celular 20

FIGURA 15- Rota de preparação de poliuretanas monocomponentes 31

FIGURA 16- Rota de preparação de poliuretanas bicomponentes 31

FIGURA 17- Triglicéride do ácido recinoleico 32

FIGURA 18- Ângulo de contato 38

FIGURA 19- Obtenção dos corpos-de-prova de cisalhamento 45

FIGURA 20-Pinus elliottii- resistência ao cisalhamento 46

FIGURA 21- Eucaliptus grandis- resistência ao cisalhamento 47

FIGURA 22- Ipê- resistência ao cisalhamento 48

FIGURA 23- Jatobá- resistência ao cisalhamento 49

FIGURA 24- Corpo-de-prova de cisalhamento na lâmina de cola 55

FIGURA 25- Corpo-de-prova de tração normal à lâmina de cola 55

FIGURA 26- Corpo-de-prova de tração paralela de emendas dentadas coladas na lâmina de cola 56

FIGURA 27-Obtenção das vigas e das peças destinadas à confecção dos corpos-de-prova $\quad 57$

FIGURA 28-Obtenção dos corpo-de-prova de cisalhamento 58

FIGURA 29- Obtenção dos corpo-de-prova de tração normal 58

FIGURA 30- Obtenção dos corpo-de-prova de tração paralela 59

FIGURA 31 - Cisalhamento- Valores médios dos resultados das combinações e dos corpos-de-prova maciços de controle- Pinus caribea hondurensis 
FIGURA 32- Forma de ruptura- Cisalhamento- Pinus caribea hondurensis

FIGURA 33- Efeitos $x$ Escores normais- Cisalhamento- Pinus caribea hondurensis

FIGURA 34- Tração normal- Valores médios dos resultados das combinações e dos corpos-de-prova maciços de controle- Pinus caribea hondurensis

FIGURA 35- Forma de ruptura- Tração normal- Pinus caribea hondurensis

FIGURA 36- Efeitos x Escores normais- Tração normal- Pinus caribea hondurensis

FIGURA 37-Tração paralela- Valores médios dos resultados das combinações e dos corpos-de-prova maciços de controle-Pinus caribea hondurensis

FIGURA 38- Formas de ruptura- Tração paralela

FIGURA 39- Efeitos x Escores normais- Tração paralela- Pinus caribea hondurensis

FIGURA 40- Tempo de cura- Valores médios dos resultados dos ensaios- Pinus caribea hondurensis

FIGURA 41- Cisalhamento- Valores médios dos resultados das combinações e dos corpos-de-prova maciços de controle- Eucaliptus grandis

FIGURA 42- Forma de ruptura- Cisalhamento- Eucaliptus grandis

FIGURA 43- Efeitos x Escores normais- Cisalhamento- Eucaliptus grandis

FIGURA 44- Tração normal- Valores médios dos resultados das combinações e dos corpos-de-prova maciços de controle- Eucaliptus grandis

FIGURA 45- Forma de ruptura- Tração normal- Eucaliptus grandis

FIGURA 46- Efeitos x Escores normais- Tração normal- Eucaliptus grandis

FIGURA 47-Tração paralela- Valores médios dos resultados das combinações e dos corpos-de-prova maciços de controle- Pinus caribea hondurensis

FIGURA 48- Formas de ruptura- Tração paralela

FIGURA 49- Efeitos x Escores normais- Tração paralela- Eucaliptus grandis

FIGURA 50- Tempo de cura- Valores médios dos resultados dos ensaios-Eucaliptus grandis 


\section{LISTA DE TABELAS}

$\begin{array}{ll}\text { TABELA 1- Composição química da madeira } & 10\end{array}$

TABELA 2- Tipos de adesivos usos e condições $\quad 42$

TABELA 3- Matriz de planejamento fatorial do tipo $3^{3}$ - Ensaios de cisalhamento e tração normal na lâmina de cola

TABELA 4- Matriz de planejamento fatorial do tipo $3^{2}$ - Ensaio de tração paralela de emendas dentadas coladas

TABELA 5- Resistência ao cisalhamento- Pinus caribea hondurensis

TABELA 6- Efeitos significativos das variáveis e sua iterações-Cisalhamento-Pinus caribea hondurensis

TABELA 7-Intervalo de confiança a 95\%-Cisalhamento-Pinus caribea hondurensis

TABELA 8- Resistência à tração normal- Pinus caribea hondurensis

TABELA 9- Efeitos significativos das variáveis e sua iterações- Tração normalPinus caribea hondurensis

TABELA 10-Intervalo de confiança a 95\%- Tração normal- Pinus caribea hondurensis

TABELA 11- Resistência à tração paralela (finger joint)-Pinus caribea hondurensis

TABELA 12- Forma de ruptura- Tração paralela- Pinus caribea hondurensis

TABELA 13- Efeitos significativos das variáveis e sua iterações- Tração paralelaPinus caribea hondurensis

TABELA 14 - Intervalo de confiança a 95\%- Tração paralela- Pinus caribea hondurensis

TABELA 15- Tempo de cura- Cisalhamento-Pinus caribea hondurensis (combinação: $3 ; 4 ; 0,4)$

TABELA 16- Tempo de cura- Tração normal- Pinus caribea hondurensis (combinação: $6 ; 6 ; 0,6$ )

TABELA 17- Tempo de cura- Tração paralela- Pinus caribea hondurensis (combinação: $0 ; 9,0$ )

TABELA 18- Resistência ao cisalhamento- Eucaliptus grandis

TABELA 19- Efeitos significativos das variáveis e sua iterações-CisalhamentoEucaliptus grandis

TABELA 20- Intervalo de confiança a 95\%-Cisalhamento-Eucaliptus grandis

TABELA 21- Resistência à tração normal- Eucaliptus grandis

TABELA 22- Efeitos significativos das variáveis e sua iterações- Tração normalEucaliptus grandis

TABELA 23- Intervalo de confiança a 95\%- Tração normal- Eucaliptus grandis

TABELA 24- Resistência à tração paralela (finger joint)-Eucaliptus grandis

TABELA 25- Forma de ruptura- Tração paralela- Eucaliptus grandis

TABELA 28- Tempo de cura- Cisalhamento- Eucaliptus grandis 
TABELA 29- Tempo de cura- Tração normal- Eucaliptus grandis (combinação: $3 ; 4 ; 0,6$ )

TABELA 30- Tempo de cura-Tração paralela-Eucaliptus grandis (combinação: $6 ; 10,0$ )

TABELA 31- Coeficientes de variação- Cisalhamento e Tração normal- Pinus caribea hondurensis

TABELA 32- Coeficientes de variação- Tração paralela- Pinus caribea hondurensis

TABELA 33- Coeficientes de variação- Cisalhamento e Tração normal- Eucaliptus grandis

TABELA 34- Coeficientes de variação- Tração paralela - Eucaliptus grandis

TABELA 35- Parâmetros de colagem- viscosidade, tempo de pressão e pressão

TABELA 36- Relação percentual entre as resistências dos corpos-de-prova colados e dos corpos-de-prova de controle

TABELA 37- Tempo de cura

TABELA 38- Efeitos mais significativos das variáveis e sua iterações 


\section{LISTA DE SIGLAS E ABREVIATURAS}

$\begin{array}{ll}\text { CEN } & \text { European Comittee for Standardization } \\ \text { DIN } & \text { Deusche Institüt für Nurmung } \\ \text { GQATP } & \text { Grupo de Química Analítica e Tecnologia de Polímeros } \\ \text { LaMEM } & \text { Laboratório de Madeiras e de Estruturas de Madeiras } \\ \text { MLC } & \text { Madeira Laminada Colada } \\ \text { PU } & \text { Resina poliuretana } \\ \text { IFQSC } & \text { Instituto de Física e Química de São Carlos } \\ \text { IQSC } & \text { Instituto de Química de São Carlos } \\ \text { USP } & \text { Universidade de São Paulo }\end{array}$




\section{LISTA DE SÍMBOLOS}

\begin{tabular}{|c|c|}
\hline$f_{g v, 0}$ & resistência ao cisalhamento na lâmina de cola paralelo às fibras \\
\hline$f_{g t, 90}$ & resistência da lâmina de cola à tração normal às fibras \\
\hline$f_{g t, 0}$ & resistência da emenda dentada à tração paralela às fibras \\
\hline $\bar{x}$ & média \\
\hline$s d$ & desvio padrão \\
\hline$c v$ & coeficiente de variação \\
\hline$\rho$ & densidade aparente \\
\hline$V$ & viscosidade \\
\hline$T p$ & tempo de pressão de colagem \\
\hline$P$ & pressão de colagem \\
\hline Tc & tempo de cura \\
\hline$A v$ & área resistente ao cisalhamento \\
\hline$P$ & parede primária \\
\hline$L M$ & lamela média \\
\hline$C L M$ & composto lamela média \\
\hline$S$ & parede secundária \\
\hline$S_{1}, S_{2}, S_{3}$ & camadas que compõem a parede secundária \\
\hline$L$ & direção axial da madeira \\
\hline$T$ & direção tangencial da madeira \\
\hline$R$ & direção radial da madeira \\
\hline$U$ & umidade da madeira \\
\hline
\end{tabular}




\section{RESUMO}

JESUS, J.M.H. (2000). Estudo do adesivo poliuretano à base de mamona em madeira laminada colada (MLC). São Carlos, 2000. 109p. Tese (Doutorado) - Área Interunidades, Escola de Engenharia de São Carlos, Instituto de Física de São Carlos, Instituto de Química de São Carlos, Universidade de São Paulo.

Este trabalho tem por finalidade, o estudo do comportamento do adesivo poliuretano à base de mamona para o emprego em madeira laminada colada (MLC). A eficiência do adesivo foi avaliada através da resistência dos seguintes ensaios mecânicos: cisalhamento, tração normal e tração paralela às fibras. Os ensaios seguiram as recomendações da norma brasileira NBR 7190/97 "Projeto de estruturas de madeiras" e por meio de seus resultados foram determinados os parâmetros de colagem como: viscosidade (V), tempo de pressão de colagem (Tp), pressão de colagem (P) e tempo de cura (Tc) e avaliadas as influências dessas variáveis e de suas iterações sobre as resistências. Duas espécies de madeira foram empregadas: o Pinus caribea hondurensis e o Eucaliptus grandis, geralmente empregadas em reflorestamento nas regiões Sul e Sudeste do Brasil, onde estão localizadas as indústrias de MLC. O adesivo estudado é do tipo bicomponente, o poliol B1640 e o prepolímero A249, oriundo de recurso natural e renovável, de cura a frio, não agressivo ao ser humano e nem ao meio ambiente e é uma tecnologia nacional. Os resultados mostraram que o adesivo à base de mamona é uma boa alternativa para a utilização tecnológica da madeira laminada colada em estruturas com espécies de reflorestamento.

Palavras chaves: adesivo de mamona, parâmetros de colagem, madeira laminada colada 


\section{ABSTRACT}

JESUS, J.M.H. Study of the polyurethane adhesive based on castor oil in glued laminated timber (GLULAM). São Carlos, 2000. 109p. Tese (Doutorado) - Área Interunidades, Escola de Engenharia de São Carlos, Instituto de Física de São Carlos, Instituto de Química de São Carlos, Universidade de São Paulo.

The aim of this work is the study of the polyurethane adhesive based on castor oil in glued laminated timber structures (GLULAM). The efficiency of the adhesive was evaluated using the following mechanical tests: shear, perpendicular and parallel tension to the grain strengths. The Brazilian Code NBR 7190/97 "Design of the timber structures" was used to the tests and based on these results were determined the gluing parameters as: viscosity $(\mathrm{V})$, gluing pressure $(\mathrm{P})$, time of pressure $(\mathrm{Tp})$ and the curing time (Tc) and evaluated the influence of these variables and interactions on the mechanical strengths. Two wood species Pinus caribea hondurensis and Eucaliptus grandis were chosen because they are used as reforestation in South and Southeast areas in Brazil where are located the glulam industries. The adhesive studied is of the two components, that is, the poliol B1640 and the prepolymer A249 and is made of a natural and renewable resource, cure in the environment conditions, not aggressive to man and the environment, and a national technology. The results showed a good performance of this adhesive, a good technical alternative for the technology utilization of GLULAM in timber structures with reforestation species.

Keywords: castor oil adhesive, gluing parameters, glulam 


\section{INTRODUÇÃO}

A madeira é um recurso natural renovável e por isso praticamente inesgotável. Apresenta resistência mecânica elevada, peso próprio reduzido, é facilmente manipulada e processada, tendo pequeno custo de produção entre outras características. O Brasil conta com grandes reservas florestais nativas, uma das maiores do mundo, além de grandes áreas de reflorestamento e potencialmente florestáveis.

A madeira tem sido largamente empregada pelo homem na construção civil podendo ser citadas, entre outras aplicações estruturais, as pontes, as formas e cimbramentos, as coberturas e as habitações. Essas estruturas são constituídas, na sua maioria, por peças de madeira maciça. Quando da sua obtenção, há uma perda considerável de material, pois suas dimensões finais, comprimento e seção transversal, são restritas às dimensões do tronco que lhes deu origem. Assim, as estruturas resultantes ficam também limitadas. Além disso, verificam-se variações nas propriedades da madeira maciça ao longo da seção transversal e comprimento decorrentes da heterogeneidade do material e da presença de nós e de bolsas de resinas.

Uma das formas de racionalização do emprego da madeira na construção de estruturas, é a madeira laminada colada (MLC). Sua composição é obtida por peças 
de madeiras coladas, de pequeno comprimento e seção, associadas de tal forma que suas fibras ficam dispostas paralelamente ao comprimento da peça a ser fabricada. Como algumas das vantagens da MLC em relação às estruturas de madeira maciça podem ser citadas:

- a facilidade na construção de grandes estruturas, a partir de peças comerciais, com dimensões reduzidas;

- produção de elementos estruturais com seção e comprimento, forma e dimensões quaisquer, a partir de tábuas curtas e pouco largas, restritas apenas à área onde serão fabricadas e às condições de transporte;

- redução considerável de rachaduras e outros defeitos, como os nós, típicos da madeira de grandes dimensões;

- e, quando do processo de fabricação, podem ser dadas contra-flechas aos elementos com a finalidade de se aumentar a sua eficiência estrutural.

Como desvantagem principal tem-se: o custo da MLC ainda é mais elevado, se comparado com o da madeira maciça uma vez que o processo de produção é industrializado e são empregados adesivos de alto custo, mão de obra especializada, além de técnicas e equipamentos especiais.

O sucesso da MLC tem como um dos responsáveis principais as características de desempenho do adesivo. Estes são divididos em dois grupos: os de origem natural e os de origem sintética. Como adesivos de origem natural tem-se: os de tanino, as colas de origem animal, as de peixe, as de albumina de sangue, as de caseína e de soja, entre outras. Os adesivos sintéticos são os mais empregados pela indústria madeireira, pela sua resistência à umidade e por serem imunes ao ataque de microorganismos. Os adesivos à base de fenol-formaldeído, uréia-formaldeído, resorcinol-formaldeído, isocianatos e resinas adesivas à base de emulsões de acetato de polivinila, são alguns exemplos de adesivos do tipo sintético.

Estudos têm sido conduzidos no sentido do desenvolvimento de novos adesivos naturais, com maior resistência mecânica e maior resistência à umidade. Este trabalho objetiva o estudo do comportamento do adesivo de resina poliuretana derivada do óleo de mamona na colagem da madeira laminada colada como uma alternativa para a utilização em MLC. 


\section{ESTRUTURA DA MADEIRA}

Neste capítulo serão estudados alguns aspectos importantes relativo ao estudo das estruturas: macroscópica, microscópica, molecular e da ultraestrutura da madeira, bem como a sua composição química para o entendimento da ligação entre o adesivo e a madeira.

\subsection{Aspectos da estrutura macroscópica da madeira}

A madeira é um dos materiais mais complexos empregados na engenharia $\mathrm{e}$ para a sua utilização em condições competitivas é essencial a compreensão das suas propriedades. É obtida de árvores oriundas de dois grupos: as coníferas (Gimnospermas) e as folhosas (Angioespermas). Ocorre dentro desses grupos grande variedade de espécies com características anatômicas, químicas e físicas próprias, que influenciam suas propriedades. Observam-se ainda, em uma mesma espécie, variações nessas características tanto ao longo da sua seção transversal quanto do seu comprimento. Em vista dessa falta de homogeneidade é considerado um material anisotrópico e também higroscópico, pois perde e ganha umidade como resultado das mudanças climáticas (temperatura e umidade relativa) observadas no ambiente onde se encontra. Por causa da sua anisotropia, a higroscopicidade produz variações dimensionais de forma diferenciada nas suas direções principais: radial e tangencial da 
seção transversal do tronco e na direção axial ou longitudinal, paralela ao eixo do seu crescimento. Devido também a esta anisotropia, a madeira possui resistência mecânica diferenciada conforme sejam aplicados os esforços nas direções principais da madeira, apresentando maior resistência na direção axial (PASHIN \& ZEEUW, 1980).

Desenvolve-se através da absorção de nutrientes, localizados no solo, pelas raízes. Esses nutrientes são transportados em um líqüido denominado "seiva bruta". Esta seiva, ascende nos troncos pelas camadas mais periféricas do alburno até alcançar as folhas e, por meio da fotossíntese, é transformada em "seiva elaborada" descendo, através de elementos anatômicos apropriados (floema), levando o alimento a todas as partes da árvore. Dessa forma a árvore se desenvolve e cresce na direção radial e axial pela sobreposição de camadas, geralmente concêntricas, alcançando grandes dimensões (BURGER \& RICHTER, 1991).

Por meio da seção transversal do tronco de uma árvore, é possível observar macroscopicamente uma série de elementos diferenciados como aqueles apresentados na figura 1.

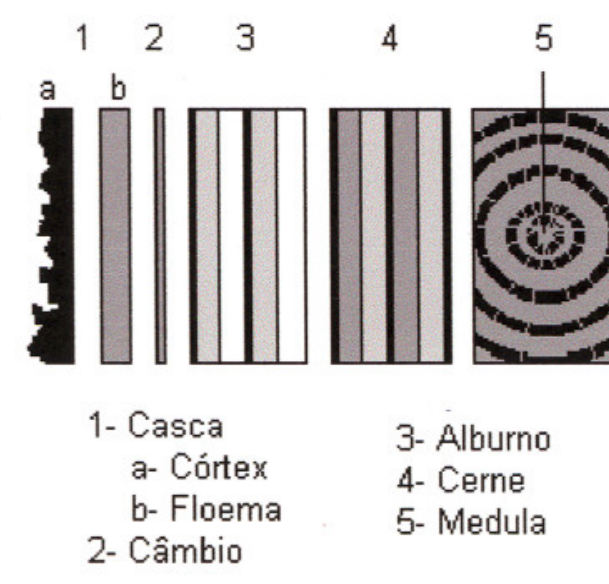

FIGURA 1- Seção transversal de um tronco. Fonte: O autor.

\section{- Casca}

Localizada na região periférica da árvore, é constituída pelo floema e pelo córtex. O floema é um tecido vivo responsável pelo armazenamento e condução de nutrientes, ou seja, a seiva elaborada. Subdivide-se em floema primário e secundário. 
O primeiro é formado apenas, por células orientadas axialmente. Já o floema secundário possui raios e sua disposição celular é axial e radial. (KOGA, 1988). O córtex é um tecido situado mais externamente, dividindo-se em duas regiões: a mais interna é denominada de periderme e a mais externa de retidoma.

Além das funções exercidas pelo floema, a casca também é responsável pela proteção dos tecidos vivos contra o ressecamento, o ataque de microorganismos e insetos e as agressões provocadas por ação mecânica ou climática (BURGER \& RICHTER, 1991).

\section{- Câmbio}

Camada fina de tecido merismático, responsável pela geração de novas células. Composta por células situadas entre o xilema ( mais precisamente o alburno) e a casca (floema), sendo visível apenas com o uso de microscópio (KOGA, 1988). O crescimento e o aumento do diâmetro da árvore (figura 2) são explicados pela atividade do câmbio, que é influenciada pelas condições climatológicas, entre outras.

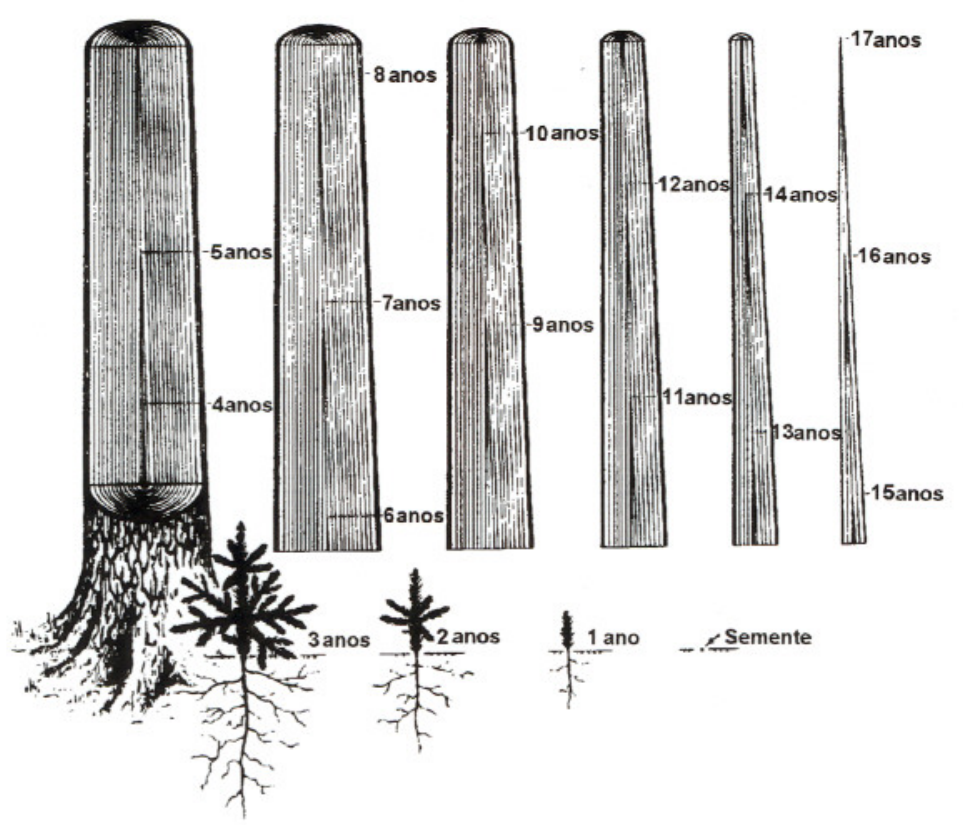

FIGURA 2- Esquema de crescimento de uma árvore. Fonte: PANSHIN \& ZEEUW (1980) 


\section{- Cerne e Alburno (Xilema)}

Entende-se por xilema as regiões compreendidas pelo cerne e alburno. $\mathrm{O}$ alburno, principal tecido condutor, é formado por células dispostas nas direções axial e radial. Na direção axial são encontrados os traqueídeos, elementos de vaso, fibras (fibrotraqueídeos e fibras libridiformes) e as células de parênquima, e na direção radial, basicamente, as células parenquimáticas. Com o passar do tempo, as células ativas das camadas mais internas do alburno perdem suas funções de condução e reserva, tornando-se inativas transformando-se em novas camadas do cerne, cuja coloração mais escura, deve-se a presença de tanino, gorduras carboidratos e outras substâncias. Seus elementos anatômicos possuem lúmens (cavidades celulares) obstruídos pela deposição de tilos, o que provoca uma redução do fluxo de substâncias nutrientes, tornando-se mais compacto, com menor teor de água, mais denso, com maior resistência mecânica, menos susceptível à ação de agentes degradadores, menos permeável e mais dificil de receber substâncias preservativas, do que o alburno (BURGER \& RICHTER, 1991).

\section{- Anéis de crescimento}

$\mathrm{Na}$ seção transversal do tronco de uma árvore, podem ser observadas camadas concêntricas, denominadas de anéis de crescimento, localizadas no alburno e cerne. A formação desses anéis é decorrente da atividade continuada do câmbio e reflete as influências das variadas condições ambientais a que a planta foi submetida durante as estações do ano. Representam geralmente um ciclo de crescimento vegetativo, isto é, um incremento anual, sendo conhecidos por anéis anuais. Em regiões de clima temperado, a contagem desses anéis pode levar à estimativa da idade da árvore. Em regiões de clima tropical, seu crescimento pode ser afetado pelo regime de secas ou de chuvas, levando a formação de mais de um anel (falsos anéis e/ou anéis descontínuos) durante o período de um ano (KOGA, 1988).

Em um anel de crescimento podem ser observadas duas partes distintas: uma mais clara de maior dimensão, conhecida por lenho inicial ou primaveril, e outra de 
menor dimensão conhecida por lenho tardio ou lenho outonal. O primeiro corresponde ao crescimento da árvore verificado na primavera, início do período vegetativo, quando termina o período de dormência da planta. As células formadas durante este período têm paredes delgadas, lúmens grandes, com função principal de condução, são menos densas e de coloração clara. Quando chega ao fim o período vegetativo, as células vão diminuindo gradativamente suas atividades fisiológicas, até chegar à dormência. Como conseqüência as paredes celulares têm maior espessura, os lúmens têm menor dimensão e sua função principal é o de sustentação, são mais densas e tem coloração mais escura. Por causa do aumento total de substâncias na parede celular, o lenho tardio tem influência dominante sobre algumas das propriedades mecânicas.

\section{- Raios}

Os raios são constituídos por agrupamentos de células parenquimáticas, ordenadas em faixas horizontais, no sentido radial, em direção a medula. Desempenham as funções do transporte horizontal e, principalmente, de armazenamento dos nutrientes (PARHAM \& GRAY, 1984).

\section{- Medula}

A medula localiza-se na região central do xilema, tem como função o armazenamento de substâncias nutrientes. Desempenha papel importante nas plantas jovens, nas quais, segundo afirma GROSSER ${ }^{1}$ apud BURGUER \& RICHTER (1991), participa também na condução ascendente dos nutrientes. Por ser um tecido parenquimático é suscetível ao ataque de microorganismos xilófagos. Por isso é comum serem encontrados troncos ocos, com a medula já deteriorada por ocasião do abate da árvore.

Outros elementos podem ser distinguidos, ainda a olho nu, como por exemplo os canais ou dutos resiníferos. São canais orientados tanto no sentido axial como no sentido radial preenchidos com resinas, gomas e outros elementos.

\footnotetext{
${ }^{1}$ GROSSER, D. (1977). Die Hölzer Mitteleuropas. Ein mikrophotographischer Lehratlas. Berlim.
} 


\subsection{Aspectos da estrutura microscópica da madeira}

Quando uma amostra de madeira é analisada microscopicamente, observa-se que ela é constituída por diferentes tipos de células. Essas células têm a forma tubular, sendo compostas por camadas distintas, possuindo uma distribuição diferenciada nos três eixos principais (axial, radial e tangencial). As estruturas celulares das coníferas e das folhosas estão representadas na figura 3 , respectivamente. $\mathrm{O}$ arranjo celular tem importância particular uma vez que afeta as propriedades físicas e mecânicas da madeira.

\section{- Coníferas}

As coníferas são constituídas por dois tipos de células: traqueídeos e parênquimas. Os traqueídeos são células longas e delgadas ocupando o maior volume.

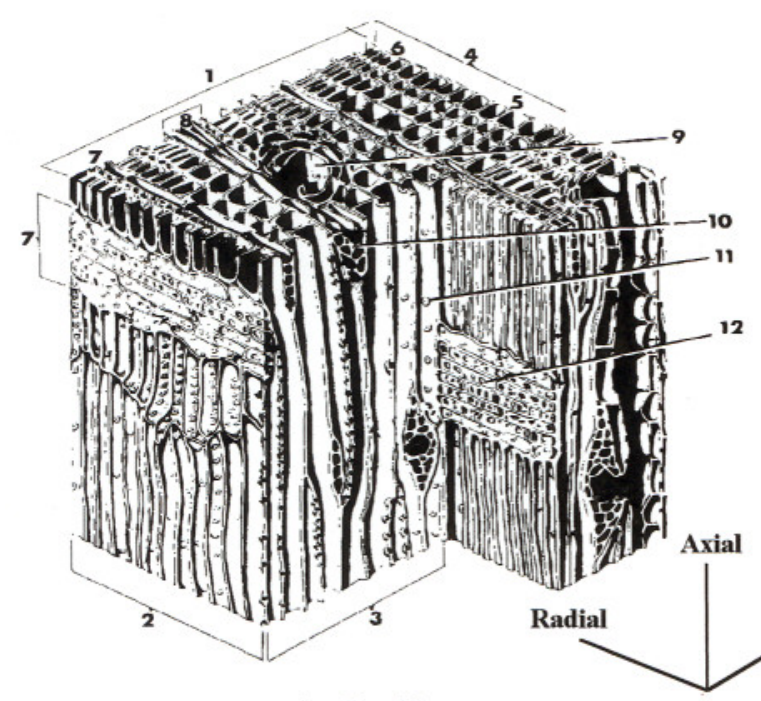

A- Conífera

1- Seção transversal

2- Seção Radial

3- Seção Tangencial

4- Anel de crescimento

5- Lenho inicial ou primaveril

6- Lenho tardio ou outonal

7- Raios medulares

8- Raio fusiforme

9- Duto resinífero vertical

10- Duto resinífero horizontal

11- Pontoação areolada

12 Pontoação simples

FIGURA 3- Estrutura celular da madeira. Fonte: BODIG \& JAYNE (1982).
1- Seção transversal

2- Seção Radial

3- Seção Tangencial

4- Anel de crescimento

5- Lenho inicial ou primaveril

6- Lenho tardio ou outonal

7- Raios medulares

8- Vasos

9- Perfurações

\section{B- Folhosa}


Estão dispostos verticalmente, paralelos à direção axial da árvore. Têm a função de suporte mecânico e são responsáveis pela condução de nutrientes. As células parenquimáticas são células no formato de pequenos blocos, localizadas com maior freqüência nos raios que têm seus eixos orientados na direção radial, mas são encontradas também envolvendo os canais de resinas e dutos de gomas. Têm como função principal a de armazenamento (DINWOODIE, 1981).

\section{- Folhosas}

As folhosas não possuem canais resiníferos, segundo afirma DINWOODIE (1981), apresentando quatro tipos de células, incluindo os traqueídeos os quais ocorrem apenas em algumas espécies de folhosas, e em menor quantidade que nas coníferas. Já BODIG \& JAYNE (1982) não mencionam a presença de traqueídeos entre as células que compõem as espécies deste grupo.

A função de condução é desempenhada pelos vasos que são células de pequeno comprimento, mas com grande diâmetro. As fibras juntamente com os vasos são as células que ocupam o maior volume das folhosas. São células longas, de pequeno diâmetro e reponsáveis pelo suporte mecânico. As células de parênquima são células pequenas com paredes geralmente finas, cuja função principal é a de armazenamento, podendo se localizar horizontalmente nos raios e verticalmente dispersas ou em regiões distintas.

\subsection{Aspectos da estrutura molecular e ultraestrutura da madeira}

\section{- Constituintes químicos}

De acordo com BODIG \& JAYNE (1982) e TSOUMIS (1991), a madeira apresenta na sua constituição cerca de $50 \%$ de carbono, $44 \%$ de oxigênio, $6 \%$ de hidrogênio, 0,2 a 0,3\% de cinzas e menos de 0,1\% de nitrogênio. Essas substâncias químicas associadas formam os compostos que constituem as paredes celulares da 
madeira, dividindo-se em carboidratos e fenóis. Fazendo parte dos carboidratos encontram-se a celulose e a hemicelulose (poliose) sendo que a lignina representa os fenóis. As quantidades desses compostos são apresentadas na tabela 1.

TABELA 1- Composição química da madeira. Fonte: DINWOODIE (1981).

\begin{tabular}{lcccc}
\hline Compostos & $\begin{array}{c}\text { Percentagem de } \\
\text { peso }\end{array}$ & Estado do polímero & $\begin{array}{c}\text { Derivativos } \\
\text { moleculares }\end{array}$ & Função \\
\hline Celulose & $40-50$ & $\begin{array}{c}\text { Cristalino } \\
\text { alternadamente orientado } \\
\text { moléculas grandes }\end{array}$ & Glicose & Fibras \\
Hemicelulose & $20-25$ & $\begin{array}{l}\text { Semi-cristalino } \\
\text { Moléculas pequenas }\end{array}$ & $\begin{array}{c}\text { Galactose } \\
\text { Manose } \\
\text { Xilose }\end{array}$ & Matriz \\
Lignina & $25-30$ & $\begin{array}{c}\text { Amorfa } \\
\text { Grandes moléculas } \\
\text { tridimensionais }\end{array}$ & Fenilpropano & Matriz \\
Extrativos & $0-10$ & Alguns polímeros & Terpenos & \\
\hline & & Outros não polímeros & Polifenóis & - \\
\hline
\end{tabular}

Segundo BODIG \& JAYNE (1982) os carboidratos representam cerca de $75 \%$ da madeira e a lignina a maior parte do material fenólico. A retirada da lignina, por processos que retêm a fração de carboidratos sem que sofram alterações, resulta no produto denominado holocelulose. A holocelulose pode ser separada em celulose e hemicelulose que por sua vez é composta pelo menos de xilose e manose. As pectinas formam um grupo menor de carboidratos, freqüentemente classificadas no grupo dos extrativos, pela sua pequena quantidade e facilidade de remoção.

Comparando-se as quantidades de compostos nas folhosas e nas coníferas, pode-se observar que as folhosas possuem um pouco mais celulose (45\%) do que as coníferas (41\%) e menor quantidade de lignina (22\% e $28 \%$ respectivamente). Por outro lado, a hemicelulose é encontrada em quantidades aproximadamente iguais nos dois grupos. As folhosas são mais ricas em xilose e as coníferas em manose (BODIG \& JAYNE,1982).

\section{- Celulose}

A celulose $\left(\mathrm{C}_{6} \mathrm{H}_{10} \mathrm{O}_{5}\right)_{n}$ é um polissacarídeo linear composto por um tipo de açúcar (PETTERSEN, 1984). Sua estrutura é a mais simples dos compostos da 
parede celular, sendo formada a partir do monômero de glicose $\left(\mathrm{C}_{6} \mathrm{H}_{10} \mathrm{O}_{6}\right)$. O número de unidades por molécula (n) fornece o grau de polimerização do composto. Sucessivas unidades de glicose ligam-se covalentemente nas posições 1, 4 (Figura 4) formando cadeias retilíneas e extensas de $\beta$-D glicose. Essa ligação covalente é verificada dentro dos anéis e entre os anéis de glicose, contribuindo para alta resistência à tração paralela às fibras da madeira (DINWOODIE, 1981).

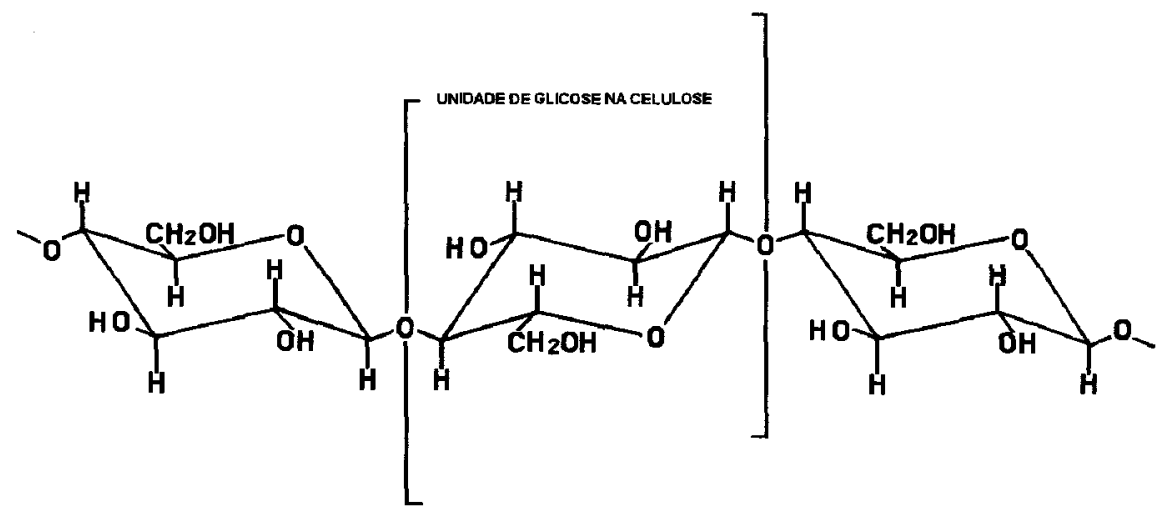

FIGURA 4- Molécula de celulose. Fonte: BODIG \& JAYNE (1982).

É observada uma tendência de ligações intramoleculares e intermoleculares das cadeias de celulose por meio de pontes de hidrogênio, como visto na figura 5. As ligações intramoleculares fornecem uma certa rigidez às cadeias, enquanto que as ligações intermoleculares são responsáveis, em última instância, pela formação da fibra vegetal.

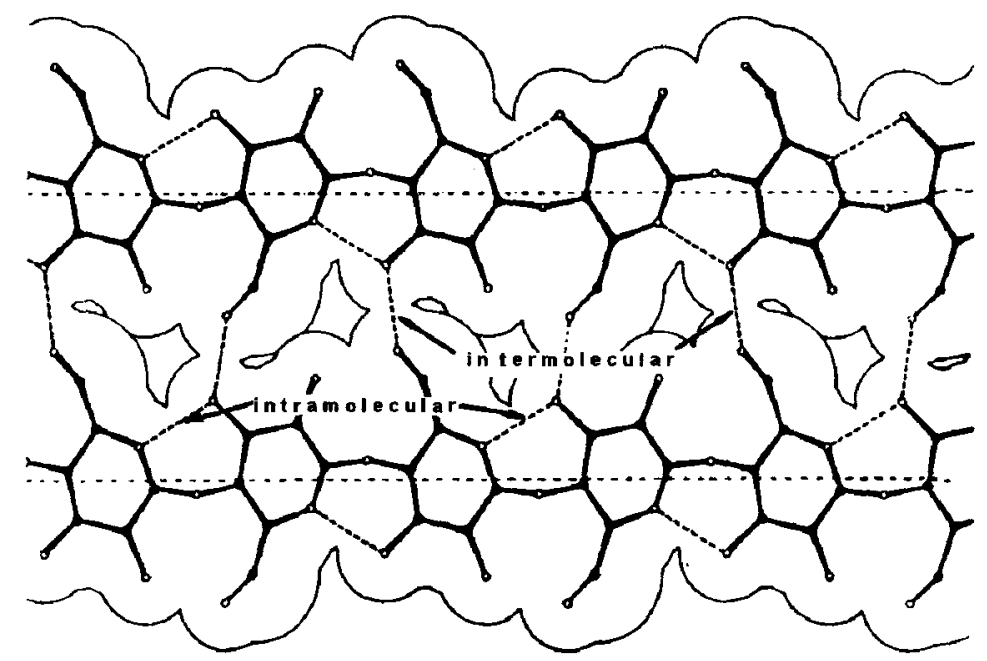

FIGURA 5- Ligações intramolecular e intermolecular. Fonte: FENGEL \& WEGENER (1984). 
As cadeias de celulose apresentam regiões cristalinas altamente ordenadas, regiões com alguma ordenação e regiões desordenadas ou amorfas. De acordo com KOGA (1988) e DINWOODIE (1981), as regiões com arranjo ordenado são conhecidas como microcristais, cristalitos e micelas. Apresentam alta resistência à tração, ao alongamento. A maioria das cadeias emerge de uma região cristalina passando para a próxima, criando um alto grau de coordenação longitudinal. Essa unidade é denominada de microfibrila.

Ainda não existe um consenso para o modelo da cela (ou célula) unitária. Cela unitária é a denominação dada ao arranjo geométrico que se repete nos eixos principais da estrutura cristalina, para formar o volume total do cristal. A figura 6 representa a estrutura da celulose proposta por MEYER \& $\mathrm{MISH}^{2}$ apud DINWOODIE (1981). Segundo este pesquisador, o modelo proposto por Gardner e Blackwell, alterando as dimensões da cela para: $a=0,817 \mathrm{~nm}, b=1,038 \mathrm{~nm}$ e $c=0,786$ $\mathrm{nm}\left(1 \mathrm{~nm}=10^{-9} \mathrm{~m}\right)$, vem ultimamente ganhando maior aceitação.

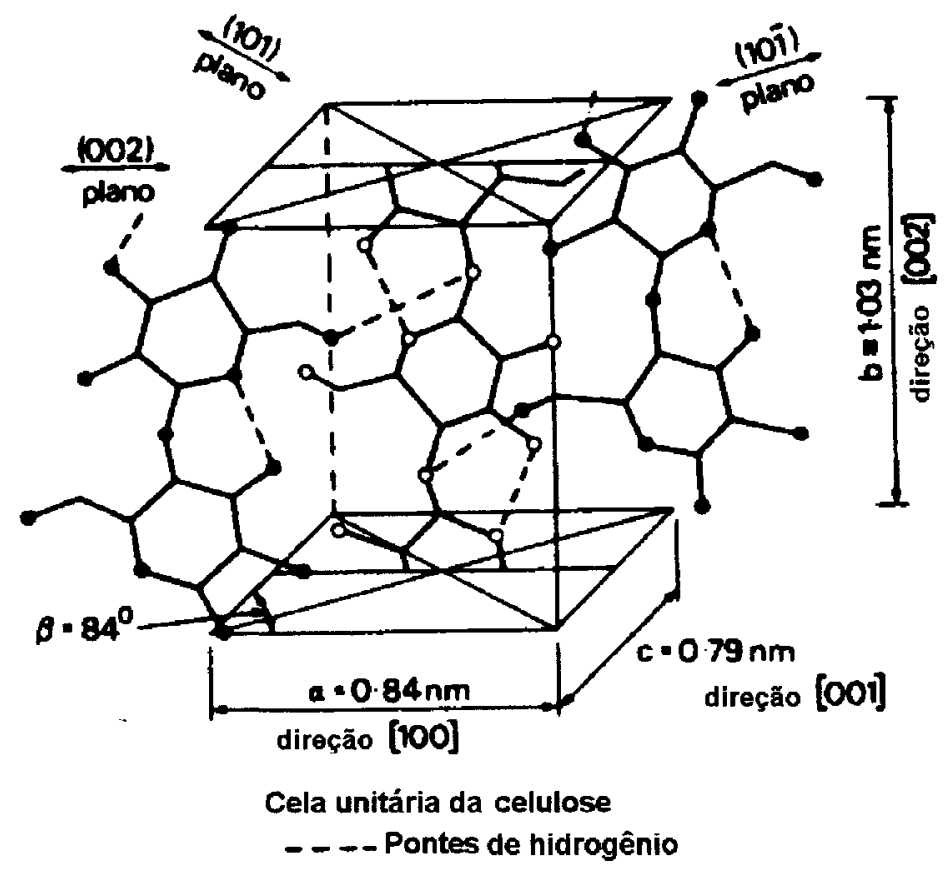

FIGURA 6- Cela unitária da celulose. Fonte: DINWOODIE (1981).

${ }^{2}$ MEYER, K. H.; MISH, L. (1937). Position des atomes dans le nouveau modele spatial de la cellulose. Helvetica Chimica Acta, 20 . 


\section{- Hemiceluloses ou Polioses}

A denominação hemicelulose leva a idéia de que esse composto representa algo como meia celulose, o que não é correto. Na realidade tem forma diferente da celulose, sendo tratada por muitos autores como poliose conforme FENGEL \& WEGENER, (1984) e SJÖSTRÖM, (1981). São uma mistura complexa de polímeros carboidratados, onde participam pelo menos dois tipos de unidades de açúcar, entre eles a xilose e a manose contidas em polissacarídeos. O grau de polimerização tanto nas folhosas como nas coníferas é baixo, contendo menos de 150 unidades por molécula. Diferente da celulose, sua presença na parede celular ocorre como moléculas individuais. Por conseqüência associam-se com maior facilidade às ligninas, apresentando-se no estado amorfo (BODIG \& JAYNE, 1982). O teor e a proporção dos componentes da hemicelulose da madeira sofrem grande influência com a variação da espécie e dentro de uma mesma árvore. Nas coníferas são encontradas mais manoses do que nas folhosas. Estas, por sua vez, são mais ricas em xiloses.

As hemiceluloses, como as ligninas, são consideradas materiais cimentantes, contribuindo para a integridade e a alta rigidez da estrutura da madeira, principalmente em condições secas.
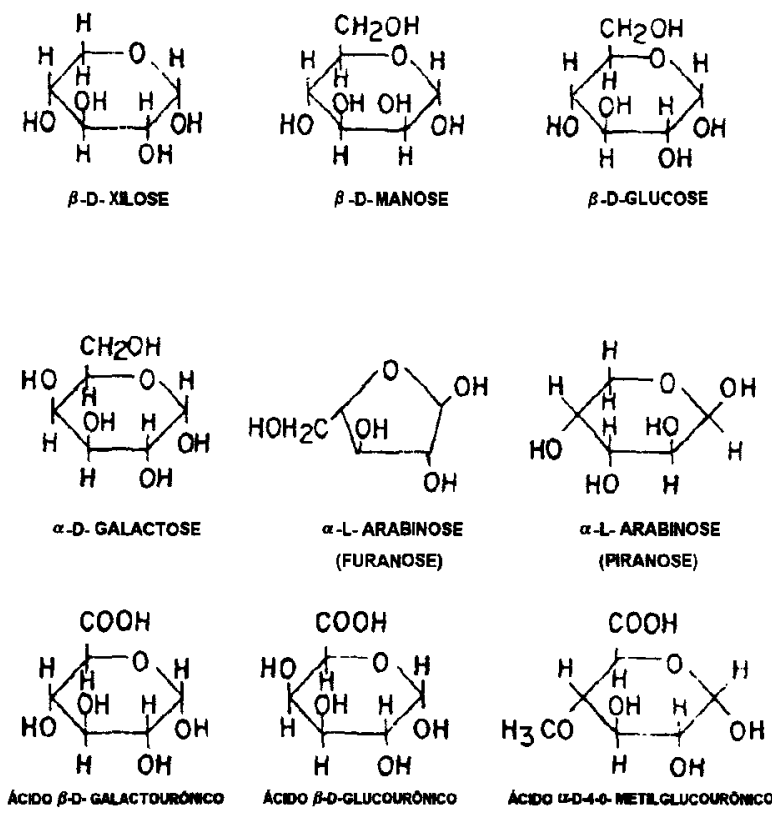

FIGURA 7- Açúcares que compõem as hemiceluloses (polioses). Fonte: FENGEL \& WEGENER (1984). 


\section{- Lignina}

A lignina se encontra presente na parede celular com, aproximadamente, as mesmas proporções da hemicelulose, sendo quimicamente diferente da celulose e da hemicelulose. É um componente aromático complexo, composto por grupos fenólicos, sendo que sua estrutura ainda não é completamente entendida. $\mathrm{O}$ volume total presente na parede celular é da ordem de $75 \%$ e é depositada seguindo a estrutura da celulose. $O$ fim desse processo de lignificação ocorre com o término do período de diferenciação, coincidindo com a morte da célula. (DINWOODIE, 1981).
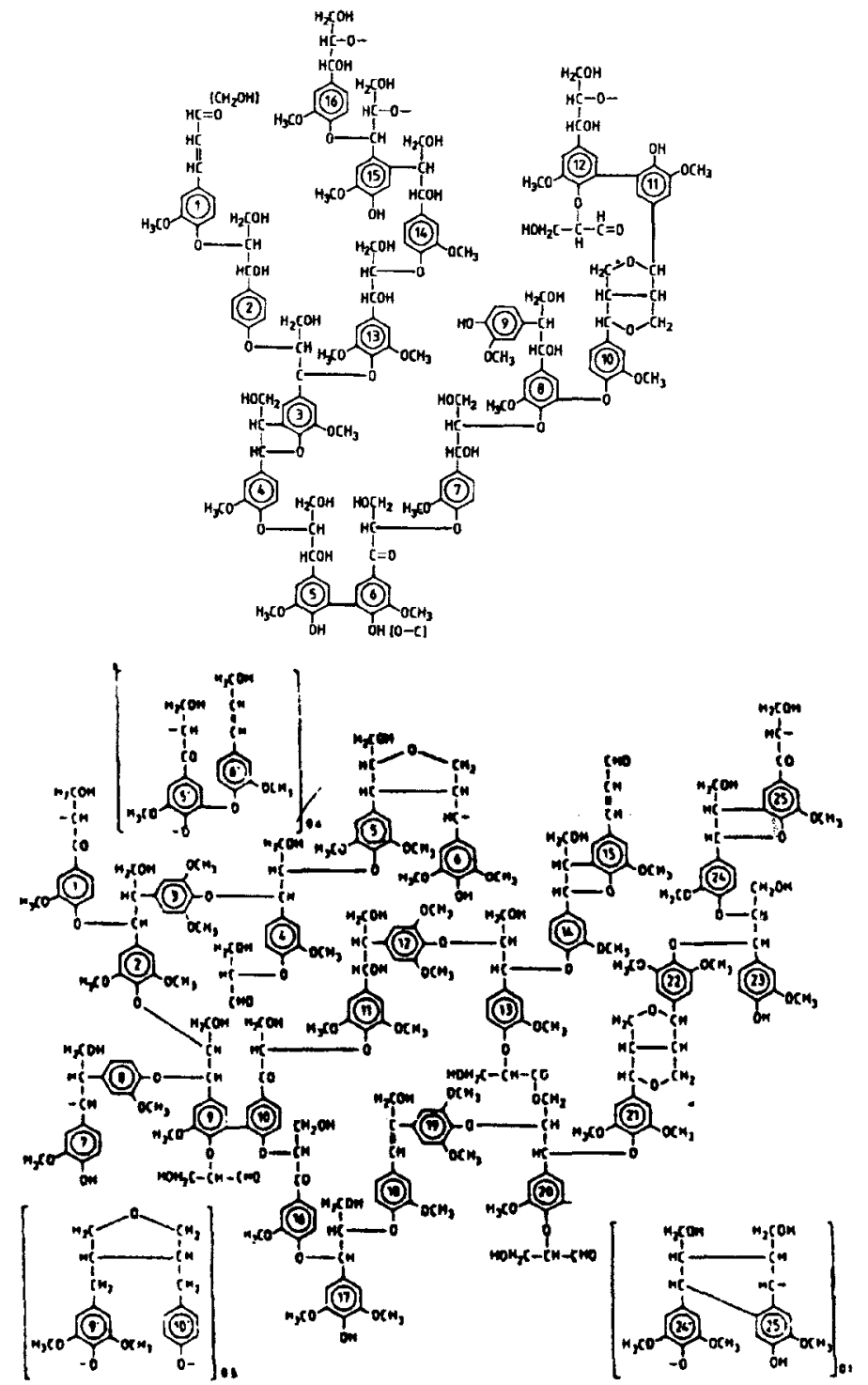

FIGURA 8- Modelo para a lignina de uma conífera e de uma folhosa, respectivamente. Fonte: FENGEL \& WEGENER (1984). 


\section{- Extrativos}

São responsáveis pelo aumento da densidade (DINWOODIE, 1981) e pela diminuição do teor da umidade de equilíbrio podendo assim influenciar sobre as propriedades mecânicas da madeira. São compostos estranhos à madeira, que preenchem os lúmens das células, localizando-se também em estruturas como os dutos resiníferos. Alguns extrativos como as graxas, açúcares e gorduras têm pouco significado econômico, ao contrário da borracha e resinas das quais é extraída, por exemplo, a terebintina. $\mathbf{O}$ alburno é normalmente considerado sem extrativos e tendo por isso, menor durabilidade que o cerne. A quantidade de extrativos pode variar entre espécies e dentro de uma mesma árvore (BODIG \& JAYNE, 1982).

\subsubsection{Organização da parede celular}

Segundo DINWOODIE (1981), o modelo mais bem sucedido na interpretação da ultraestrutura da madeira foi obtido após várias análises químicas e de raio $\mathrm{X}$ e atribue-se à microfibrila celulósica a função de fibra, enquanto que a lignina e as hemiceluloses são consideradas componentes separados da matriz.

As moléculas de celulose agrupam-se formando as fibrilas elementares ou micelas cuja seção transversal possui o valor de 3,5 x 3,5 nm, considerado aceitável para esse elemento de seção quadrada ou elíptica. As fibrilas elementares se unem dando origem às microfibrilas, que compõem as macrofibrilas. Por sua vez as macrofibrilas se unem resultando nas lamelas, que constituem as camadas das paredes celulares, que formam um elemento anatômico (fibra, vaso traqueídeo, etc.), figura 9, dando origem ao xilema (cerne e alburno).

A figura 10 apresenta uma seção longitudinal hipotética de uma fibrila elementar ou micela. As moléculas de celulose estão representadas como elementos longos e finos. As moléculas maiores representam a lignina, as hemiceluloses e os extrativos. As moléculas menores representam a água. $\mathrm{O}$ arranjo dessas moléculas na parede celular influencia as propriedades físicas da madeira. 


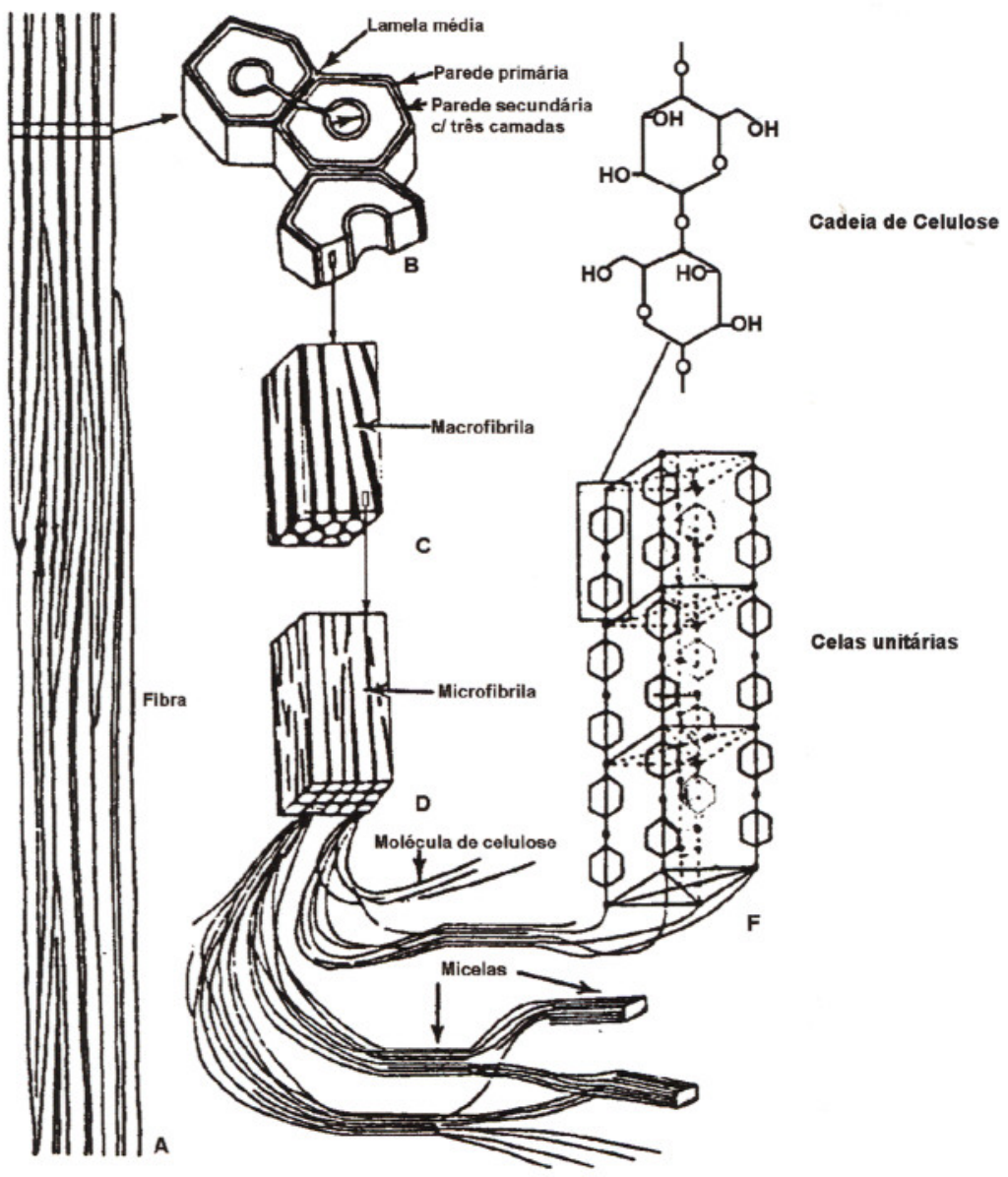

FIGURA 9- Localização dos elementos que compõem a parede celular. Fonte: D'ALMEIDA (1988).

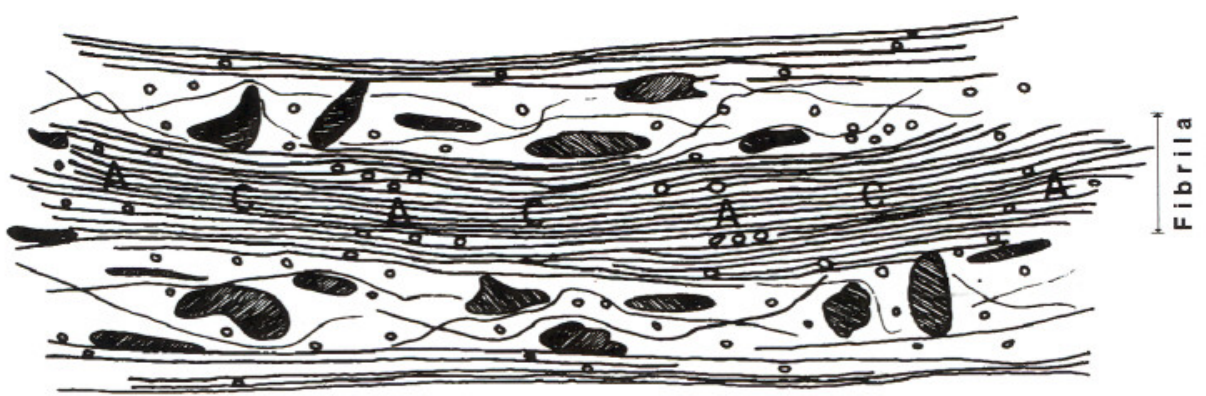

FIGURA 10- Seção longitudinal hipotética de uma fibrila elementar. Fonte: BODIG \& JAYNE (1982).

PRESTON (1964), mostrou que as hemiceluloses estão geralmente associadas internamente às celuloses, unindo efetivamente as microfibrilas. Os feixes de celulose são vistos como apresentando uma envoltória de material hemicelulósico, resultando em um alto grau de ligações por pontes de hidrogênio. A lignina está 
depositada de forma variada em diferentes partes da parede celular e sua função principal é a de proteger a celulose e as hemiceluloses, hidrofilicas (carentes de água), mecanicamente fracas quando úmidas. Localizada em uma camada externa às microfibrilas, a lignina forma um escudo protetor, sendo responsável por mante-las unidas e cimentadas, o que resulta em um aumento da resistência ao cisalhamento e da rigidez, e pela transferência das tensões por todo composto.

A Figura 11 apresenta dois modelos que explicam a localização dos componentes da matriz, a lignina e hemicelulose, dentro da microfibrila.

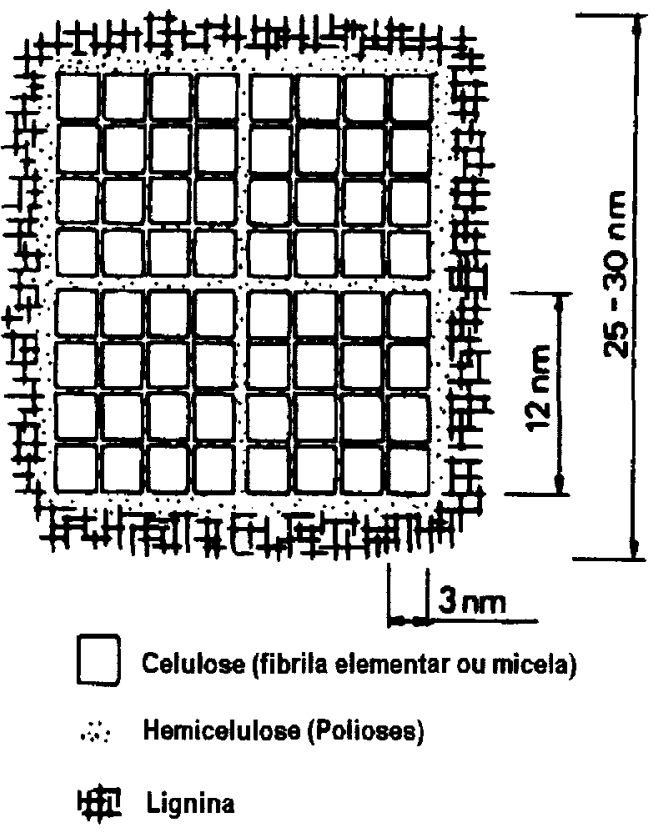

(a)

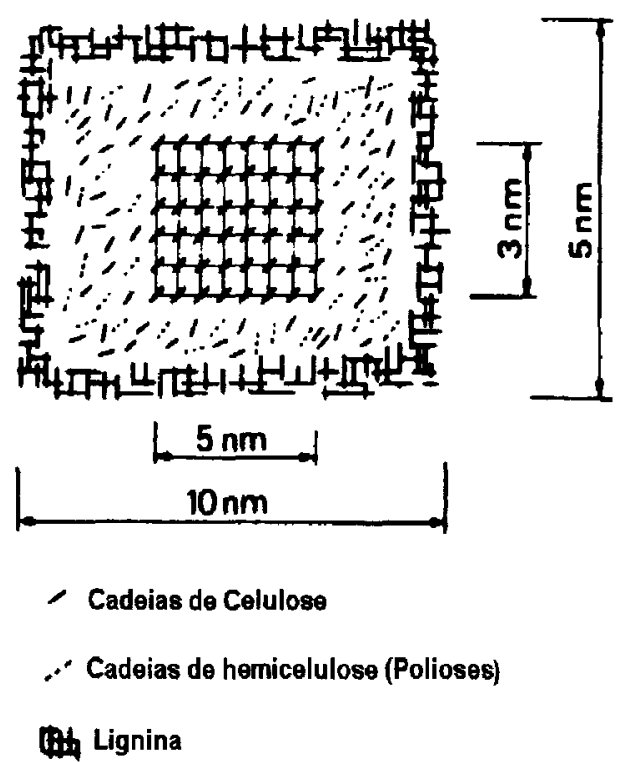

(b)

FIGURA 11- Modelo da seção transversal de uma microfibrila. Fonte: DINWOODIE (1981).

Segundo BODIG \& JAYNE (1982) a retração e o inchamento da madeira são o resultado da adição de moléculas de água nas regiões amorfas das microfibrilas. Os espaços entre elas estão disponíveis para a deposição de substâncias químicas e para absorção de água. Esses espaços são os principais responsáveis pelo inchamento ou retração da madeira em função da variação da umidade. 


\subsubsection{Camadas da parede celular}

A madeira é constituída por diferentes células que podem apresentar grande diferença na organização de suas paredes e que, por sua vez, já apresentam elevada complexidade. Em todas as células da madeira as microfibrilas e outros elementos, estão organizados em pequenas lâminas, também conhecidas por lamelas, que por sua vez, organizam-se dentro das camadas da parede celular conforme figura 12.

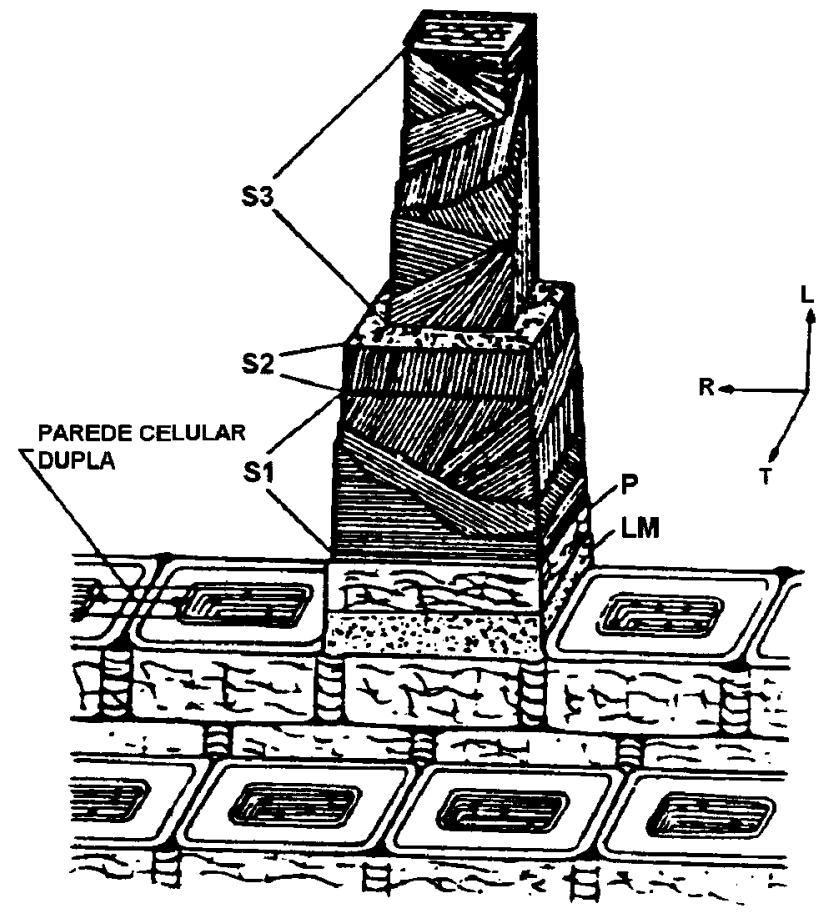

FIGURA 12- Estrutura da parede celular. Fonte WINANDY \& ROWELL (1984).

Quando as células cambiais dividem-se para formar duas células filhas, uma nova parede é formada compreendendo uma lamela média e duas paredes primárias, uma para cada célula. A parede secundária é formada a partir de mudanças verificadas nessas novas células, que ocorrem em cerca de três dias (DINWOODIE, 1981). A espessura da parede depende da função que a célula desempenhará, mas sua constituição básica é igual para todas as células. A lamela média (LM) não pertence à parede celular sendo um meio de interligação entre as células. Segundo este autor, é formada a partir de um complexo de lignina-pectina, isenta de microfibrilas celulósicas. Na parede primária $(\mathrm{P})$ as microfibrilas estão dispostas de forma aleatória. A espessura dessa parede é muito fina, cerca de $0,1 \mu \mathrm{m}$, contribuindo muito pouco no 
comportamento físico da madeira. A combinação da lamela média e a parede primária é freqüentemente denominada de "composto lamela média" (CLM). Após a formação da parede primária verifica-se um engrossamento, resultando na formação da parede secundária $S$, camadas $S_{1}, S_{2}$ e $S_{3}$. Nessas camadas as lamelas estão bem próximas e paralelas entre si. Na figura 13 estão representados o ângulo microfibrilar e a porcentagem de cada constituinte da parede celular nas faces tangencial ( $\mathrm{T}$ ) e radial (R).

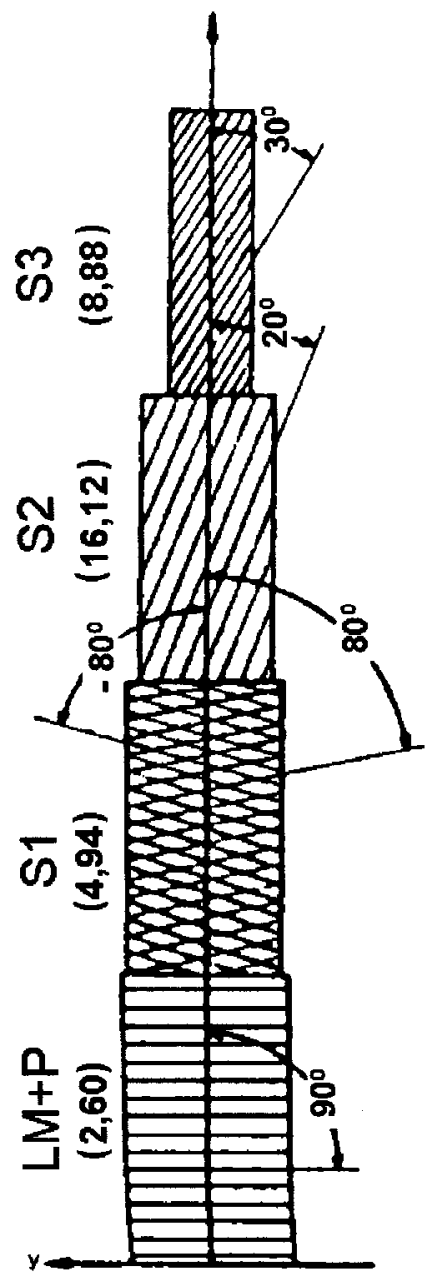

(T)

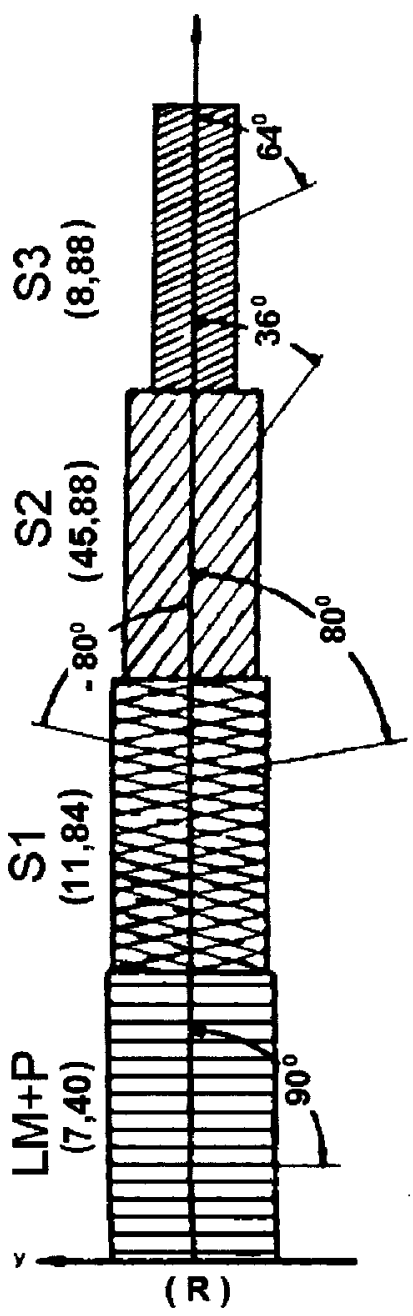

( R )

FIGURA 13- Disposição e ângulo das microfibrilas nas paredes celulares. Fonte: TOMAZELLO FILHO (1996).

- Constituintes químicos das camadas da parede celular

Os componentes químicos, segundo BODIG \& JAYNE (1982), não estão distribuídos uniformemente entre as células ou entre as camadas da parede celular 
(figura 14). Na lamela média a lignina é o constituinte predominante. $\mathrm{O}$ composto lamela média (lamela média mais parede primária) das essências florestais pertencentes ao grupo das coníferas têm de 65 a $75 \%$ de lignina sendo que nas folhosas esse percentual está compreendido entre 75 a $85 \%$. Na camada $S_{1}$ a lignina também é o principal constituinte (ROWELL, 1990).

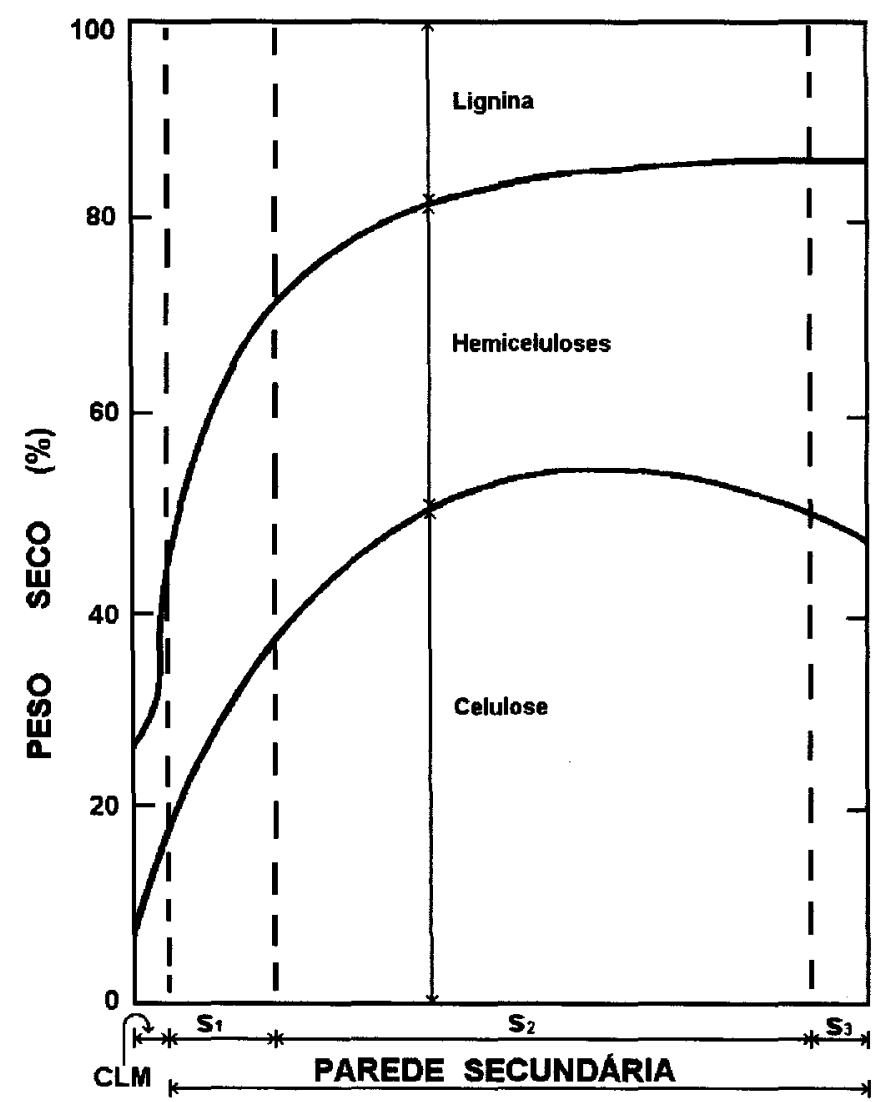

FIGURA 14- Distribuição dos componentes químicos em uma parede celular. Fonte: BODIG \& JAYNE (1982).

A celulose, por sua vez, está presente em todas as camadas da parede celular, sendo que na lamela média seu teor é bem pequeno, cerca de $10 \%$. Na camada $S_{2}$, das essências pertencentes ao grupo das coníferas, o seu teor é de aproximadamente $70 \%$ do total de celulose da parede celular. A camada $\mathrm{S}_{3}$ é composta principalmente por hemiceluloses e celulose.

A composição química da parede celular dos raios é um pouco diferente dos outros tecidos. A hemicelulose está presente em maiores quantidades sendo que em alguns casos, com até 50\% (BODIG \& JAYNE,1982). 


\subsection{Conclusões}

Neste capítulo pôde ser vista a grande complexidade da madeira, característica de um ser vivo. Até hoje, estruturas como as das polioses, entre nós mais conhecidas como hemiceluloses e as da lignina, para não se estender a outros compostos que constituem este polímero natural e renovável, ainda não são perfeitamente compreendidas.

Foram observados alguns aspectos referentes às direções principais da madeira, suas estruturas micro e macro, seus constituintes químicos e organização da parede celular. $O$ estudo desses aspectos objetivou a compreensão de como pode ocorrer a ligação do adesivo estudado à madeira. Foi possível constatar a possibilidade de ligações químicas pela presença dos grupos $-\mathrm{OH}$ nos compostos da madeira. Por outro lado os lúmens existentes, como por exemplo nos vasos e traqueídeos, podem possibilitar o desenvolvimento da ligação do tipo mecânica com a sua impregnação com adesivo. 


\section{ADESIVOS E ADESÃO}

Neste capítulo é feito um histórico dos adesivos, sua classificação e apresentação, dando ênfase especial ao adesivo poliuretano a base de mamona, objeto do estudo. São estudados os mecanismos de adesão, a escolha do adesivo e os fatores que influenciam a ligação adesiva.

\subsection{Adesivos - histórico}

O uso de adesivos pelo homem remonta a mais de 3000 anos antes de Cristo. Há informações de que os egípcios utilizavam a goma arábica retirada de essências florestais como a acácia e de resinas de outras árvores, assim como do ovo e da borracha. Empregando uma cola feita com pasta de farinha, confeccionaram os primeiros papiros compostos de lâminas finas, justapostas e coladas (LAURIE, 1910). Conheciam colas de peixe, de leite coalhado, entre outras, que foram empregadas para unir objetos de madeira (SKEIST, 1962).

Pouca evolução foi observada no estudo dos adesivos até o início deste século. Porém, com a primeira guerra mundial, onde ainda predominavam os adesivos obtidos à base de proteínas animais, começaram a surgir novos tipos que tinham como características a de serem utilizados à temperatura ambiente e que apresentavam certa 
resistência à água, como aqueles à base de caseína. Estes adesivos são empregados até hoje pelos países mais desenvolvidos, na colagem de madeira estrutural para interiores. Foram criados adesivos à base de albumina sangüínea com elevada resistência à ação da água, porém devendo a madeira ser prensada à quente. Em seguida surgiu o adesivo à base de farinha de soja.

$\mathrm{Na}$ década de 30 foi empregada, com uso em escala industrial na madeira, a primeira resina sintética com base no fenol-formaldeído, apesar de ter sido desenvolvido 65 anos antes por Baekeland. Ainda nesta época, foi introduzido um adesivo à base de uréia-formaldeído, por I. G. Farben-Industrie, para a produção de móveis e madeira compensada para interiores. Apresentava pouca resistência à água se comparado com as resinas fenólicas, porém sua cura era processada à temperatura mais baixa e tinha menor custo (SKEIST, 1962).

Com a segunda guerra mundial novos adesivos foram desenvolvidos como o resorcinol-formaldeído, de maior custo, porém com cura à temperatura ambiente e mais resistente à água e os primeiros adesivos poliuretanos, criados por Bayer, na Alemanha.

Para ser possível a produção de madeira laminada estrutural e compensados de madeira para uso exterior, foram misturados adesivos à base de resina resorcinol com os adesivos à base de resinas fenólicas.

As emulsões de acetado de polivinila começaram a substituir, nessa época, aqueles adesivos à base de proteína animal, em várias aplicações da madeira. Estas resinas têm aplicação a frio, sua solidificação é por perda de água e produzem uma linha de colagem incolor.

Com o grande o avanço ocorrido no estudo da química das macromoléculas, uma grande variedade de polímeros, com melhores características quanto ao seu aspecto adesivo, foram desenvolvidos possibilitando grande expansão das indústrias de adesivos à base de resinas vinílicas, de poliester, poliuretanas, etc. e das aplicações dos processos de colagem com as finalidades mais variadas (MANTILLA CARRASCO, 1984).

No início da década de oitenta, importante contribuição nacional foi dada ao estudo dos adesivos à base de resinas poliuretanas, pelo Departamento de Química e 
Física Molecular, do atual Instituto de Química de São Carlos. Os pesquisadores do Grupo de Química Analítica e Tecnologia de Polímeros, desenvolveram uma resina poliuretana à base de mamona que possui várias vantagens como: manipulação em temperatura ambiente, grande resistência à ação da água e de raios ultravioleta, grande resistência mecânica e ser oriundo de um recurso natural e renovável, facilmente encontrado na maior parte do território nacional.

\subsection{Classificação dos Adesivos}

Os adesivos são classificados em vários tipos. De acordo com a sua composição química podem ser inorgânicos ou orgânicos.

\subsubsection{Adesivos Inorgânicos}

Dentre os adesivos inorgânicos, os mais comuns são à base de silicatos, produzindo ligações com elevada resistência mecânica, sendo dificil a diferenciação entre o adesivo e o cimento. Nos adesivos a ligação se dá pela desidratação do solvente dos adesivos. Já os cimentos são formados através de reações químicas. Foi observado aumento da resistência à água e ao fogo quando da utilização dos cimentos na produção de madeira compensada (MANTILLA CARRASCO, 1984).

\subsubsection{Adesivos Orgânicos}

Os adesivos orgânicos são divididos em sintéticos e naturais. Os adesivos orgânicos sintéticos são os mais importantes e mais empregados pela indústria madeireira por apresentarem grande resistência à ação da água e por não sofrerem ação dos microrganismos. Podem ser classificados em termofixos e termoplásticos. 


\subsubsection{Termofixos}

Os adesivos termofixos endurecem por meio de reações químicas ativadas pela temperatura ou catalisadores. São resistentes a umidade e ao calor. Entre os principais adesivos podem ser citados: o fenol-formaldeído, a uréia-formaldeído, o resorcinol-formaldeído e os poliuretânicos (WATAI, 1987; SUBRAMANIAN,1984).

\section{- Adesivos de Fenol-Formaldeído}

São adesivos formados a partir de resinas fenólicas sintéticas, primeiras a serem empregadas com aplicação comercial em madeiras. Necessitam de altas temperaturas para a cura $\left(130\right.$ a $\left.160^{\circ} \mathrm{C}\right)$, sendo comercializadas em filmes secos, reconstituídas pela ação da água. Precisam de um endurecedor a ser dosado com a resina, produzindo boa resistência das uniões colocadas mesmo que atuem sob a ação de condições extremamente adversas. Estas condições podem ser: longo tempo de exposição à água quente ou fria, ciclos de secagem e de endurecimento, variações extremas de temperaturas e umidade relativa, temperaturas em torno da temperatura de carbonização da madeira, ataque de microorganismos e exposição à ação de vários tipos de componentes, como aqueles usados na preservação de madeiras, os óleos e álcalis (KOLLMANN et al., 1975).

Se os processos de colagem e endurecimento forem adequadamente conduzidos, as colagens feitas com adesivos fenólicos apresentarão grande durabilidade, podendo ultrapassar a da própria madeira. Sua linha de cola possui coloração escura e um dos fatores negativos é o alto custo do fenol, cuja matéria prima é o petróleo.

\section{- Adesivos de Uréia-Formaldeído}

Foram introduzidos após as resinas de fenol-formaldeído. Apesar de classificados como resistentes à ação da umidade, perdem resistência quando atuam sob a ação da umidade por tempo relativamente curto. Dessa forma exposições 
repetidas a ambientes com alto teor de umidade, temperaturas iguais ou superiores a $65^{\circ} \mathrm{C}$ poderão provocar mal desempenho das peças, afetando-as negativamente.

São apresentados freqüentemente na forma líqüida, adicionando-se um catalisador, ou na forma de pó, quando emprega-se um catalisador combinado, necessitando apenas serem misturados com a água. Têm coloração clara e são muito empregados nos Estados Unidos em carpintarias. Possuem um sério inconveniente em virtude da emanação de formaldeído e seu emprego é problemático em países cujo controle ambiental é rigoroso (PETERSON, 1964; SAMLAIC, 1983).

\section{- Adesivos de Resorcinol-Formaldeído}

Possuem as mesmas características das colas fenólicas, exceto em relação ao seu tempo de cura por ser bem mais baixo devido à presença do resorcinol (STAMM, 1964). São empregados em estruturas de madeira expostas à temperatura ambiente ou pouco aquecidas. Quando a colagem é feita com aquecimento moderado, freqüentemente são misturadas com resinas fenólicas, formando o fenol-resorcinolformaldeído.

Comercializados na forma líquiida, utiliza-se um reagente endurecedor que deve ser adicionado pouco antes do seu uso. Isto porque o resorcinol junto ao endurecedor tem vida útil bastante reduzida em decorrência da reatividade da cola. Podem ser armazenados por longo tempo, no máximo 6 meses, a temperaturas inferiores a $21^{\circ} \mathrm{C}$ e têm custos mais elevados que as resinas fenólicas. Segundo PETERSON (1964), vieram a preencher as necessidades do mercado por um adesivo impermeável e usado em baixas temperaturas. Possuem ainda alta resistência estrutural, maior que a da própria madeira, suportando quaisquer condições a que venha ser exposta, mesmo às alterações climáticas, mantendo sua capacidade resistente em relação ao carregamento. Segundo SKEIST (1977), têm excelente desempenho à fadiga, a condições cíclicas de umidade e temperatura e a muitos solventes, exceto aqueles altamente caústicos. São empregados quando as condições de impermeabilidade são obrigatórias e onde as colas fenólicas, cuja cura é promovida em altas temperaturas, não forem adequadas. A colagem de vigas e painéis estruturais 
e a colagem de laminados marítimos são algumas das aplicações (MYERS, 1988).

\section{- Adesivos Poliuretânicos}

Seu emprego teve início na produção de chapas de madeira aglomerada, na década de 60 . Estas chapas tinham as mesmas características das produzidas com adesivos fenólicos e usadas externamente. Os estudos desenvolvidos indicaram que o emprego dessas chapas, com esta destinação e coladas com adesivos à base de poliuretano, apresentavam propriedades superiores às das chapas coladas com o adesivo fenólico. Possue a vantagem de não emanar formaldeído proporcionando também um produto com alta resistência à umidade.

\section{- Epoxi}

Produzido a partir de resinas à base de epicloridrina e resinas formadas por peroxidação, tem pouca utilização na indústria madeireira devido ao seu alto custo e dificuldade de afinidade com algumas espécies. Tem aplicação em ligações de concreto, metais, vidro e cerâmica.

\subsubsection{Termoplásticos}

Os adesivos termoplásticos apresentam como característica principal a sua cura reversível. Podem ser fundidos ou amolecidos quando é aumentada a temperatura, tornando a solidificar ao serem resfriados. São usados como solução ou em dispersão em água.

O grupo dos acetatos sintéticos polivinílicos, que são adesivos prépolimerizados, é empregado em colagem de madeira onde a cura é feita por perda do solvente dispersante. Tem vida útil muito longa devido à alta estabilidade química e física da dispersão. Com grande resistência à ação de microorganismos, não mancham a madeira. São facilmente manuseados, apresentando propriedades de contato e 
prensagem semelhantes aos adesivos anteriormente citados e exigindo pouca pressão de prensagem. Não devem ser aplicados em construções pesadas, onde a resistência das juntas deve ser alta e em peças coladas de construções expostas ao intemperismo.

Os adesivos orgânicos naturais são obtidos de proteínas animais e vegetais, tanino, celulose, gomas naturais e amidos, entre outros.

\section{- Adesivos Animais}

São obtidos através de proteínas da pele, cartilagem e ossos de animais (SELBO, 1975). Utilizados na forma de placas ou escamas secas, são amolecidos em água fria e dissolvidos em banho-maria. É provável, segundo BROTERO (1946), que tenha sido a primeira cola a ser utilizada pelo homem. Sua principal aplicação é em carpintaria de móveis e em outras destinadas a ambientes internos e não agressivos, devido a facilidade do emprego de sua alta resistência mecânica a seco e de não produzir alteração no aspecto final da madeira como as manchas. HOUWINK \& SALOMON (1965) informam que o colágeno é a principal proteína na composição química desses adesivos, sendo classificados principalmente em dois tipos: a cola obtida de ossos e a cola obtida do couro. A diferença entre as duas é devida ao método de processamento empregado.

\section{- Adesivos de Albumina de Sangue}

De acordo com HOUWINK \& SALOMON (1965) essas colas são obtidas de sangue solúvel, na forma de pó e água. $\mathrm{O}$ sangue seco solúvel é obtido do sangue fresco de animais, pela evaporação do soro, sob pressão reduzida, a uma baixa temperatura, para que seja impedida a coagulação. A albumina coagulada é insolúvel, apresentando pouco poder de adesão. Para melhorar suas propriedades adesivas, empregam-se alcalis na mistura albumina com a água. As suas principais aplicações estão na produção de madeira laminada e na produção de compensados de madeira prensados a quente a fim de tornar insolúvel a proteína. Dessa forma esse adesivo adquire boa resistência à umidade, moderada resistência mecânica, tendo como 
desvantagem a de ser atacada por fungos e bactérias.

\section{- Adesivos de Caseína}

Obtidos principalmente da proteína do leite desnatado, por precipitação com ácido sulfúrico, clorídrico ou lático (HOUWINK \& SALOMON, 1965), são empregados em estruturas, móveis e madeira compensada para interiores não agressivos (SELBO, 1975).

\section{- Adesivos de Soja}

Esses adesivos são obtidos a partir da farinha de soja sendo o mais importante dos vários adesivos oriundos da proteína vegetal. São bastante empregados pela indústria da madeira na fabricação de compensados para interiores, devido ao seu baixo custo. Segundo STAMM (1964) o adesivo à base de soja é semelhante ao adesivo à base de caseína mas apresenta menor resistência do que este.

\section{- Adesivos de Tanino}

Os adesivos de tanino são obtidos a partir de espécies vegetais como a Acácia, cuja pesquisa na África do Sul apresentou o desenvolvimento de uma gama enorme de resinas adesivas para a aplicação em painéis de madeira e vigas laminadas.

O tanino obtido do Quebracho foi introduzido na Europa como constituinte na produção de compensados e aglomerados. Os resultados obtidos com esses adesivos, segundo SAMLAIC (1983), são geralmente superiores aos encontrados com colas de fenol-formol. Experimentalmente os adesivos à base de tanino têm apresentado, a longo prazo, resistência melhor ao intemperismo do que os adesivos fenólicos, possuindo também menor custo. 


\subsection{Objeto do Estudo - Adesivo Poliuretano à Base de Mamona}

\subsubsection{Obtenção do Adesivo}

Conhecida internacionalmente como "Castor Oil" e entre nós por Caturra, a Mamona é uma planta da família das Euforbiáceas, de onde é extraído o óleo de mamona, também conhecido como óleo de rícino. É facilmente encontrada na maioria das regiões do país, principalmente no estado nativo. Tem importantes aplicações industriais como, por exemplo, matéria prima na produção de óleos lubrificantes de alta performance, como fluidos de freios de aviação, cosméticos, polímeros, tintas, entre outras.

A partir deste recurso natural e renovável é possível sintetizar polióis e prepolímeros com diferentes características que, quando misturados, dão origem a um poliuretano. Possuem grande versatilidade da aplicação com propriedades superiores aos polímeros derivados de petróleo. Essas propriedades são governadas pelo seu peso molecular, grau de entrecruzamentos, forças intermoleculares, rigidez dos segmentos que compõem a cadeia e pela sua cristalinidade. Sua competitividade em relação aos outros polímeros, além das propriedades mecânicas, deve-se basicamente a outros dois fatores: polímero originário de matéria prima natural e renovável e aos preços razoáveis dos di-isocianatos disponíveis no país.

Existem duas rotas básicas para se obter uma resina poliuretana. A primeira, ilustrada na figura 15 , está a representação de um processo para a preparação das poliuretanas monocomponente, onde é apresentando o bloqueio linear destacando-se na estrutura básica dos três tipos de intermediários de síntese: o poliól, di-isocianatos e extensores de cadeia. Esta rota de processo, em uma única etapa, resulta em um monocomponente ou como também é conhecido "one shot". Já na figura 16 está representada a rota de preparação de uma resina poliuretana bicomponente. A partir desta rota, obtem-se um polímero onde a polimerização está incompleta, que pode ser denominado de prepolímero. Este prepolímero, quando misturado estequeometricamente a um poliol, resulta em um poliuretano.

Assim as propriedades do polímero tais como a flexibilidade, a rigidez, 
interpenetração de segmentos, força inter-cadeia e entrecruzamento molecular são explicadas a partir do balanceamento e das características químicas do poliol empregado na reação final com o prepolímero.

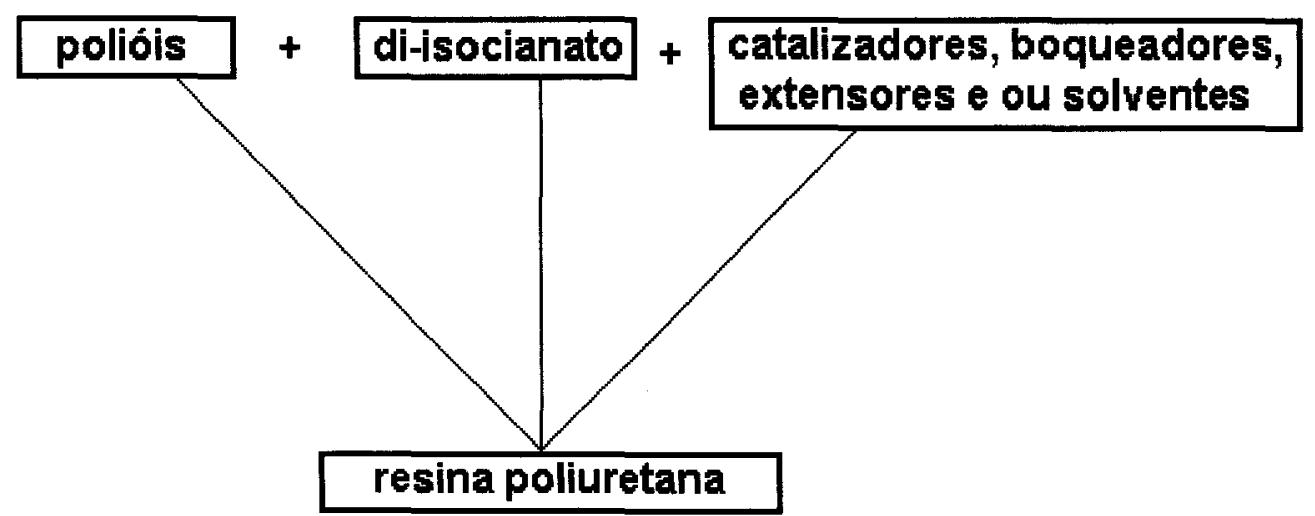

FIGURA 15- Rota de preparação de poliuretanas monocomponentes. Fonte: ARAÚJO, (1992) modificado.

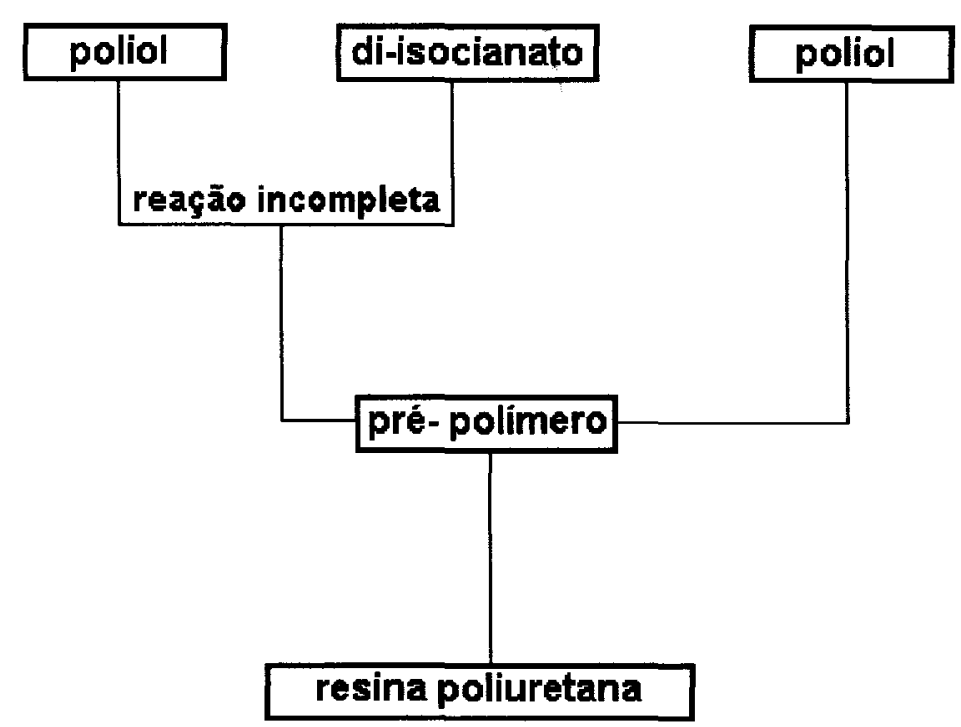

FIGURA 16- Rota de preparação de poliuretanas bicomponentes. Fonte: ARAÚJO, (1992) modificado.

\section{- Poliol}

O óleo obtido da mamona, é um triglicéride natural não comestível. Sua estrutura é apresentada na figura $17 \mathrm{e}$, em termos de sintese de resinas de 
poliuretanos, age quimicamente como um triol, isto é, tem três agrupamentos $-\mathrm{OH}$ secundários não terminais, possuindo menos reatividade em relação a grupos $-\mathrm{NCO}$, quando comparado ao grupamento - $\mathrm{OH}$ primário.

É composto de $89 \%$ de triglicéride do ácido 12-hidroxioleico (ou ácido recinoleico). Possui um sítio de insaturação, ou uma dupla ligação olefinica, entre os carbonos 9 e 10 do ácido ricinoleico e uma hidroxila no carbono 12. São três os sítios de ataque químico que conferem ao óleo de mamona a excepcional versatilidade como matéria prima oleoquímica. Esta versatilidade, aliada ao fato de ser, provavelmente, o único produto natural com pureza próxima da analítica, torna o óleo de mamona um produto ímpar do ponto de vista tecnológico.

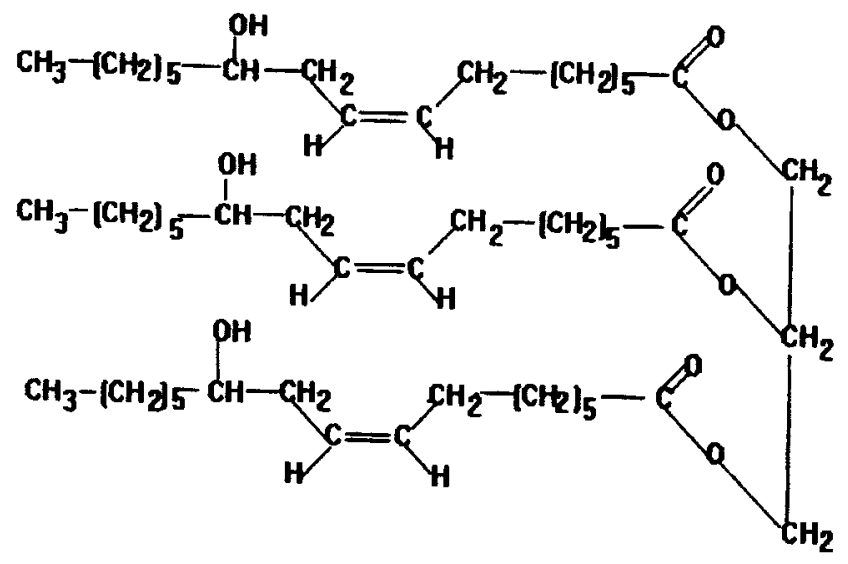

FIGURA 17- Triglicéride do ácido recinoleico. Fonte: ARAÚJO (1992).

De acordo com o fim a que se destina, o óleo de mamona pode apresentar valores diferentes em relação à sua acidez, umidade, entre outros índices. Esta diferença é em decorrência do tipo de prensagem, condicionamento do óleo, tratamento e métodos de purificação empregados.

A característica mais importante é a presença dos três sítios distintos para a preparação dos mais variados produtos industriais. Sua utilização e sua caracterização como matéria prima industrial foram relatadas por $\mathrm{HILDITCH}^{3}, \mathrm{CONGENECKER}^{4} \mathrm{e}$ TALLENT $^{5}$ apud ARAÚJO (1992). Tem uma excepcional estabilidade química

\footnotetext{
${ }^{3}$ HILDITCH, C. P. (1947). The chemical constituition of natural fats. $2^{\text {nd }}$ ed., Chapman and Hall, London.

${ }^{4}$ CONGENECKER (1946). Chem. Ver., vol. 29. p. $201-224$.

${ }^{5}$ TALLENT, W. H.; SUMARELL (1974). J. Am. Oil Chem. Soc., vol. 51 (3), 65-71.
} 
(PALOSE $^{6}, 1964$ apud ARAÚJO, 1992), sendo um composto facilmente não oxidável. Para as reações uretanas o óleo de mamona , pode ser utilizado "in natura", onde deve ter um padrão de pureza, baixa acidez e técnicas de controle de qualidade específicas PLATNER et al $^{7}$, SUPREX $^{8}$ e WHITE \& HOUCK ${ }^{9}$ apud ARAÚJO (1992), ou utilizado como matéria prima de partida para a obtenção de outros polióis.

\section{- Prepolímero - Reações químicas que podem ocorrer com o prepolímero durante a polimerização}

Como o prepolímero possue em sua estrutura isocianatos livres, podem ocorrer reações químicas paralelas durante o processo de polimerização. Algumas dessas reações como as que ocorrem com a água, a amina primária e a uréia dissubstituída e com a ligação uretana equações $1,2,3$ e 4 aumentam o entrecruzamento e a rigidez das cadeias. Outra reação como aquela que ocorre com os compostos hidroxilados, presentes nos compostos da madeira, equação 5, explica a forma com que o adesivo se liga quimicamente com a madeira. (CLARO NETO, 1997).

\section{Reação do isocianato com $\mathrm{H}_{2} \mathrm{O}$}

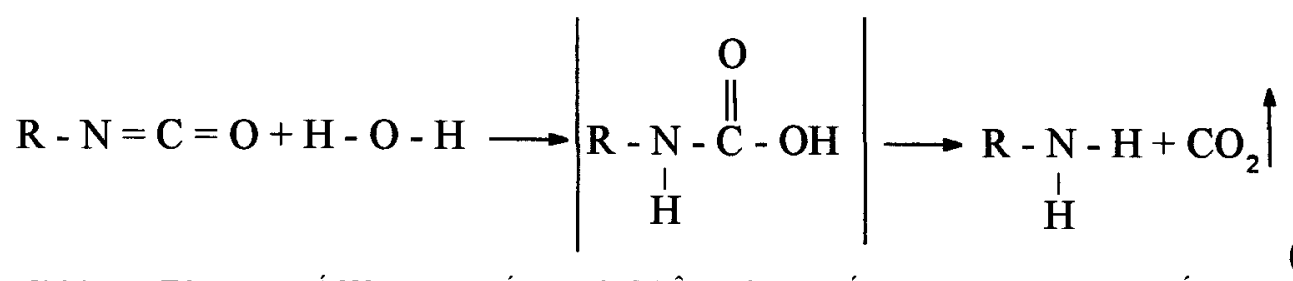

ISOCIANATO ÁGUA ÁCIDO CARBÂMICO-INSTÁVEL AMINA PRIMÁRIA

(Eq. 1)

\footnotetext{
${ }^{6}$ PALOSE, M. M.; ACHAYA,K. T. (1964). Stability of castorseed and oil. Part III- Resistence of oxidation of castor oil. Indian Oilseed Joumal, vol. 8, p. 337-347.

${ }^{7}$ PLATNER, R. D.; SPENCER G. F.; KLEIMEM (1977). Trigliccerides separation by reversal phase high performance liquid chromatography. Joumal of Am. Oil Chem. Soc.,vol. 54 (10).

${ }^{8}$ SUPREX CORPORATION. (1985). Supercritical fluid systems, instruments and process for mono, di and triglycerides.

Tecnical Note.

${ }^{9}$ WHITE, C. D; HOUCK, R. K. (1985). Analysis of mono, di and triglycerides by capillary supercritical fluid chromatography.

Joumal of High Resolution Chromatography Communication, vol. 8, pag. 293-296.
} 


\section{Reação do isocianato com a amina primária}<smiles></smiles>

ISOCIANATO AMINA PRIMÁRIA URÉIA DISSUBSTITUIDA

Reação do isocianato com a uréia dissubstituída<smiles></smiles>

\section{Reações do isocianato com ligação uretana}<smiles></smiles>

ISOCIANATO
(Eq. 4)

ALOFANATO

\section{Reações do isocianato com hidroxilas dos componentes da madeira}

$$
\mathrm{R}-\mathrm{N}=\mathrm{C}=\mathrm{O}+\mathrm{HO}-\mathrm{R}_{2} \longrightarrow \mathrm{R}-\mathrm{N}_{\substack{\text { COMPOSTO } \\ \text { ISOCIANATO } \\ \text { DA MADEIRA }}}
$$

Em 1983, o Grupo de Química Analítica e Tecnologia de Polímeros (GQATP) iniciou no Instituto de Física e Química (IFQSC-USP) a pesquisa e desenvolvimento de polióis para poliuretana. $O$ principal objetivo da pesquisa foi 0 de desenvolver materiais para aplicações em telecomunicações, especialmente em "bloqueio de pressurização de cabos telefônicos", o que permitiu adquirir conhecimento na área de síntese de intermediários para resinas poliuretanas ( PU's). 
A mistura poliól e prepolímero (à base de mamona), a frio, leva a reação de polimerização da mistura. Esta reação conduz à formação da poliuretana, podendo-se variar a porcentagem de poliól, que definirá maior ou menor dureza, bem como o emprego de catalisador adequado a fim de se aumentar a velocidade da reação.

ARAÚJO (1992) conduziu uma série de ensaios a fim de determinar as características das várias composições de resinas poliuretanas, baseadas no óleo de mamona utilizadas no estudo. Por meio de análise química da reação poliol/prepolímero foi realizada uma caracterização através dos índices oleoquímicos como o índice de acidez, índice de hidroxila e o índice de NCO livre (teor de NCO). Com relação à estabilidade térmica das poliuretanas, verificou-se através dos termogramas dos ensaios, que até $220^{\circ} \mathrm{C}$ ocorre apenas uma pequena perda de massa, o que evidencia a estabilidade térmica das resinas até esta temperatura.

Os ensaios mecânicos mostraram concordância com a teoria em relação aos números de sítios rígidos das poliuretanas proporcional ao aumento da porcentagem de -NCO livre na mistura final em relação ao $-\mathrm{OH}$. Para um aumento total do teor de -NCO livre da mistura final entre 7,5 e $12 \%$ foi registrado um acréscimo superior a 155 vezes no valor da carga de ruptura a tração 0,2 Kgf e 31,7 Kgf ou, em termos de tensão de tração 0,09 MPa e 18,15 MPa.

Com relação aos ensaios de dureza Shore A foi observada uma variação nos resultados que indicaram desde resinas muito macias, dureza nula, até valores com dureza 80 Shore A (quase no limite da escala) o que evidencia a versatilidade do sistema. Para um incremento de $1,25 \%$ no teor de -NCO livre da mistura final (intervalo de 7,5 a $12 \%$ ) a dureza aumenta 80 vezes. Isto significa que, quanto maior a porcentagem do prepolímero na mistura reagente, maior a dureza superficial.

\subsection{Mecanismos de Adesão}

O termo adesão significa atração entre uma superfície sólida e uma segunda fase. Esta segunda fase pode consistir de partículas individuais, como pequenas gotas, pó, etc., ou de uma película líqüida ou sólida (HOUWINK \& SOLOMON, 1965). Também pode-se dizer que a adesão é a força atrativa entre moléculas de substâncias 
diferentes, ao contrário de coesão que é a força de atração verificada entre moléculas ou átomos de uma mesma substância.

A adesão é atribuída a várias e diferentes forças, como as forças moleculares e forças de Van der Waals. Estas só podem ser desenvolvidas quando as moléculas estão muito próximas entre si. Por esta razão aplica-se pressão sobre as superfícies das juntas a serem coladas, tanto para colagens a frio, quanto para colagens a quente (OLIVEIRA \& FREITAS, 1995).

Para que haja uma perfeita união entre peças coladas, é de grande importância o conhecimento do mecanismo pelo qual o processo de adesão acontece. Os estudos desses fundamentos tiveram início em 1920 com McBain, na Inglaterra, e Browne, Trnax e Brouse, nos Estados Unidos. Três mecanismos de adesão foram definidos: a adesão mecânica, a adesão específica e a adesão química. Segundo relata KNIGHT (1952), McBbain definiu a adesão mecânica e a adesão específica, enquanto que a adesão química é citada por HOEKSTRA \& FRITZUIS (1951).

A adesão mecânica se dá entre superficies porosas baseadas no entrelaçamento da cola endurecida na junta de colagem e nos poros do aderente (GALAZ, 1979). A colagem fica então dependente da estrutura superficial do substrato, (conhecido também por aderente), da pressão, da viscosidade, etc..

A adesão específica se processa entre duas superficies lisas, onde as forças básicas de adesão entre as macromoléculas são devidas às ligações químicas secundárias de atração. As forças mais significativas para a resistência da ligação são, em especial, as forças de polarização e as pontes de hidrogênio (KOCH et al., 1987), considerando-se também as forças entre moléculas não polares, também conhecidas como forças de dispersão, responsáveis pela formação dos cristalitos dos adesivos.

$\mathrm{Na}$ adesão química, as forças básicas envolvidas são as de ligações primárias, de natureza essencialmente eletrônica (ligações entre átomos ou íons, podendo ser ligações metálicas, eletrovalentes e covalentes). A ặåp dessas forças, especificamente químicas, não é considerada como promotora da adesão, uma vez que as forças secundárias podem responder pela resistência e versatilidade da maioria dos adesivos industriais. Segundo MANTILLA CARRASCO (1984), o emprego criterioso das ligações químicas entre o adesivo e o aderente é responsável, em última instância, pela 
resistência e duração da ligação adesiva. Só se justificando o emprego dos adesivos químicos reativos quando os adesivos convencionais não são capazes de produzir uma adesão satisfatória, por causa do seu alto custo, fraca estabilidade no armazenamento e grande seletividade relativa ao tipo de aderente. De qualquer forma o estudo deste tipo de adesão possibilita uma expansão maior do emprego dos adesivos em estruturas. O problema a ser resolvido está na produção de um promotor de adesão química com atuação generalizada.

\subsection{Escolha do Adesivo}

A escolha do adesivo deve passar pela análise de alguns fatores, a fim de que seja feita uma avaliação correta em relação ao seu comportamento desde a sua elaboração até a cura e a obtenção da ligação adesiva. Entre esses fatores podem ser citados:

\section{- Penetração}

A penetração ocorre pela ação capilar, por difusão e pela diferença de temperatura. A porosidade do sólido e a viscosidade do líquido exercem influência fundamental sendo que a combinação desses dois fatores garante uma eficiente penetração do adesivo na superficie aderente.

\section{- Extensão}

Este fator está ligado com a fluidez da cola e interfere no escoamento da massa líqüida do adesivo sobre plano do aderente. Ao se colocar uma gota de um líqüido sobre a superficie de um sólido, polido e sem contaminações, esta formará um ângulo com a superficie do sólido. Quando a gota se estende de tal forma que fica impossível a medição do ângulo de contato, o líqüido terá umedecido completamente a superfície do sólido, ou seja, apresenta o maior grau de molhagem, encontrando-se dessa forma em estreito contato com a mesma (umectação completa figura 18A). 
Quando a gota não se comporta dessa maneira, surge um ângulo nítido (umectação incompleta figura 18B). Pode ocorrer ainda o caso de um contato praticamente sem umectação (figura 18C).

Um ângulo de contato próximo a zero é condição necessária mas não suficiente para que haja uma boa penetração do adesivo no aderente, possibilitando uma ligação mais resistente.

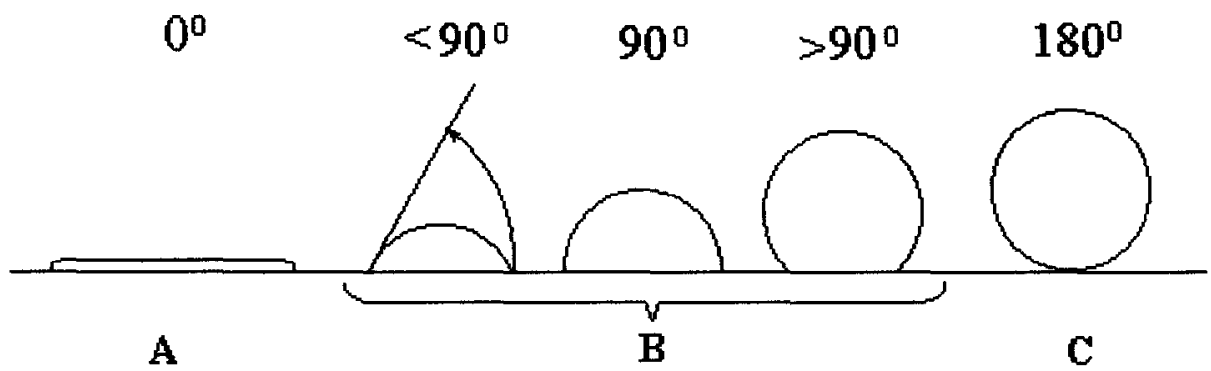

FIGURA 18 - Ângulo de contato. Fonte: HOUWINK \& SOLOMON (1965)

\section{- Difusão}

Quando um sólido entra em contato com as moléculas de um líqüido, as absorve até atingir a saturação. Neste instante não haverá mais absorção, a não ser que ocorram mudanças nas condições externas ou um gradiente que force a migração das moléculas.

As ligações adesivas são consideravelmente influenciadas pelo processo de difusão. Deve-se ter cuidado quando da escolha dos solventes para se obter uma boa difusão do adesivo no aderente.

\section{- Solubilidade}

A solubilidade é a causa de um material se misturar de forma mais rápida. Quando se emprega um aderente de material orgânico, o conhecimento de sua solubilidade ajudará na seleção do adesivo mais adequado. Quanto mais próximos forem os parâmetros de solubilidade dos adesivos e aderentes, maior sua afinidade (REINHART \& CALLOMON, 1959). 


\section{- Deformação e Fluxo - Reologia}

A capacidade de um líqüido fluir é influenciada pela viscosidade, plasticidade e elasticidade. $\mathrm{O}$ adesivo é uma substância visco-elástica que se caracteriza por uma elasticidade retardada. Nos sólidos que obedecem à lei de Hooke, a deformação é imediata e proporcional à tensão. Já os visco-elásticos podem demorar algum tempo para atingirem sua deformação elástica final. A velocidade de deformação para estas substâncias, mantida a carga constante, é inicialmente rápida diminuindo até completar-se a deformação elástica (HOEKSTRA \& FRITZIUS, 1951).

$\mathrm{O}$ adesivo deve fluir ou deformar-se, buscando penetrar nos poros do aderente, deslocando o ar e chegando a um contato estreito com a superficie do mesmo. Deve possuir consistência suficiente para alcançar espessura adequada da linha de cola, quando do seu espalhamento.

\section{- Adesividade}

É definida como sendo a força capaz de promover a separação entre o adesivo e o aderente, na região da interface, logo após terem sido postos em contato. Não é uma propriedade fundamental, podendo ser alterada quando da aplicação do adesivo.

\section{- Tensões Térmicas e de Retração}

Um sólido pode se contrair ou expandir, em função da variação de sua temperatura. Se os coeficientes de dilatação térmica do adesivo e do aderente forem diferentes, serão desenvolvidas, nas interfaces, tensões tangenciais que podem contribuir para uma redução da resistência da ligação.

\section{- Viscosidade}

Este fenômeno é definido como sendo a resistência que um líqüido apresenta ao escoamento. Influi diretamente na capacidade que o adesivo tem de se espalhar, penetrar e se deformar. 


\section{- Tempo de Cura}

Corresponde ao tempo que o adesivo, recém preparado, leva para desenvolver sua resistência. Este tempo pode ser modificado em função do tipo e quantidade do catalisador empregado ou com as alterações das condições externas de temperatura e pressão.

\section{- Vida Útil}

Definida como o tempo decorrente entre a preparação ou mistura do adesivo até a sua aplicação final, sem que se observem alterações nas suas características iniciais ou ocorra endurecimento.

\section{- Tempo de Armazenamento}

É o tempo compreendido entre a data de fabricação do adesivo e o instante em que ele, armazenado, apresenta alterações nas suas propriedades físico-químicas.

\section{- Rendimento}

Compreende a relação entre a quantidade em peso do adesivo gasto, por área da superficie de aplicação.

\subsection{Fatores que Influenciam a Ligação Adesiva}

A análise do comportamento de uma ligação adesiva deve ser feita considerando-se o desempenho do sistema adesivo/aderente. Entre os fatores que influenciam esse comportamento estão, sem dúvida, a solubilidade do adesivo ao aderente, a rugosidade do aderente, a penetração do adesivo no aderente, a fluidez e consistência do adesivo, a espessura da linha de colagem e a pressão aplicada.

Quanto menor a diferença entre os parâmetros de solubilidade do sistema adesivo/aderente, maior a afinidade. $\mathrm{O}$ maior grau de molhagem permite um maior contato entre adesivo e aderente, o que resulta em uma ligação mais resistente. 
A rugosidade da superficie do aderente pode proporcionar maior eficiência nas ligações, por apresentar maior área de contato do adesivo com o aderente. Isto pode ser observado, em especial, quando da ocorrência de solicitações tangenciais (cisalhamento).

A profundidade de penetração do adesivo no interior do aderente é dependente da permeabilidade e do tipo de porosidade (forma e dimensões dos poros) do aderente, da viscosidade, do tempo de cura e da tensão de adesão. A fluidez do adesivo tem importância para que a sua penetração ocorra de forma adequada sendo que a falta ou excesso de penetração produz espessura da linha de cola deficiente, colaborando com o enfraquecimento da junta, diminuindo a sua resistência.

A temperatura atua como um catalisador nas reações químicas que ocorrem durante o processo de colagem. Dessa forma influencia no período de tempo em que o adesivo pode ser manipulado, no tempo de montagem das peças, na pressão aplicada durante a colagem no tempo de prensagem, entre outros fatores.

A espessura da linha adesiva deve ser a mais fina possível sem, no entanto, comprometer a quantidade de adesivo necessário na ligação. Essa espessura além de ser influenciada pela consistência é, também, dependente da pressão aplicada sobre os elementos a serem unidos, uma vez que esta pressão, sendo feita antes da cura, produz a expulsão do ar da interface do aderente e o enchimento dos seus poros (MANTILLA CARRASCO, 1984).

\subsection{Conclusões}

A tabela 2, a seguir, ressalta que a grande maioria dos adesivos estudados nesta revisão tem seu emprego restrito à fabricação de móveis, compensados e aglomerados de madeira, com uso em ambientes interiores, não agressivos, pois são afetados negativamente pela umidade e por possuírem baixa resistência mecânica.

A grande lacuna observada situa-se no grupo dos adesivos para uso estrutural (grande resistência mecânica) e com emprego em ambientes internos e externos (resistência ao intemperismo).

A caseína tem boa resistência mecânica, podendo ser usada em ligações de peças estruturais de madeira, mas com o inconveniente de ser pouco resistente à ação 
da umidade, restringindo seu uso para ambientes internos não agressivos.

O fenol-formaldeído tem grande emprego na fabricação de compensados e em madeira aglomerada. É resistente à ação do intemperismo, podendo ser usado em ambientes internos ou externos e possui grande resistência mecânica.

TABELA 2- Tipos de adesivos, usos e condições

\begin{tabular}{|c|c|c|c|}
\hline ADESIVOS & BASE & USO & CONDIÇÕES DE USO \\
\hline Origem animal & $\begin{array}{l}\text { Proteínas de peixe, } \\
\text { de cartilagem, de } \\
\text { ossos, de tendões. }\end{array}$ & $\begin{array}{l}\text { Carpintaria de } \\
\text { móveis }\end{array}$ & $\begin{array}{l}\text { Ambientes internos não } \\
\text { agressivos. }\end{array}$ \\
\hline Sangue & Albumina de sangue & Compensados & $\begin{array}{l}\text { Ambientes internos não } \\
\text { agressivos. }\end{array}$ \\
\hline Caseína & Proteína do leite & $\begin{array}{l}\text { Móveis, } \\
\text { compensados, } \\
\text { estruturas }\end{array}$ & $\begin{array}{l}\text { Ambientes internos não } \\
\text { agressivos, boa resistência } \\
\text { mecânica }\end{array}$ \\
\hline Soja & $\begin{array}{l}\text { Amido, farinha de } \\
\text { soja }\end{array}$ & Compensados & $\begin{array}{l}\text { Ambientes internos e externos, } \\
\text { baixa resistência ao } \\
\text { intemperismo }\end{array}$ \\
\hline Tanino & Acácia, Quebracho & $\begin{array}{l}\text { Compensados, } \\
\text { aglomerados }\end{array}$ & $\begin{array}{l}\text { Ambientes internos e externos, } \\
\text { moderada resistência ao } \\
\text { intemperismo }\end{array}$ \\
\hline Fenol-formaldeído & $\begin{array}{l}\text { Resina termofixa, } \\
\text { Fenólica }\end{array}$ & $\begin{array}{l}\text { Compensados, } \\
\text { aglomerados }\end{array}$ & $\begin{array}{l}\text { Exteriores, boa resistência } \\
\text { mecânica }\end{array}$ \\
\hline Uréia-formaldeído & $\begin{array}{l}\text { Resina termofixa, } \\
\text { Fenólica }\end{array}$ & $\begin{array}{l}\text { Compensados, } \\
\text { aglomerados }\end{array}$ & $\begin{array}{l}\text { Ambientes interiores, boa } \\
\text { resistência mecânica }\end{array}$ \\
\hline $\begin{array}{l}\text { Resorcinol- } \\
\text { Formaldeído; } \\
\text { Fenol-Resorcinol- } \\
\text { Formaldeído }\end{array}$ & $\begin{array}{l}\text { Resina termofixa, } \\
\text { Fenólica } \\
\text { Resorcínica }\end{array}$ & $\begin{array}{l}\text { Compensados, } \\
\text { estruturas, } \\
\text { madeira } \\
\text { laminada }\end{array}$ & $\begin{array}{l}\text { Interiores e exteriores, boa } \\
\text { resistência mecânica }\end{array}$ \\
\hline Isocianato & $\begin{array}{l}\text { Resina termofixa } \\
\text { isocianato, metano }\end{array}$ & Aglomerados & Interiores \\
\hline $\begin{array}{l}\text { Acetato de } \\
\text { polivinil }\end{array}$ & $\begin{array}{l}\text { Resina } \\
\text { termoplástica }\end{array}$ & $\begin{array}{l}\text { Uso não } \\
\text { estrutural }\end{array}$ & Interiores \\
\hline $\begin{array}{l}\text { Poliuretano/ } \\
\text { mamona }\end{array}$ & $\begin{array}{l}\text { Resina termofixa, de } \\
\text { mamona }\end{array}$ & $\begin{array}{l}\text { Uso estrutural } \\
\text { (indicações } \\
\text { preliminares) }\end{array}$ & $\begin{array}{l}\text { Interiores e exteriores, resistente } \\
\text { ao intemperismo, boa resistência } \\
\text { mecânica (indicação preliminar) }\end{array}$ \\
\hline Epoxi & $\begin{array}{l}\text { Resina termofixa } \\
\text { multi-componente }\end{array}$ & $\begin{array}{l}\text { Reparos } \\
\text { estruturais }\end{array}$ & $\begin{array}{l}\text { Exteriores e interiores úmidos, } \\
\text { boa resistência mecânica }\end{array}$ \\
\hline
\end{tabular}


O resorcinol-formaldeído é empregado na fabricação de estruturas de madeira laminada colada (MLC), em ligações estruturais de madeira e em embarcações. Tem grande resistência mecânica e grande resistência ao intemperismo, sendo empregado tanto em ambientes internos como em ambientes externos, com colagem processada a temperatura ambiente. Pode ser utilizado em misturas com resinas fenólicas, dando origem ao fenol-resorcinol-formaldeído, porém com a colagem feita com aquecimento moderado e possuindo as mesmas características do resorcinol-formaldeído, mas com custo menos elevado.

O epoxi tem sua maior aplicação em reparos estruturais, apresentando resistência mecânica e à umidade. Tem como inconvenientes seu alto custo e pouca afinidade com algumas espécies de madeira.

Dos adesivos comercializados no país, o CASCOPHEN, segundo informações do fabricante (ALBA QUÍMICA, 1998), uma resina à base de resorcinol-formol, é o único que tem as características indicadas para o uso de estruturas de madeira em ambientes internos e externos Seu custo é elevado e é produzido apenas por uma única indústria.

Partindo do exposto, o estudo do emprego do adesivo poliuretano à base de mamona em MLC, se coloca como uma alternativa, pois sua tecnologia é de domínio de pesquisadores nacionais e obtido de um recurso natural renovável que é a mamona. Há indicativos do seu bom desempenho mecânico e de sua resistência ao intemperismo, sendo que sua colagem é processada em temperatura ambiente. 


\section{ENSAIOS PRELIMINARES}

A condução dos ensaios preliminares teve como objetivo a verificação da influência de alguns fatores na eficiência da adesão e no processo de colagem, auxiliando na definição da metodologia a ser empregada na pesquisa. Além disso observou-se o comportamento do adesivo poliuretano à base de mamona frente ao adesivo comercial Cascophen RS 212-M, um resorcinol-formaldeído, o mais empregado pela indústria brasileira da madeira laminada colada.

\subsection{Espécies de madeira, adesivos, obtenção dos corpos- de-prova e condução dos ensaios}

Para a avaliação da eficiência do adesivo foram realizados ensaios de cisalhamento na lâmina de cola, de corpos-de-prova de madeira colados, empregandose quatro espécies de madeira sendo duas nativas de alta densidade, Jatobá (Hymenaea spp) e Ipê (Tabebuia serratifolia) e duas exóticas de reflorestamento, de baixa densidade, Pinus elliottii e Eucaliptus grandis. A escolha dessas espécies deuse em função de se poder promover uma pré-avaliação do comportamento dos adesivos frente a diferentes densidades. Estes ensaios foram conduzidos de acordo 
com as recomendações da norma brasileira NBR 7190/97. De cada espécie, por tempo de cura, foram retirados 10 pares de corpos-de-prova, com as mesmas características, ou seja pares gêmeos possuindo os mesmos anéis de crescimento. De cada par, um corpo-de-prova foi utilizado para avaliação do adesivo em estudo e outro, de controle, para avaliação da resistência ao cisalhamento da madeira maciça (figura 19), correspondendo a cinco réplicas por adesivo estudado.

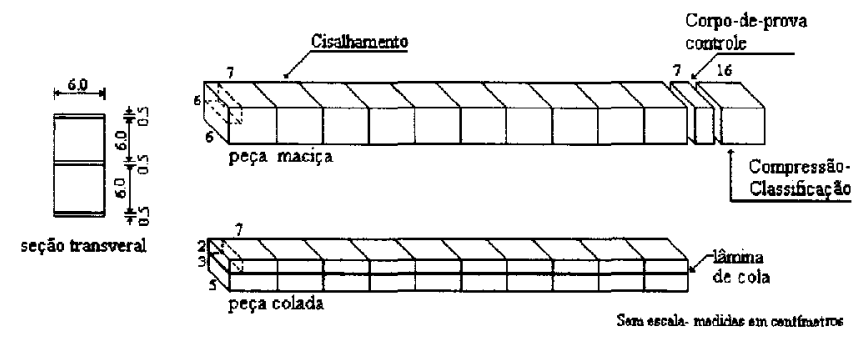

FIGURA 19- Obtenção dos corpos-de-prova de cisalhamento

Foram utilizados dois tipos de adesivos: o Cascophen e o adesivo poliuretano à base de resina de mamona. O Cascophen RS216M foi empregado com o preparador endurecedor FM60M, na proporção de cinco partes de cola para uma de endurecedor e o adesivo à base de resina de mamona na proporção de uma parte de prepolímero A249 para uma parte de poliol B1640. A escolha do adesivo Cascophen deve-se ao fato de ser o único fabricado no país com as características recomendadas para o uso de estruturas, tanto em ambientes internos como em externos, por sua colagem ser processada em temperatura ambiente e por possuir grande resistência mecânica.

$O$ experimento foi conduzido em temperatura ambiente, utilizando os parâmetros de colagem citados pela literatura (FERREIRA et al., 1988; MANTILLA CARRASCO, 1984 e 1989; MACEDO, 1996) como: pressão de colagem de 0,6 MPa, tempo de montagem aberta 7 minutos, fechada 25 minutos, consumo de cola de $350 \mathrm{~g} / \mathrm{m}^{2}$, tempo de prensagem de 8 horas. O tempo de cura variou de $4,6,8,10$ até 18 dias.

\subsection{Resultados}

Nas figuras a seguir são apresentados os valores médios obtidos nos ensaios 
realizados com os adesivos Cascophen e o adesivo poliuretano à base de mamona e com os corpos-de-prova maciços de controle.

Pode-se observar na figura 20, com a espécie Pinus elliottii, que os valores médios dos ensaios do adesivo à base de mamona foram superiores aos do Cascophen, exceto aqueles ensaiados com o tempo de cura de 6 dias, onde o valor do Cascophen foi de 7,82 $\mathrm{MPa}$ e o derivado da mamona 7,63 $\mathrm{MPa}$.

Aos 10 dias obteve-se o valor máximo de resistência para o adesivo à base de mamona, 12,05 MPa, superior à média dos corpos-de-prova de controle, 10,89 $\mathrm{MPa} \mathrm{e}$ superior ao do Cascophen 9,44 $\mathrm{MPa}$.

Com relação à forma de ruptura, tanto os corpos-de-prova colados com o adesivo à base de mamona quanto aqueles colados com o Cascophen, apresentaram o mesmo comportamento. $20 \%$ romperam na lâmina de cola, outros $20 \%$ na lâmina de cola e na madeira e $60 \%$ na madeira.

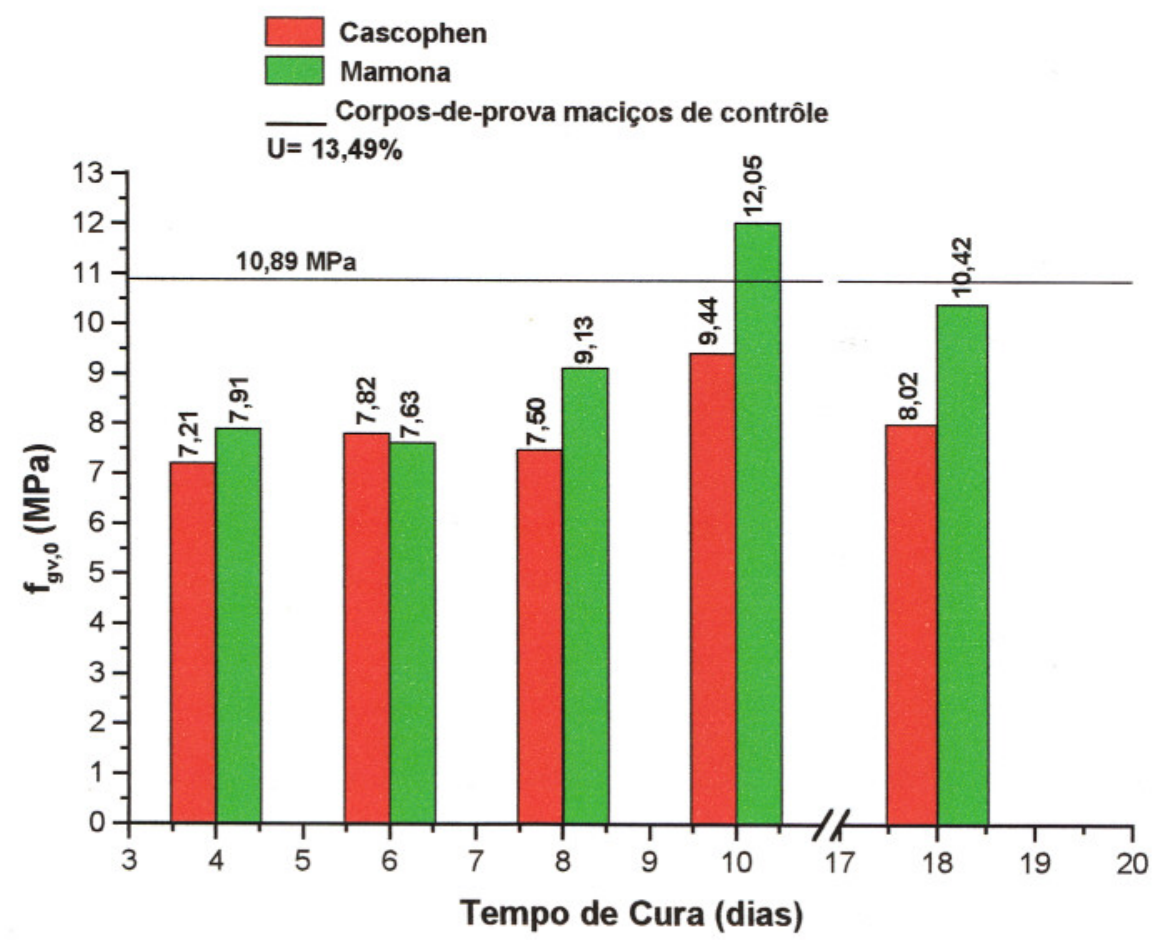

FIGURA 20- Pinus elliotii - resistência ao cisalhamento

Os resultados dos ensaios com o Eucaliptus grandis são apresentados na figura 21 , onde se verifica um comportamento mais uniforme dos resultados do 
adesivo à base de mamona em relação aos resultados do Cascophen. Os resultados dos ensaios do Cascophen foram ligeiramente superiores aos obtidos para a mamona aos 8 dias e 18 dias de cura. Aos 8 dias o adesivo Cascophen alcançou 9,21 MPa e a mamona 8,99 $\mathrm{MPa}$ enquanto que aos 18 dias esses valores foram de 10,16 $\mathrm{MPa}$ e 9,37 MPa para o Cascophen e para a mamona, respectivamente. Os corpos-de-prova de controle tiveram o valor médio de resistência de 8,81 MPa.

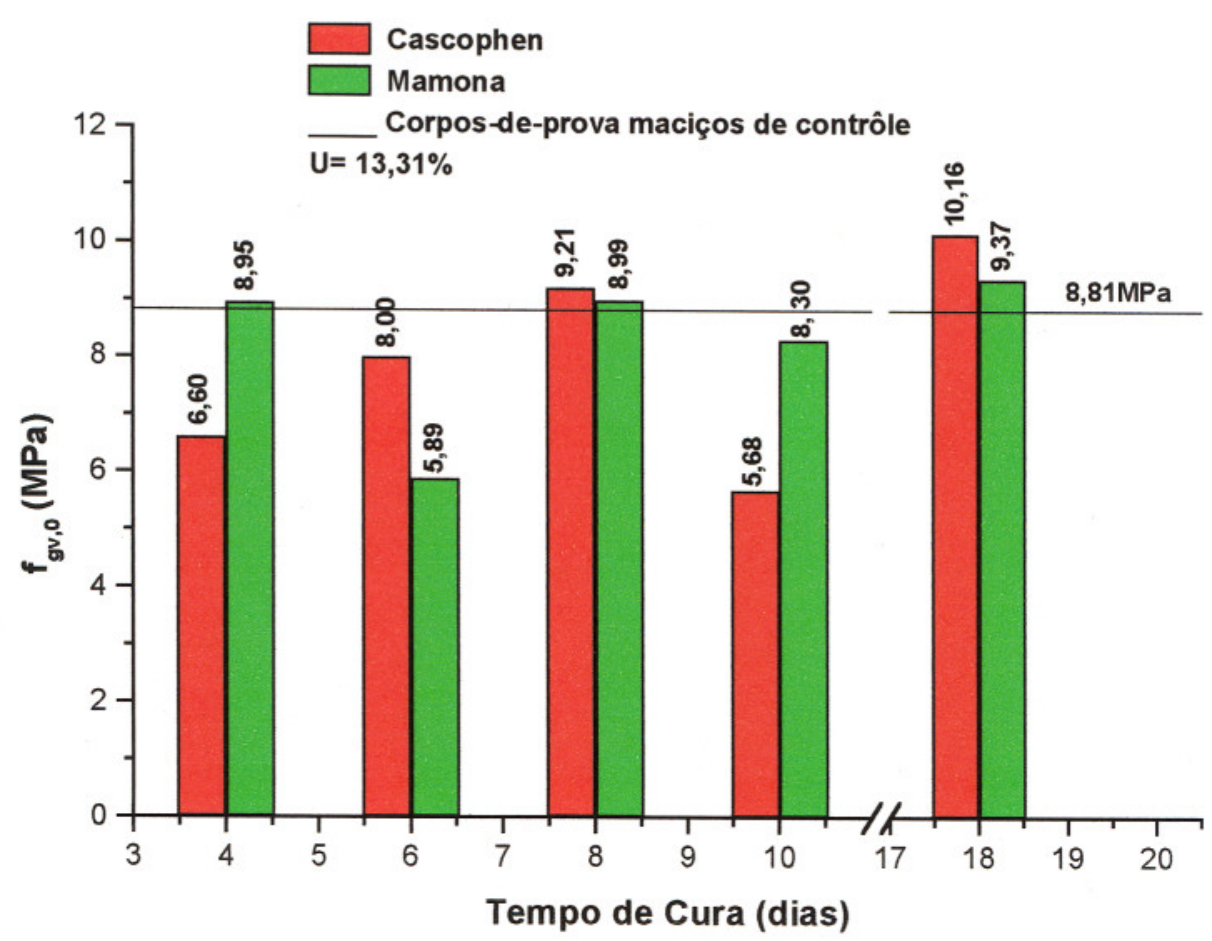

FIGURA 21- Eucaliptus grandis - resistência ao cisalhamento

Dos corpos-de-prova colados com o adesivo à base de mamona, $50 \%$ romperam na madeira, $40 \%$ na lâmina de cola e na madeira e $10 \%$ na lâmina de cola. Para o Cascophen, $40 \%$ romperam na madeira e $60 \%$ na lâmina de cola e na madeira.

Na figura 22 estão os resultados dos ensaios com o Ipê, onde fica evidenciado o melhor comportamento do Cascophen em comparação com o adesivo à base de mamona, mas inferior à média dos corpos-de-prova de controle 25,81 $\mathrm{MPa}$. 


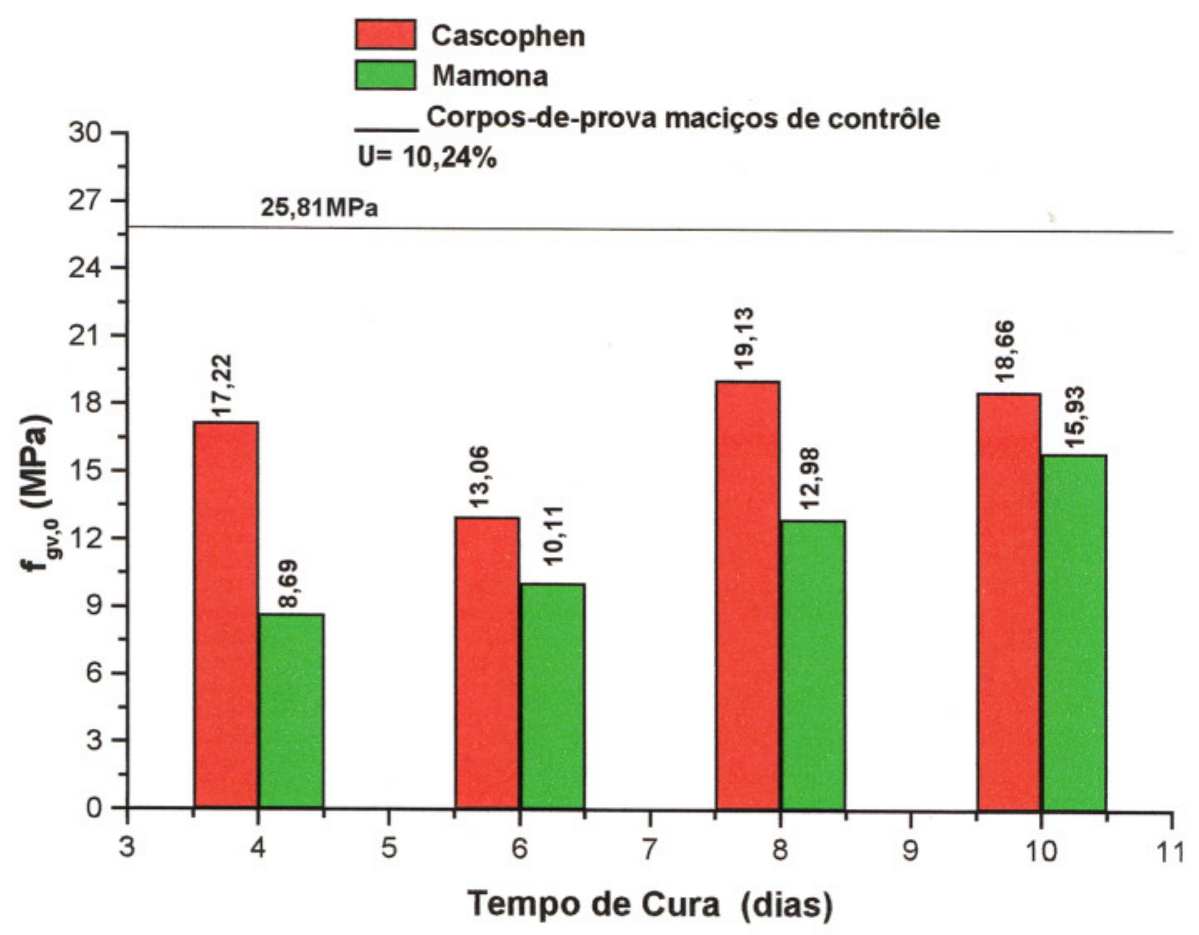

FIGURA 22- Ipê - resistência ao cisalhamento

Observa-se uma tendência de aumento na resistência com o tempo de cura para o adesivo à base de mamona, o que não ocorreu com o Cascophen.

O valor máximo encontrado para o Cascophen ocorreu aos 8 dias de cura com o valor de $19,13 \mathrm{MPa}(12,98 \mathrm{MPa}$ para a mamona). Aos 10 dias de cura o adesivo à base de mamona alcançou o valor de $15,93 \mathrm{MPa}$ e o Cascophen 18,66 MPa.

Todos os corpos de prova ensaiados com os adesivos apresentaram ruptura na lâmina de cola.

Os valores encontrados para o ensaio do Jatobá estão apresentados na figura 23 e mostram que o Cascophen foi superior ao adesivo à base de mamona e inferior à média dos corpos-de-prova de controle $(20,75 \mathrm{MPa})$.

Para o tempo de cura de 6 dias o Cascophen alcançou a resistência de 13,97 $\mathrm{MPa}$ e a mamona $12,99 \mathrm{MPa}$. Aos 8 dias os valores encontrados foram: Cascophen $17,06 \mathrm{MPa}$ e mamona $12,74 \mathrm{MPa}$.

A ruptura dos corpos-de-prova para os dois adesivos ocorreu na lâmina de cola. 


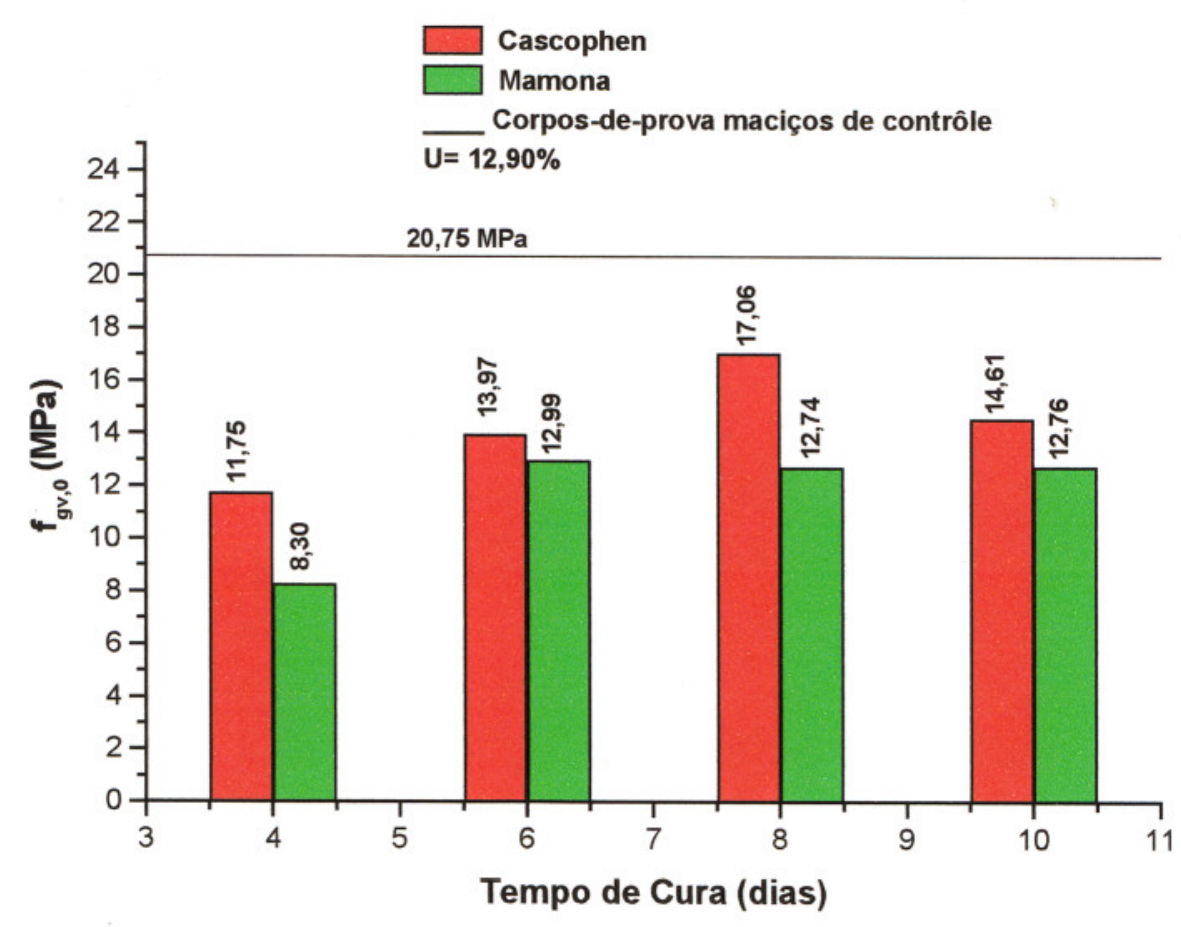

FIGURA 23- Jatobá - resistência ao cisalhamento

\subsection{Conclusões preliminares}

Os resultados dos ensaios de cisalhamento permitem algumas conclusões preliminares:

- Os resultados da resistência ao cisalhamento dos corpos-de-prova colados com o adesivo à base de mamona apresentaram valores e comportamento superiores aos ensaios com o adesivo Cascophen para o Pinus elliottii. Alcançaram aos 10 dias de cura $(12,05 \mathrm{MPa})$, desempenho superior a média dos corpos-de-prova de controle $(10,89 \mathrm{MPa})$.

- O desempenho dos corpos-de-prova de Eucaliptus grandis, colados com adesivo à base de mamona, foi superior ao do adesivo Cascophen pois seus valores apresentaram comportamento mais uniformes.

- Estas espécies, por serem mais permeáveis, absorvem mais o polímero, alterando 
a estrutura da madeira na interface madeira/adesivo, resultando em um aumento dos valores de resistência que, por vezes, ultrapassaram os valores encontrados para a madeira maciça. Isto não foi verificado com o Ipê e o Jatobá por serem espécies mais densas e menos porosas.

- Nos corpos-de-prova de Ipê colados com o adesivo à base de mamona, ficou evidenciada a tendência do aumento da resistência com o aumento do tempo de cura. Este fato deve-se, provavelmente, à baixa permeabilidade do Ipê. Isto faz com que a adesão química assuma maior responsabilidade no processo de colagem do que a mecânica. No caso do Jatobá esta tendência de aumento de resistência com o tempo não foi verificada. Um outro fator que pode prejudicar o processo de adesão são os extrativos da madeira como, por exemplo, a “ipeína" presente no Ipê.

- Observou-se uma tendência de que o melhor tempo de cura foi de 8 dias. Para o Pinus elliottii , o tempo de 10 dias também é um valor aceitável.

- Os parâmetros de colagem empregados nos ensaios (pressão de colagem 0,6 MPa, tempo de prensagem 8 horas e consumo $350 \mathrm{~g} / \mathrm{m}^{2}$ ), situam-se na faixa daqueles recomendados na literatura para outros adesivos com finalidade estrutural e se mostram adequados como ponto de partida para os ensaios principais com o adesivo poliuretano à base de mamona. $\mathrm{O}$ tempo de cura, como indicaram os ensaios, ficou em 8 dias.

Partindo desses resultados preliminares, pode-se afirmar que o estudo do emprego do adesivo poliuretano à base de mamona em MLC, se coloca como uma alternativa para a indústria, pois sua tecnologia é de domínio de pesquisadores nacionais e obtido de um recurso natural renovável que é a mamona. Tem ainda como vantagens a da sua colagem poder ser processada em temperatura ambiente e as evidências de sua boa resistência ao intemperismo reveladas pelas pesquisas do GQATP do IQSC. Na continuação pretende-se determinar os melhores parâmetros para a sua utilização industrial.

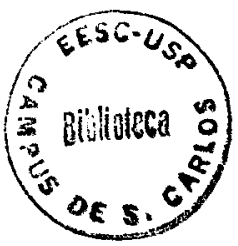




\section{MATERIAIS E MÉTODOS}

Neste capítulo serão descritos os materiais e os métodos empregados no desenvolvimento do trabalho, como as espécies de madeiras, o adesivo e os equipamentos, assim como suas especificações. Serão descritas as metodologias de obtenção dos diferentes corpos-de-prova, suas dimensões, condução dos ensaios e o planejamento estatístico empregado.

\subsection{Materiais}

\subsubsection{Essências Florestais}

Para o desenvolvimento deste trabalho, foram escolhidas duas espécies de madeira de reflorestamento, o Pinus caribea hondurensis, uma conífera, e o Eucaliptus grandis, uma folhosa. De cada espécie foi obtida uma árvore doada pelo Instituto Florestal do Estado de São Paulo, Horto Florestal de Itirapina, possuindo 29 e 25 anos de idade, respectivamente. A escolha dessas espécies foi motivada por serem madeiras de reflorestamento, por sua abundância nas regiões Sul e Sudeste, 
pela localização nestas regiões das indústrias que produzem madeira laminada colada (MLC) e por serem algumas das espécies das mais empregadas na construção de estruturas de MLC.

\subsubsection{Adesivo}

O adesivo estudado, o poliuretano derivado do óleo de mamona, é do tipo bicomponente, composto pelo poliol B1640 e pelo prepolímero A249, de cura a frio. Após a mistura dos componentes sua viscosidade aumenta e seu tempo de utilização é de aproximadamente 20 minutos. $\mathrm{O}$ adesivo foi obtido junto ao Laboratório de Química e Física Molecular do Instituto de Química de São Carlos.

\subsubsection{Equipamentos}

Para a caracterização mecânica do adesivo estudado, foram realizados os ensaios estáticos de cisalhamento, tração normal na lâmina de cola e tração paralela de emendas dentadas coladas, previstos na norma brasileira NBR7190/97 'Projeto de Estruturas de Madeira”. Para a condução dos ensaios utilizou-se duas máquinas universais de ensaios, uma AMSLER com capacidade de carregamento de $250 \mathrm{KN}$ e uma DARTEC M1000/RC, para ensaios estáticos e dinâmicos, com capacidade 100 KN.

As dimensões dos corpos-de-prova foram obtidas empregando-se paquímetro digital com precisão de $0,01 \mathrm{~mm}$.

Em ensaios mecânicos foram avaliados alguns fatores que influenciam o processo de adesão, como a pressão de colagem, o tempo de aplicação de pressão, a viscosidade do adesivo (através do controle do tempo decorrido entre a mistura dos componentes do adesivo e seu espalhamento sobre as superficies a serem coladas) e o tempo de cura, procurando-se os valores mais adequados para que se possa desenvolver maior resistência. Essas avaliações foram conduzidas por espécie de madeira e por tipo de ensaio realizado. 


\subsection{Métodos}

\subsubsection{Ensaios}

Os ensaios mecânicos empregados neste trabalho foram: ensaio de cisalhamento na lâmina de cola, solicitação mais crítica para o processo de colagem; ensaio de tração normal na lâmina de cola, aquele que mais exige de estruturas de MLC curvas e o ensaio de tração paralela de emendas dentadas coladas, o mais crítico para as emendas longitudinais de estruturas de MLC.

Os ensaios de cisalhamento e tração normal na lâmina de cola foram conduzidos de acordo com a NBR7190/97, adotando-se três níveis de pressão de colagem $(0,4 ; 0,6$ e $0,8 \mathrm{MPa})$ e de tempo de aplicação de pressão (4, 6 e 8 horas). Os valores medianos desses níveis correspondem aos valores recomendados na literatura, NEIVA \& HELLMEISTER (1988), FERREIRA et al. (1988), MACÊDO, (1996) e MANTILLA CARRASCO (1984 e 1989).

Conforme os estudos de STRICKLER (1967), nos ensaios de tração paralela de emendas dentadas coladas a pressão de colagem, para madeiras coníferas, varia entre 7,0 MPa e 8,4 MPa e para as folhosas 10,5 MPa e 12,6 MPa. Neste trabalho adotou-se os níveis de pressão de 7, 8 e $9 \mathrm{MPa}$ para as coníferas e 8, 10 e $12 \mathrm{MPa}$ para as folhosas. A pressão foi aplicada de forma quase que instantânea, sem que fosse necessário mantê-la por algum tempo, como ocorreu nos ensaios de cisalhamento e tração normal na lâmina de cola, descritos anteriormente.

Nos ensaios de cisalhamento e de tração normal, a pressão de colagem foi aplicada nas peças a serem coladas, de forma uniforme, utilizando-se uma estrutura de reação e anéis dinamométricos de $100 \mathrm{KN}$. No ensaio de tração paralela, a pressão de colagem foi aplicada nas peças, através de máquina universal de ensaios de $250 \mathrm{KN}$.

Em todos os ensaios foram adotados os níveis de 0,3 e 6 minutos para a viscosidade (tempo decorrido desde o preparo do adesivo até a sua aplicação nas peças). 
Baseado na literatura (MACÊDO, 1996) adotou-se o tempo de montagem aberta de 7 minutos (tempo decorrido entre a aplicação do adesivo nas peças e sua união), tempo de montagem fechada de 25 minutos (tempo decorrido entre a união das peças e a aplicação da pressão de colagem) e tempo de cura de 8dias.

Esses fatores (pressão de colagem, tempo de pressão e viscosidade) tiveram seus níveis combinados três a três a fim de que fosse definida a relação ideal que conduzisse à maior resistência mecânica, por tipo de ensaio e por espécie de madeira. Conhecida a combinação dos fatores/níveis mais favorável, foi definido o tempo de cura partindo-se dos niveis 4, 8, 12, 16 e 20 dias. Todas as combinações tiveram três repetições. Para cada tipo de ensaio realizado foram ensaiados corpos-de-prova maciços, que auxiliaram como "controle" dos ensaios dos corpos-de-prova com adesivo. De cada viga usada foram retirados, ainda, corpos-de-prova para a determinação da classe de resistência a que pertence cada espécie e para a determinação da densidade e da umidade inicial da madeira.

A proporção utilizada para o preparo do adesivo poliuretano à base de mamona foi de uma parte, em peso, de prepolímero para uma parte, em peso, de poliol. Para o espalhamento do adesivo sobre as peças de madeira coladas, de onde foram obtidos os corpos-de-prova, foi empregada a técnica do pincelamento. Segundo MANTILLA CARRASCO (1984), os valores do consumo de adesivos, com finalidade estrutural, variam entre $350 \mathrm{a} 400 \mathrm{~g} / \mathrm{m}^{2}$. Adotou-se neste trabalho o valor de $350 \mathrm{~g} / \mathrm{m}^{2}$.

Os ensaios foram realizados à temperatura ambiente e com a madeira seca em estufa, na umidade de equilíbrio com o ambiente $( \pm 12 \%)$.

\subsection{Dimensões dos corpos-de-prova}

Para a determinação das características de resistência do adesivo foram confeccionados corpos-de-prova de cisalhamento, de tração paralela (emendas dentadas) e de tração normal da lâmina de cola além dos corpos-de-prova maciços destinados ao "controle", seguindo as recomendações da NBR7190/97, apresentados a seguir. 


\subsubsection{Cisalhamento na lâmina de cola}

De acordo com as recomendações da NBR7190/97 os corpos-de-prova maciços, utilizados como controle, foram obtidos de forma que a seção de cisalhamento fosse paralela à direção radial da madeira. Para os corpos-de-prova destinados à determinação do cisalhamento na lâmina de cola a seção de cisalhamento ficou paralela à direção tangencial da madeira.

A figura 24 apresenta as dimensões e forma dos corpos-de-prova destinados ao ensaio de cisalhamento na lâmina de cola.

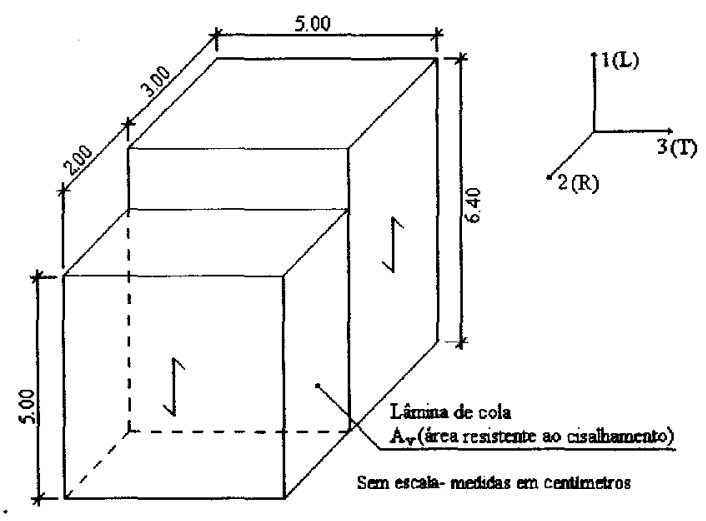

FIGURA 24 - Corpo-de-prova de cisalhamento na lâmina de cola.

\subsubsection{Tração normal à lâmina de cola}

A figura 25 apresenta a forma e as dimensões dos corpos-de-prova empregados na avaliação da resistência à tração normal à lâmina de cola.

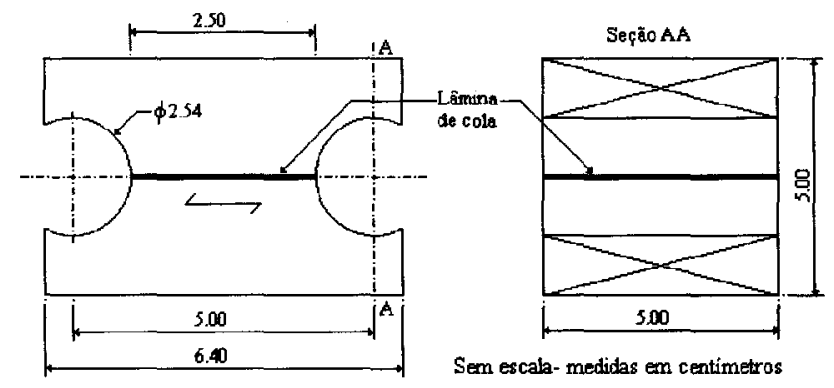

FIGURA 25 - Corpo-de-prova de tração normal à lâmina de cola. 


\subsubsection{Tração paralela de emendas dentadas coladas}

Os corpos-de-prova deste ensaio, figura 26, possuiam emendas dentadas com as dimensões recomendadas por MACEDO (1996), comprimento do dente de $2 \mathrm{~cm}$ correspondente à classe estrutural da DIN 68140 (1971) e com comprimento de ancoragem (fixação dos corpos-de-prova) reduzido de $12 \mathrm{~cm}$ para $5 \mathrm{~cm}$, uma vez que a garra da máquina universal de ensaios DARTEC apresenta um sistema de regulagem de pressão. As demais dimensões seguiram as recomendações previstas na NBR7190/97.

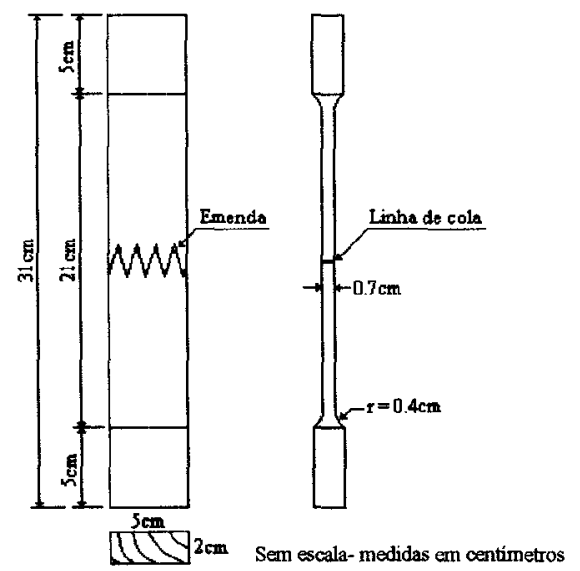

FIGURA 26 - Corpo-de-prova de tração paralela de emendas dentadas na lâmina de cola.

\subsubsection{Confecção dos corpos-de-prova}

\subsection{3 .1 Obtenção das peças para a confecção dos corpos-de- prova}

Dos troncos das duas espécies empregadas Eucaliptus grandis e Pinus caribea hondurensis, com diâmetros médio de $54,75 \mathrm{~cm}$ e 41,25 cm respectivamente, foram obtidas vigas denominadas, por exemplo, $T_{1} V_{1}, T_{1} V_{2}, T_{1} V_{3}$, com $6 \mathrm{~cm} \mathrm{x12,5}$ $\mathrm{cm}$ de seção transversal e com a sua maior dimensão $(\mathrm{h}=12,5 \mathrm{~cm})$ coincidente com a direção tangencial da madeira. Cada viga, por sua vez, foi subdividida em duas peças menores de $6 \mathrm{~cm}$ x $6 \mathrm{~cm}$ de seção transversal e comprimento de $85 \mathrm{~cm}$ denominadas, 
$\mathrm{T}_{1} \mathrm{~V}_{1} \mathrm{~A} / \mathrm{T}_{1} \mathrm{~V}_{1} \mathrm{~A}^{\prime}, \mathrm{T}_{1} \mathrm{~V}_{2} \mathrm{~B} / \mathrm{T}_{1} \mathrm{~V}_{2} \mathrm{~B}^{\prime}$, por exemplo. Foram retiradas amostras para a determinação do teor de umidade da espécies e as peças destinadas à confecção dos corpos-de-prova colocadas para secar. Os trechos que apresentavam defeitos foram descartados. Os corpos-de-prova para a caracterização do adesivo e aqueles, maciços, destinados ao "controle" dos ensaios foram retirados de tal forma que possam ser considerados idênticos (possuindo os mesmos anéis de crescimento e ao longo do comprimento do tronco) como apresentado na figura 27.
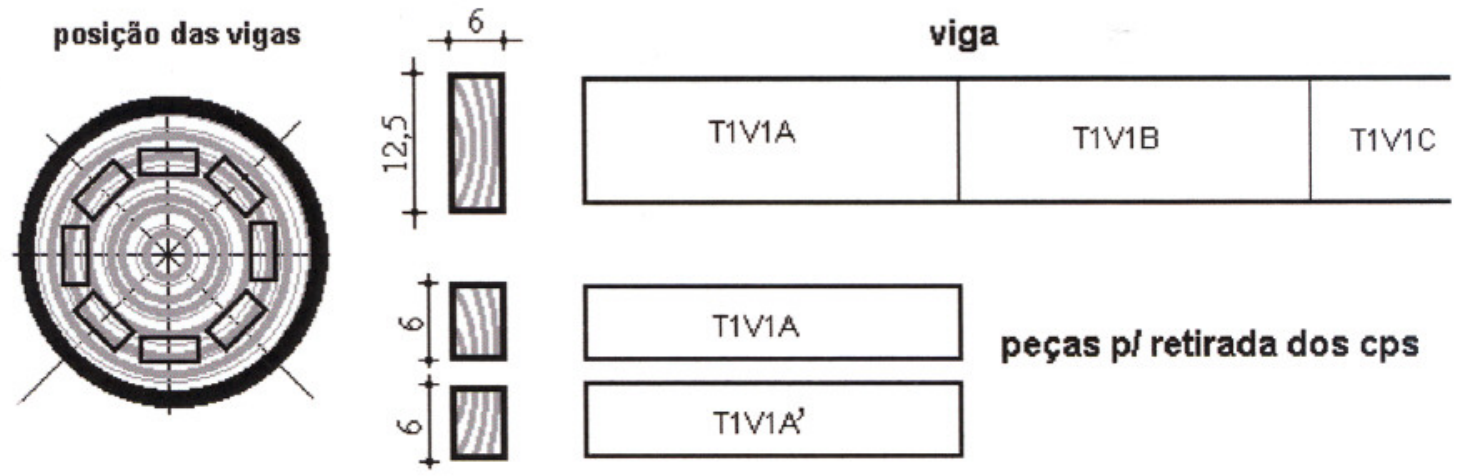

peças $\mathrm{p} /$ retirada dos cps

FIGURA 27- Obtenção das vigas e das peças destinadas à confecção dos corpos-deprova.

\subsubsection{Extração dos corpos-de-prova de cisalhamento}

Os corpos-de-prova de cisalhamento, por espécie, foram obtidos de 10 peças com seção de $6 \mathrm{~cm}$ x $6 \mathrm{~cm}$ e comprimento de $85 \mathrm{~cm}$ (Figura 28). De uma dessa peças, foram retirados dois corpos-de-prova para a determinação da umidade e da densidade e três de compressão paralela para o enquadramento das espécies nas classes de resistência conforme a NBR7190/97. De cada uma das outras peças, além dos dois corpos-de-prova para a determinação da umidade e da densidade, foram retirados os corpos-de-prova de cisalhamento para a caracterização do adesivo e os corpos de prova de cisalhamento maciços, de controle, todos com a mesma forma e dimensões apresentados na figura 24 . O número total de corpos-de-prova de cisalhamento foi de: 81 colados e 12 maciços. 

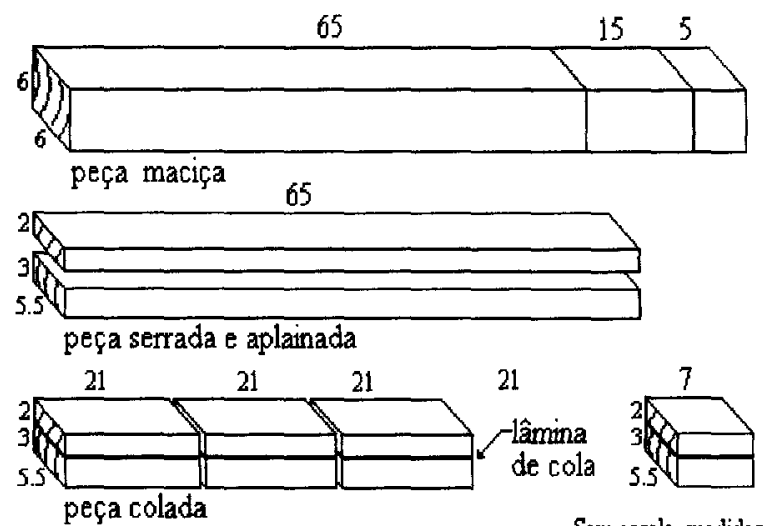

Sem escala- medidas en centímetros

FIGURA 28- Obtenção dos corpos-de-prova de cisalhamento.

\subsubsection{Extração dos corpos-de-prova de tração normal}

Os corpos-de-prova de tração normal, por espécie, foram obtidos de 10 peças com seção de $6 \mathrm{~cm} \times 6 \mathrm{~cm}$ e comprimento de $85 \mathrm{~cm}$ (Figura 29). De uma dessa peças, foram retirados dois corpos-de-prova para a determinação da umidade e da densidade e três de compressão paralela para o enquadramento das espécies nas classes de resistência conforme a NBR7190/97. De cada uma das outras peças, além dos dois corpos-de-prova para a determinação da umidade e da densidade, foram retirados os corpos-de-prova de tração normal para a caracterização do adesivo e os corpos de prova de tração normal maciços, de controle, todos com a mesma forma e dimensões apresentados na figura 25 . O número total de corpos-de-prova de tração normal foi de: 81 colados e 12 maciços.

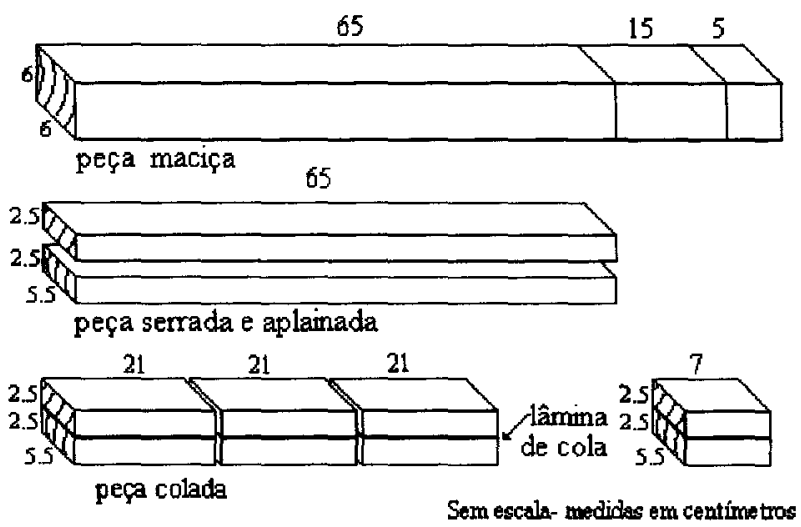

FIGURA 29 - Obtenção dos corpos-de-prova de tração normal. 


\subsubsection{Extração dos corpos-de-prova de tração paralela}

Os corpos-de-prova de tração paralela, por espécie, foram obtidos de 10 peças com seção de $6 \mathrm{~cm}$ x $6 \mathrm{~cm}$ e comprimento de $85 \mathrm{~cm}$ (Figura 30). De uma dessa peças, foram retirados dois corpos-de-prova para a determinação da umidade e da densidade e três de compressão paralela para o enquadramento das espécies nas classes de resistência conforme a NBR7190/97. De cada uma das outras peças, além dos dois corpos-de-prova para a determinação da umidade e da densidade, foram retirados os corpos-de-prova de tração paralela para a caracterização do adesivo e os corpos de prova de tração paralela maciços, de controle, todos com a mesma forma e dimensões apresentados na figura 26. O número total de corpos-de-prova de tração paralela foi de: 27 colados e 9 maciços.

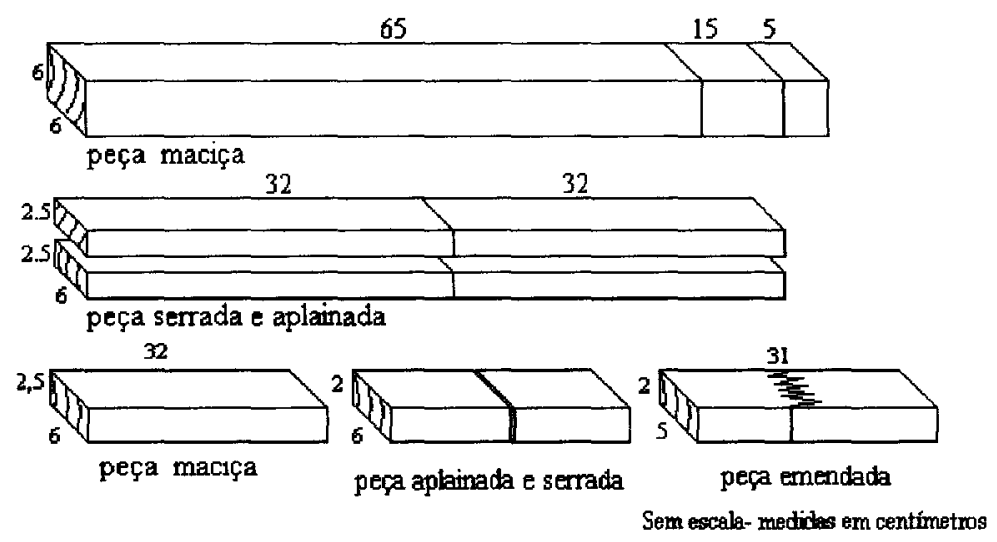

FIGURA 30- Obtenção dos corpos-de-prova de tração paralela.

\subsection{Planejamento estatístico}

A técnica empregada para o planejamento deste trabalho foi motivada pela necessidade de se encontrar os valores para as variáveis, pressão de colagem, tempo de aplicação da pressão e viscosidade, de tal modo a proporcionar a otimização da resistência mecânica do adesivo. Para estas variáveis, partiu-se de valores consagrados para outros adesivos industriais e recomendados na literatura. Estes valores foram considerados como o nível intermediário, adotando-se um nível inferior e outro superior com igual acréscimo em módulo. As três variáveis com seus três 
níveis distintos, foram combinadas entre si

Para o planejamento dos ensaios de cisalhamento e de tração normal, na lâmina de cola, a técnica estatística mais adequada nestes casos é conhecida por

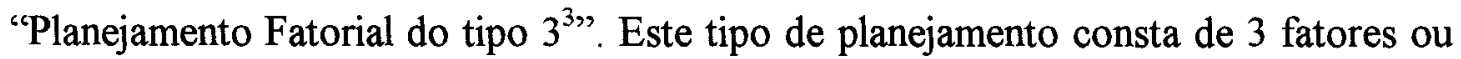
variáveis com 3 níveis cada um. Geralmente representam-se os fatores por letras maiúsculas $(\mathrm{A}, \mathrm{B}, \mathrm{C})$ e seus níveis podem ser definidos por dígitos, como por exemplo, nível inferior (-1), intermediário (0) e superior (1).

A combinação desses fatores e seus respectivos níveis totalizam 27 ensaios e cada ensaio com 3 repetições, com o propósito de alcançar uma estimativa do erro experimental. A tabela 3 representa a matriz modelo de planejamento empregada na pesquisa experimental.

TABELA 3- Matriz de planejamento fatorial do tipo $3^{3}$ - Ensaios de cisalhamento e de tração normal na lâmina de cola.

\begin{tabular}{|c|c|c|c|c|c|c|}
\hline \multirow{2}{*}{ ENSAIOS } & \multicolumn{3}{|c|}{ VARIÁVEIS } & \multicolumn{3}{|c|}{ RESPOSTA } \\
\hline & $\mathbf{A}$ & $\mathbf{B}$ & $\mathrm{C}$ & $Y_{1}$ & $\mathbf{Y}_{2}$ & $\mathbf{Y}_{3}$ \\
\hline 1 & -1 & -1 & -1 & & & \\
\hline 2 & 0 & -1 & -1 & & & \\
\hline 3 & 1 & -1 & -1 & & & \\
\hline 4 & -1 & 0 & -1 & & & \\
\hline 5 & 0 & 0 & -1 & & & \\
\hline 6 & 1 & 0 & -1 & & & \\
\hline 7 & -1 & 1 & -1 & & & \\
\hline 8 & 0 & 1 & -1 & & & \\
\hline 9 & 1 & 1 & -1 & & & \\
\hline 10 & -1 & -1 & 0 & & & \\
\hline 11 & 0 & -1 & 0 & & & \\
\hline 12 & 1 & -1 & 0 & & & \\
\hline 13 & -1 & 0 & 0 & & & \\
\hline 14 & 0 & 0 & 0 & & & \\
\hline 15 & 1 & 0 & 0 & & & \\
\hline 16 & -1 & 1 & 0 & & & \\
\hline 17 & 0 & 1 & 0 & & & \\
\hline 18 & 1 & 1 & 0 & & & \\
\hline 19 & -1 & -1 & 1 & & & \\
\hline 20 & 0 & -1 & 1 & & & \\
\hline 21 & 1 & -1 & 1 & & & \\
\hline 22 & -1 & 0 & 1 & & & \\
\hline 23 & 0 & 0 & 1 & & & \\
\hline 24 & 1 & 0 & 1 & & & \\
\hline 25 & -1 & 1 & 1 & & & \\
\hline 26 & 0 & 1 & 1 & & & \\
\hline 27 & 1 & 1 & 1 & & & \\
\hline
\end{tabular}


No caso dos ensaios de tração paralela como só há duas variáveis, viscosidade e pressão, com três níveis cada, o planejamento fatorial é do tipo $3^{2}$. A combinação desses fatores e seus níveis totalizam 9 ensaios, cada ensaio apresenta 3 repetições, com o propósito de alcançar uma estimativa do erro experimental. A tabela 4 representa a matriz modelo de planejamento empregada. na pesquisa experimental.

TABELA 4- Matriz de planejamento fatorial do tipo $3^{2}$ - Ensaio de tração paralela de emendas dentadas coladas.

\begin{tabular}{c|c|c|c|c|c}
\hline \multirow{2}{*}{ ENSAIOS } & \multicolumn{2}{|c|}{ VARIÁVEIS } & \multicolumn{3}{c}{ RESPOSTA } \\
\hline & A & B & $\mathbf{Y}_{\mathbf{1}}$ & $\mathbf{Y}_{\mathbf{2}}$ & $\mathbf{Y}_{\mathbf{3}}$ \\
\hline 1 & -1 & -1 & & & \\
\hline 2 & 0 & -1 & & & \\
\hline 3 & 1 & -1 & & & \\
\hline 4 & -1 & 0 & & & \\
\hline 5 & 0 & 0 & & & \\
\hline 6 & 1 & 0 & & & \\
\hline 7 & -1 & 1 & & & \\
\hline 8 & 0 & 1 & & & \\
\hline 9 & 1 & 1 & & & \\
\hline
\end{tabular}

A análise dos efeitos mais significativos de $1^{\mathrm{a}}$ e $2^{\mathrm{a}}$ ordem (BOX \& DRAPPER, 1997) das variáveis independentes (pressão de colagem, tempo de pressão e viscosidade) e suas iterações sobre a variável resposta (resistência ao cisalhamento, à tração normal e à tração paralela), de cada tipo de ensaio e por espécie, foi feita empregando-se o programa estatístico Minitab (RAYAN et al., 1985) e a sub-rotina Algoritmo de Yates. 


\section{RESULTADOS E DISCUSSÕES}

Neste capítulo são apresentados os resultados dos parâmetros de colagem, obtidos na condução dos ensaios, sistematizados em tabelas e com seus valores médios plotados em gráficos, por espécie e por tipo de ensaio. A análise da ruptura dos corpos-de-prova foi feita em função da sua área de ruptura, sendo apresentadas em figuras para os ensaios de tração paralela, por serem as rupturas mais complexas e variadas. São apresentadas as análises dos resultados, procurando-se determinar os valores mais significativos dos efeitos das variáveis independentes, individualmente e de suas iterações até $2^{\mathrm{a}}$ ordem, sobre as variáveis respostas: resistência ao cisalhamento, resistência à tração normal e resistência à tração paralela. Com o auxilio do programa de análise estatística Minitab, elaborou-se a sub-rotina Algoritmo de Yates que possibilita a identificação dos efeitos significativos das variáveis e de suas iterações por meio das tabelas "Efeitos significativos das variáveis e suas iterações" (colunas "ortogona" $\mathrm{e}$ "nomeefe") e das figuras "Efeitos $x$ Escores normais". Os valores plotados nesses gráficos, não alinhados, são provavelmente os correspondentes aos valores mais significativos. As tabelas "Intervalo de confiança a 95\%" (colunas C26- C20- C27) auxiliam na confirmação desses valores, detectados anteriormente nos gráficos, por meio dos intervalos que não contiverem o zero.

Verificou-se ainda, através da análise dos coeficientes de variação, se os procedimentos de: produção, colagem e ensaios dos corpos-de-prova foram bem conduzidos. Durante o processo de colagem e ensaios dos corpos-de-prova a temperatura e umidade relativa médias foram de $28^{\circ} \mathrm{C}$ e $62 \%$, respectivamente. 


\subsection{Pinus caribea hondurensis}

A madeira empregada apresentava densidade aparente $\rho=0,503 \mathrm{~g} / \mathrm{cm}^{3}$, umidade $U=12,71 \%$ e foi classificada na classe C30 coníferas (NBR 7190/97), segundo sua resistência à compressão paralela às fibras.

\subsubsection{Resistência ao cisalhamento na lâmina de cola paralela às fibras da madeira $\left(f_{g v, 0}\right)$}

$\mathrm{Na}$ tabela 5 são apresentados os resultados dos ensaios de cisalhamento por combinação de parâmetros e níveis. Na figura 31 estão plotados os valores médios dos resultados das combinações e o valor médio dos corpos-de-prova maciços utilizados como controle.

TABELA 5- Resistência ao cisalhamento - Pinus caribea hondurensis.

\begin{tabular}{|c|c|c|c|c|c|c|c|}
\hline \multirow[b]{2}{*}{ ENSAIOS } & \multicolumn{3}{|c|}{ VARIÁVEIS INDEPENDENTES } & \multicolumn{4}{|c|}{ VARIAVEL RESPOSTA (MPa) } \\
\hline & $\begin{array}{l}\text { VSCOSIDADE } \\
\text { (min.) } \\
\end{array}$ & $\begin{array}{c}\text { TEMPO DE } \\
\text { PRESSĀO (h.) }\end{array}$ & $\begin{array}{c}\text { PRESSĀo } \\
\text { (MPa) }\end{array}$ & $Y_{1}$ & $Y_{2}$ & $\mathbf{Y}_{\mathbf{3}}$ & $\overline{\mathrm{Y}}$ \\
\hline 1 & 0 & 4 & 0,4 & 10,05 & 10,77 & 9,51 & 10,11 \\
\hline 2 & 3 & 4 & 0,4 & 10,50 & 11,02 & 11,31 & 10,94 \\
\hline 3 & 6 & 4 & 0,4 & 9,86 & 10,45 & 9,26 & 9,86 \\
\hline 4 & 0 & 6 & 0,4 & 11,42 & 10,51 & 10,15 & 10,69 \\
\hline 5 & 3 & 6 & 0,4 & 10,52 & 9,98 & 10,58 & 10,36 \\
\hline 6 & 6 & 6 & 0,4 & 10,09 & 10,02 & 10,03 & 10,05 \\
\hline 7 & 0 & 8 & 0,4 & 9,77 & 11,16 & 10,52 & 10,48 \\
\hline 8 & 3 & 8 & 0,4 & 8,80 & 10,64 & 9,80 & 9,75 \\
\hline 9 & 6 & 8 & 0,4 & 8,82 & 11,29 & 10,25 & 10,12 \\
\hline 10 & 0 & 4 & 0,6 & 9,15 & 9,89 & 8,35 & 9,13 \\
\hline 11 & 3 & 4 & 0,6 & 10,16 & 9,68 & 9,98 & 9,94 \\
\hline 12 & 6 & 4 & 0,6 & 10,09 & 10,75 & 10,53 & 10,46 \\
\hline 13 & 0 & 6 & 0,6 & 10,26 & 9,21 & 10,13 & 9,87 \\
\hline 14 & 3 & 6 & 0,6 & 9,83 & 9,83 & 10,63 & 10,10 \\
\hline 15 & 6 & 6 & 0,6 & 8,58 & 8,23 & 8,12 & 8,31 \\
\hline 16 & 0 & 8 & 0,6 & 9,84 & 8,01 & 8,09 & 8,65 \\
\hline 17 & 3 & 8 & 0,6 & 6,46 & 7,56 & 8,43 & 7,48 \\
\hline 18 & 6 & 8 & 0,6 & 6,82 & 7,48 & 8,46 & 7,59 \\
\hline 19 & 0 & 4 & 0,8 & 10,62 & 9,94 & 9,14 & 9,90 \\
\hline 20 & 3 & 4 & 0,8 & 10,54 & 7,50 & 8,13 & 8,72 \\
\hline 21 & 6 & 4 & 0,8 & 8,02 & 8,52 & 10,33 & 8,96 \\
\hline 22 & 0 & 6 & 0,8 & 7,13 & 10,17 & 8,77 & 8,69 \\
\hline 23 & 3 & 6 & 0,8 & 9,39 & 9,93 & 9,30 & 9,54 \\
\hline 24 & 6 & 6 & 0,8 & 9,31 & 9,91 & 8,86 & 9,36 \\
\hline 25 & 0 & 8 & 0,8 & 8,45 & 9,34 & 8,88 & 8,89 \\
\hline 26 & 3 & 8 & 0,8 & 8,78 & 7,38 & 8,14 & 8,10 \\
\hline 27 & 6 & 8 & 0,8 & 8,00 & 8,09 & 8,05 & 8,05 \\
\hline
\end{tabular}

Obs: $Y_{1}, Y_{2}, Y_{3}$ e $\bar{Y}$ são as réplicas e a média da variável resposta, respectivamente. 
Pode-se observar, em destaque, que o melhor resultado da combinação entre a viscosidade $\mathrm{V}$ (minutos), o tempo de pressão Tp (horas) e a pressão $\mathrm{P}$ (MPa) ocorreu para $\mathrm{V}=3, \mathrm{Tp}=4$ e $\mathrm{P}=0,4$ quando foi registrada a tensão média $\mathrm{f}_{\mathrm{gv}, 0}=10,94 \mathrm{MPa}$.

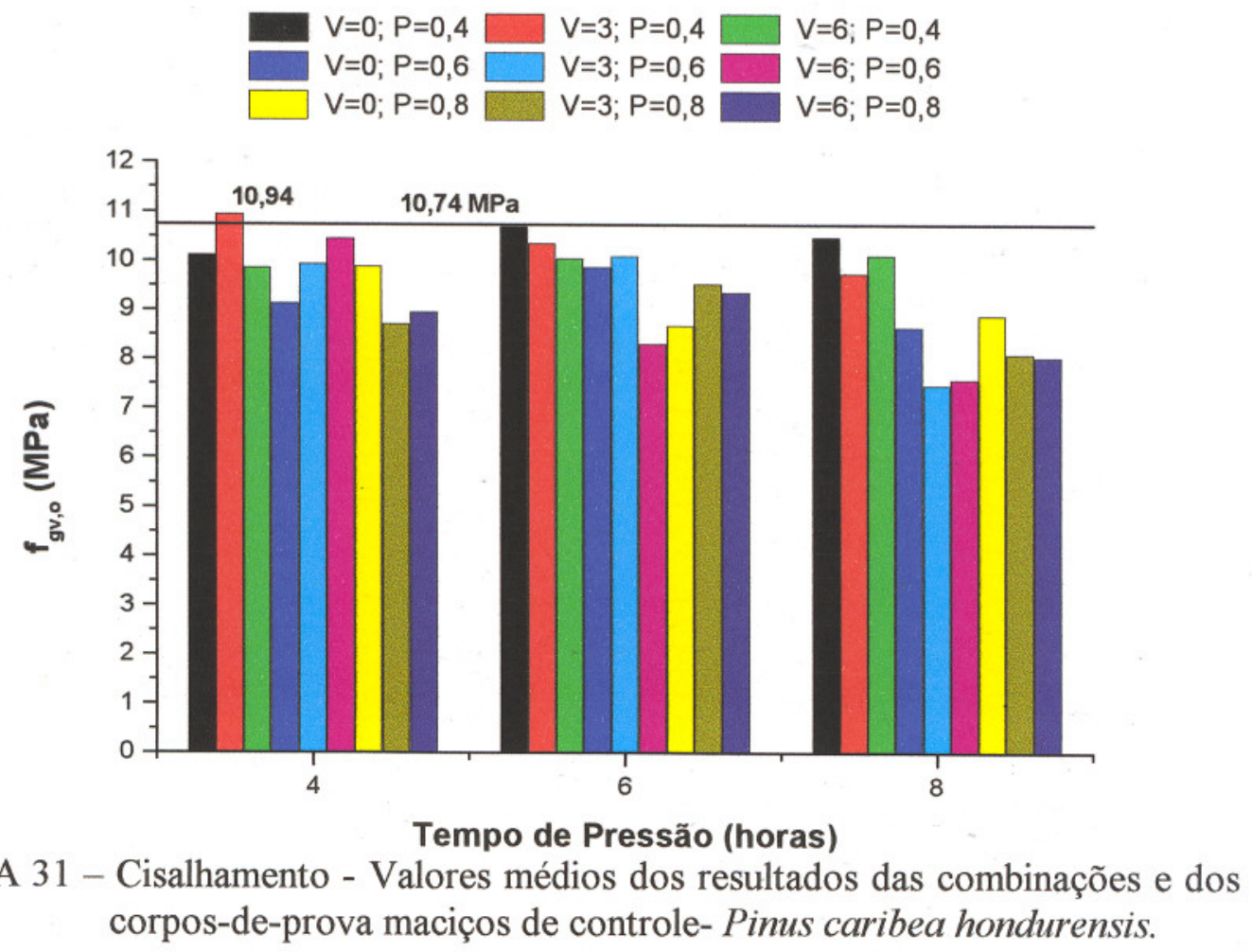

- Forma de ruptura

Os corpos-de-prova foram avaliados quanto a forma de ruptura e as respectivas porcentagens de cada intervalo de ruptura apresentadas na figura 32.

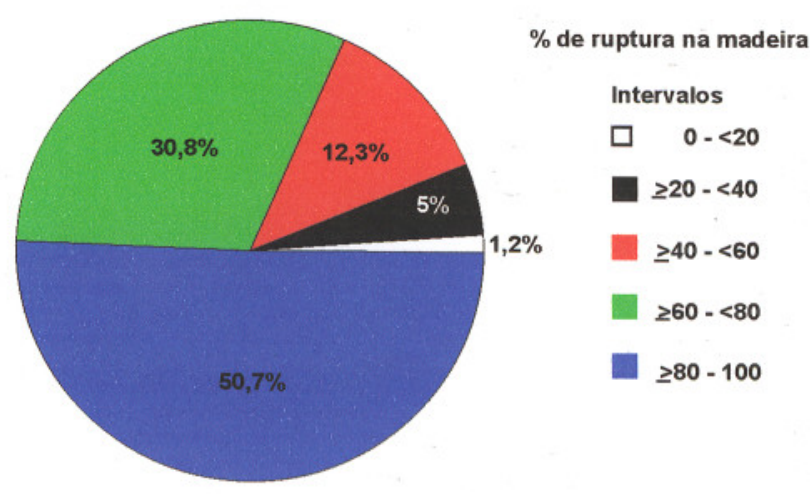

FIGURA 32- Forma de ruptura - Cisalhamento- Pinus caribea hondurensis. 


\section{- Análise dos resultados}

As análises dos valores encontrados nas tabelas 6 e 7, e na figura 33, permitiram definir os efeitos mais significativos das variáveis e suas iterações apresentados em destaque a seguir:

Tp- Efeito linear da variável "tempo de pressão".

P- Efeito linear da variável "pressão".

TpP' - Iteração entre o efeito linear da variável "tempo de pressão" com o efeito de $2^{a}$ ordem da variável "pressão".

TABELA 6 - Efeitos significativos das variáveis e suas iterações- CisalhamentoPinus caribea hondurensis.

\begin{tabular}{|c|c|c|c|c|c|c|c|c|}
\hline Row & RESPOSTA & (1) & (2) & (3) & DIVISOR & ORTOGONA & nomeefe & MS \\
\hline 1 & 30.33 & 92.73 & 277.08 & 762.25 & 81 & 9.41049 & 0 & 7173.15 \\
\hline 2 & 32.83 & 93.30 & 244.55 & -11.01 & 54 & -0.20389 & $\mathrm{~V}$ & 2.24 \\
\hline 3 & 29.57 & 91.05 & 240.62 & -2.15 & 162 & -0.01327 & $\overline{V^{2}}$ & 0.03 \\
\hline 4 & 32.08 & 88.58 & -3.79 & -26.74 & 54 & -0.49519 & $\mathrm{TP}$ & 13.24 \\
\hline 5 & 31.08 & 84.82 & -3.87 & -7.19 & 36 & -0.19972 & VTp & 1.44 \\
\hline 6 & 30.14 & 71.15 & -3.35 & 11.75 & 108 & 0.10880 & $\mathrm{~V}^{2} \mathrm{Tp}$ & 1.28 \\
\hline 7 & 31.45 & 82.74 & -2.37 & -20.42 & $1 \overline{62}$ & -0.12605 & $T p^{2}$ & 2.57 \\
\hline 8 & 29.24 & 82.77 & -3.13 & 2.79 & 108 & 0.02583 & $\mathrm{VTp}^{2}$ & 0.07 \\
\hline 9 & 30.36 & 75.11 & 3.35 & 25.09 & 324 & 0.07744 & $\mathrm{~V}^{2} \mathrm{Tp}^{2}$ & 1.94 \\
\hline 10 & 27.39 & -0.76 & -1.68 & -36.46 & 54 & -0.67519 & $\mathbf{D}$ & 24.62 \\
\hline 11 & 29.82 & -1.94 & -17.43 & 0.44 & 36 & 0.01222 & $\mathrm{VP}$ & 0.01 \\
\hline 12 & 31.37 & -1.09 & -7.63 & 5.72 & 108 & 0.05296 & $\mathrm{~V}^{2} \mathrm{P}$ & 0.30 \\
\hline 13 & 29.60 & 3.98 & -0.33 & -5.95 & 36 & -0.16528 & $\mathrm{TpP}$ & 0.98 \\
\hline 14 & 30.29 & -4.67 & -7.16 & 0.63 & 24 & 0.02625 & VTpP & 0.02 \\
\hline 15 & 24.93 & -3.18 & 0.30 & -11.11 & 72 & -0.15431 & $\mathrm{~V}^{2} \mathrm{TpP}$ & 1.71 \\
\hline 16 & 25.94 & -2.83 & 9.09 & -4.87 & 108 & -0.04509 & $\mathrm{Tp}^{2} \mathrm{p}$ & 0.22 \\
\hline 17 & 22.45 & 2.01 & 4.68 & -11.41 & 72 & -0.15847 & $V T p^{2} p$ & 1.81 \\
\hline 18 & 22.76 & -2.53 & -2.02 & 15.17 & 216 & 0.07023 & $\mathrm{~V}^{2} \mathrm{Tp}^{2} \mathrm{P}$ & 1.07 \\
\hline 19 & 29.70 & -5.76 & -2.82 & 28.60 & 162 & 0.17654 & $\mathrm{P}^{2}$ & 5.05 \\
\hline 20 & 26.17 & 0.06 & -9.91 & 0.60 & 108 & 0.00556 & $\mathrm{VP}^{2}$ & 0.00 \\
\hline 21 & 26.87 & 3.33 & -7.69 & 7.24 & 324 & 0.02235 & $\mathrm{~V}^{2} \mathrm{P}^{2}$ & 0.16 \\
\hline 22 & 26.07 & -0.88 & 2.03 & 25.55 & 108 & 0.23657 & $\mathrm{TPP}^{2}$ & 6.04 \\
\hline 23 & 28.62 & -6.05 & 10.14 & 14.29 & 72 & 0.19847 & $\mathrm{VTpP}^{2}$ & 2.84 \\
\hline 24 & 28.08 & 3.80 & -9.38 & -2.29 & 216 & -0.01060 & $\mathrm{~V}^{2} \mathrm{Tp} \mathrm{P}^{2}$ & 0.02 \\
\hline 25 & 26.67 & 4.23 & -2.55 & 9.31 & 324 & 0.02873 & $T p^{2} p^{2}$ & 0.27 \\
\hline 26 & 24.30 & -3.09 & 15.02 & -27.63 & 216 & -0.12792 & $V T p^{2} p^{2}$ & 3.53 \\
\hline 27 & 24.14 & 2.21 & 12.62 & -19.97 & 648 & -0.03082 & $\mathrm{~V}^{2} \mathrm{Tp}^{2} \mathrm{P}^{2}$ & 0.62 \\
\hline
\end{tabular}




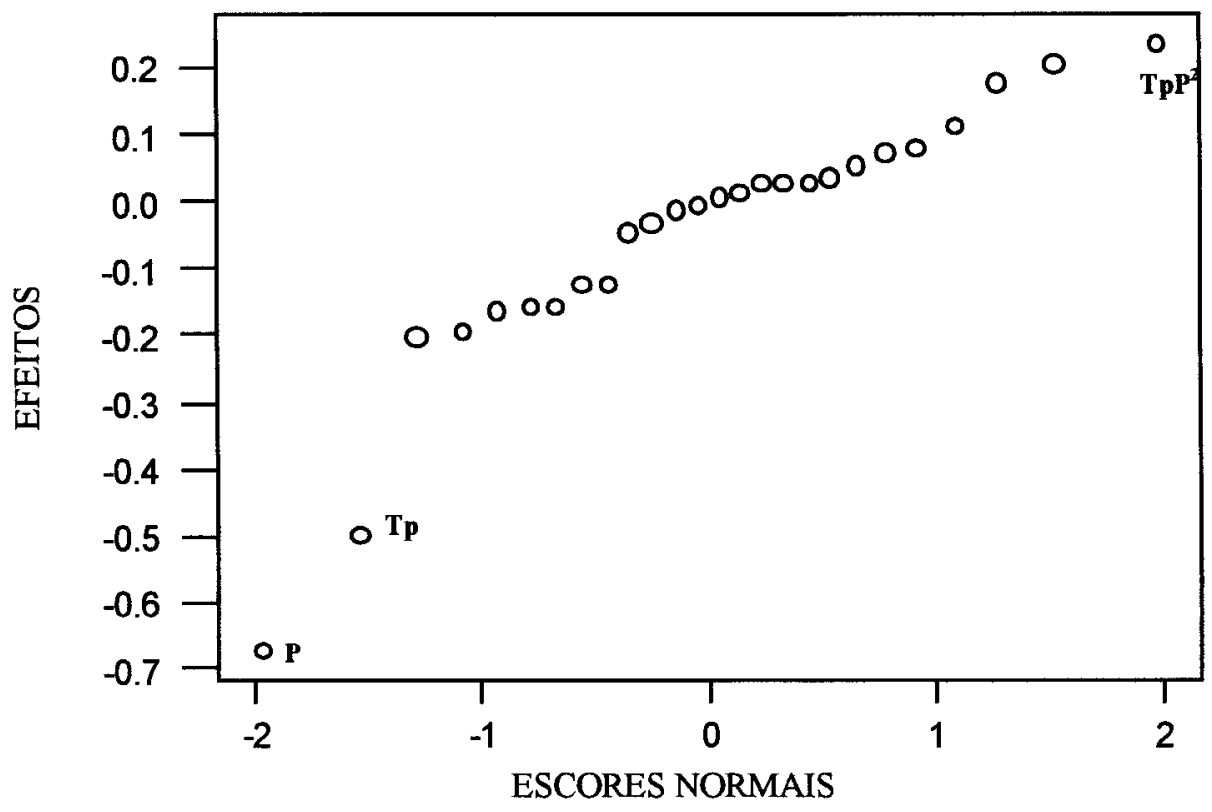

FIGURA 33 - Efeitos $x$ Escores normais - Cisalhamento- Pinus caribea hondurensis.

TABELA 7- Intervalo de confiança a 95\%- Cisalhamento- Pinus caribea hondurensis.

\begin{tabular}{|c|c|c|c|c|}
\hline Row & $\mathrm{C26}$ & $\mathrm{C} 20$ & $\mathrm{C} 27$ & Efeito \\
\hline 2 & -0.373725 & -0.203889 & -0.034053 & $\mathrm{~V}$ \\
\hline 3 & -0.183107 & -0.013272 & 0.156564 & $\mathrm{~V}^{2}$ \\
\hline 4 & -0.665021 & -0.495185 & -0.325350 & TP \\
\hline 5 & -0.369558 & -0.199722 & -0.029887 & VTp \\
\hline 6 & -0.061039 & 0.108796 & 0.278632 & $\mathrm{~V}^{2} \mathrm{Tp}$ \\
\hline 7 & -0.295885 & -0.126049 & 0.043786 & $\mathrm{Tp}^{2}$ \\
\hline 8 & -0.144002 & 0.025833 & 0.195669 & $V T p^{2}$ \\
\hline 9 & -0.092397 & 0.077438 & 0.247274 & $\mathrm{~V}^{2} \mathrm{Tp}^{2}$ \\
\hline 10 & -0.845021 & -0.675185 & -0.505350 & P \\
\hline 11 & -0.157613 & 0.012222 & 0.182058 & VP \\
\hline 12 & -0.116873 & 0.052963 & 0.222799 & $\mathrm{~V}^{2} \mathrm{P}$ \\
\hline 13 & -0.335114 & -0.165278 & 0.004558 & $\mathrm{TpP}$ \\
\hline 14 & -0.143586 & 0.026250 & 0.196086 & VTpP \\
\hline 15 & -0.324141 & -0.154305 & 0.015530 & $\mathrm{~V}^{2} \mathrm{TpP}$ \\
\hline 16 & -0.214928 & -0.045093 & 0.124743 & $\mathrm{Tp}^{2} \mathrm{P}$ \\
\hline 17 & -0.328308 & -0.158472 & 0.011363 & $V T p^{2} P$ \\
\hline 18 & -0.099604 & 0.070231 & 0.240067 & $\mathrm{~V}^{2} \mathrm{Tp}^{2} \mathrm{P}$ \\
\hline 19 & 0.006707 & 0.176543 & 0.346379 & $\mathrm{P}^{2}$ \\
\hline 20 & -0.164280 & 0.005556 & 0.175391 & $\mathrm{VP}^{2}$ \\
\hline 21 & -0.147490 & 0.022346 & 0.192181 & $V^{2} P^{2}$ \\
\hline 22 & 0.066738 & 0.236574 & 0.406410 & $T_{P P^{2}}$ \\
\hline 23 & 0.028636 & 0.198472 & 0.368308 & $\mathrm{VTpP}^{2}$ \\
\hline 24 & -0.180437 & -0.010602 & 0.159234 & $\mathrm{~V}^{2} \mathrm{Tp} \mathrm{P}^{2}$ \\
\hline 25 & -0.141101 & 0.028735 & 0.198570 & $T p^{2} p^{2}$ \\
\hline 26 & -0.297752 & -0.127917 & 0.041919 & $V T p^{2} P^{2}$ \\
\hline 27 & -0.200654 & -0.030818 & 0.139018 & $V^{2} T p^{2} P^{2}$ \\
\hline
\end{tabular}




\subsubsection{Resistência da lâmina de cola à tração normal $\left(f_{g t, 90}\right)$}

$\mathrm{Na}$ tabela 8 são apresentados os resultados dos ensaios de tração normal por combinação de parâmetros e níveis. Na figura 34 estão plotados os valores médios dos resultados das combinações e o valor médio dos corpos-de-prova maciços utilizados como controle.

TABELA 8 - Resistência à tração normal- Pinus caribea hondurensis.

\begin{tabular}{|c|c|c|c|c|c|c|c|}
\hline \multirow[b]{2}{*}{ ENSAIOS } & \multicolumn{3}{|c|}{ VARIÁVEIS INDEPENDENTES } & \multicolumn{4}{|c|}{ VARIAVEL RESPOSTA (MPa) } \\
\hline & $\begin{array}{c}\text { VSCOSIDADE } \\
\text { (min.) } \\
\end{array}$ & $\begin{array}{c}\text { TEMPO DE } \\
\text { PRESSAOO (h.) } \\
\end{array}$ & $\begin{array}{c}\text { PRESSÃO } \\
(\mathrm{MPa}) \\
\end{array}$ & $Y_{1}$ & $Y_{2}$ & $Y_{\mathbf{3}}$ & $\overline{\mathbf{Y}}$ \\
\hline 1 & 0 & 4 & 0,4 & 3,68 & 3,23 & 3,46 & 3,46 \\
\hline 2 & 3 & 4 & 0,4 & 2,97 & 3,76 & 3,95 & 3,56 \\
\hline 3 & 6 & 4 & 0,4 & 3,88 & 3,66 & 3,80 & 3,78 \\
\hline 4 & 0 & 6 & 0,4 & 3,06 & 3,56 & 3,64 & 3,42 \\
\hline 5 & 3 & 6 & 0,4 & 4,13 & 3,20 & 3,19 & 3,51 \\
\hline 6 & 6 & 6 & 0,4 & 3,75 & 2,67 & 2,58 & 3,00 \\
\hline 7 & 0 & 8 & 0,4 & 3,31 & 2,87 & 3,69 & 3,29 \\
\hline 8 & 3 & 8 & 0,4 & 3,75 & 3,79 & 3,95 & 3,83 \\
\hline 9 & 6 & 8 & 0,4 & 2,71 & 3,09 & 3,26 & 3,02 \\
\hline 10 & 0 & 4 & 0,6 & 2,47 & 2,57 & 2,25 & 2,43 \\
\hline 11 & 3 & 4 & 0,6 & 3,73 & 2,78 & 3,24 & 3,25 \\
\hline 12 & 6 & 4 & 0,6 & 3,49 & 2,89 & 2,61 & 3,00 \\
\hline 13 & 0 & 6 & 0,6 & 3,95 & 4,03 & 4,14 & 4,04 \\
\hline 14 & 3 & 6 & 0,6 & 4,20 & 3,65 & 4,19 & 4,01 \\
\hline 15 & 6 & 6 & 0,6 & 5,00 & 5,17 & 392 & 470 \\
\hline 16 & 0 & 8 & 0,6 & 3,02 & 4,47 & 4,13 & 3,87 \\
\hline 17 & 3 & 8 & 0,6 & 3,51 & 4,12 & 3,64 & 3,76 \\
\hline 18 & 6 & 8 & 0,6 & 3,47 & 3,26 & 3,08 & 3,27 \\
\hline 19 & 0 & 4 & 0,8 & 3,30 & 3,45 & 3,05 & 3,27 \\
\hline 20 & 3 & 4 & 0,8 & 3,40 & 3,94 & 3,62 & 3,65 \\
\hline 21 & 6 & 4 & 0,8 & 3,54 & 3,06 & 3,82 & 3,47 \\
\hline 22 & 0 & 6 & 0,8 & 3,73 & 4,17 & 3,18 & 3,69 \\
\hline 23 & 3 & 6 & 0,8 & 3,57 & 3,71 & 3,46 & 3,58 \\
\hline 24 & 6 & 6 & 0,8 & 3,03 & 2,97 & 2,66 & 2,89 \\
\hline 25 & 0 & 8 & 0,8 & 4,05 & 3,21 & 3,05 & 3,44 \\
\hline 26 & 3 & 8 & 0,8 & 3,95 & 4,01 & 3,52 & 3,83 \\
\hline 27 & 6 & 8 & 0,8 & 4,26 & 4,13 & 4,77 & 4,39 \\
\hline
\end{tabular}

Obs: $Y_{1}, Y_{2}, Y_{3}$ e $\bar{Y}$ são as réplicas e a média da variável resposta, respectivamente.

Pode-se observar, em destaque, que o melhor resultado da combinação entre a viscosidade V (minutos), o tempo de pressão $\mathrm{Tp}$ (horas) e a pressão $\mathrm{P}$ (MPa) ocorreu para $\mathrm{V}=6, T p=6$ e $P=0,6$ quando foi registrada a tensão média $\mathrm{f}_{\mathrm{gt}, 90}=4,70 \mathrm{MPa}$. 


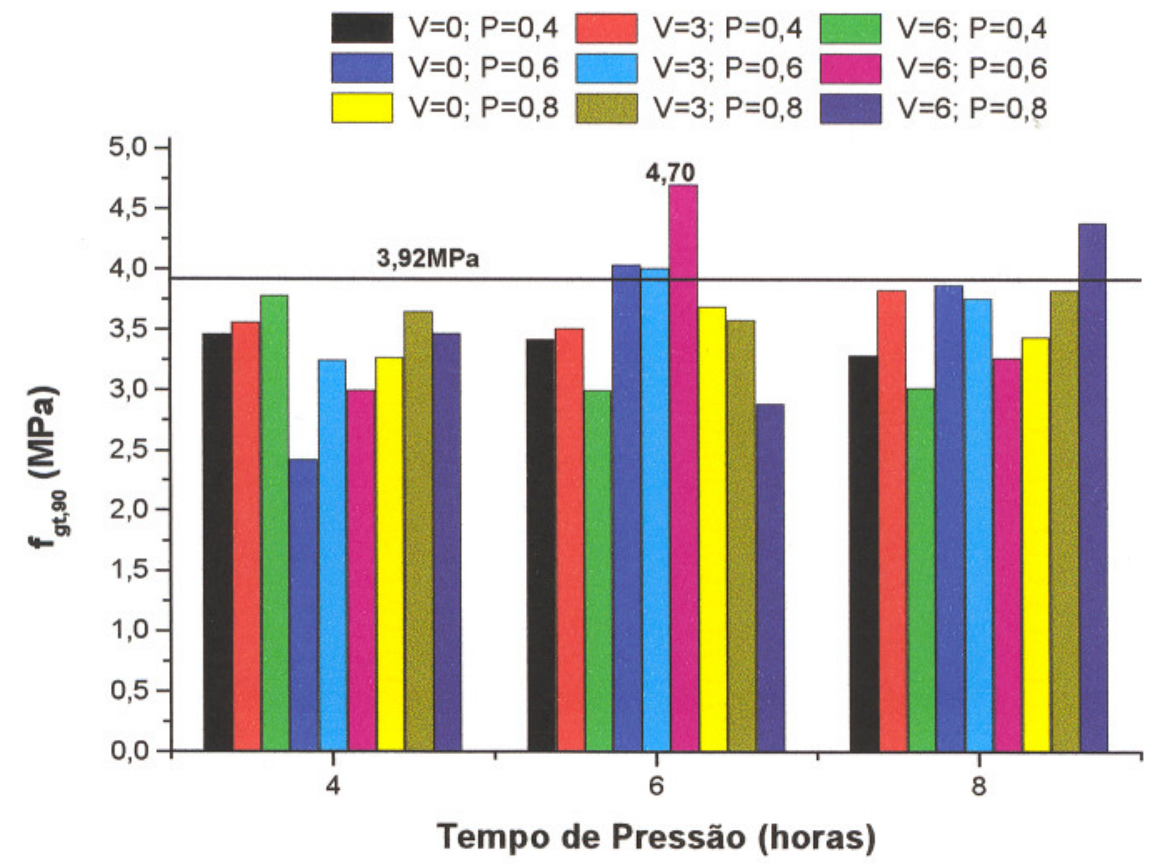

FIGURA 34 - Tração normal - Valores médios dos resultados das combinações e dos corpos-de-prova maciços de controle- Pinus caribea hondurensis.

\section{- Forma de Ruptura}

Os corpos-de-prova foram avaliados quanto a forma de ruptura e as respectivas porcentagens de cada intervalo de ruptura apresentadas na figura 35 .

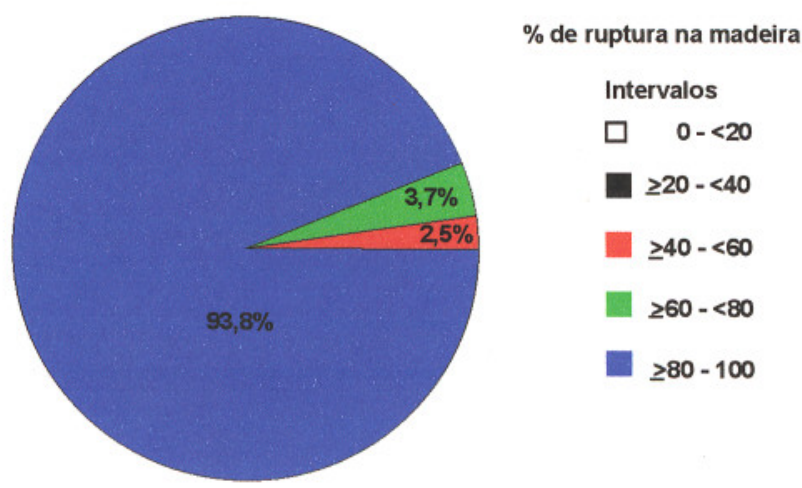

FIGURA 35 - Forma de ruptura - Tração normal- Pinus caribea hondurensis. 


\section{- Análise dos resultados}

As análises dos valores encontrados nas tabelas 9 e 10, e na figura 36, permitiram definir os efeitos mais significativos das variáveis e suas iterações apresentados em destaque a seguir:

Tp- Efeito linear da variável "tempo de pressão".

TpP- Iteração entre os efeitos lineares das variáveis "tempo de pressão" e "pressão".

VTpP- Iteração entre os efeitos lineares das variáveis "viscosidade", "tempo de pressão" e "pressão".

$\mathbf{T p}^{2} \mathbf{P}^{2}$ Iteração entre os efeitos de $2^{\mathrm{a}}$ ordem das variáveis "tempo de pressão" e "pressão".

TABELA 9 - Efeitos significativos das variáveis e suas iterações- Tração normalPinus caribea hondurensis.

\begin{tabular}{|c|c|c|c|c|c|c|c|c|}
\hline Row & RESPOSTA & (1) & (2) & (3) & DIVISOR & ORTOGONA & Nomeefe & MS \\
\hline 1 & 10.37 & 32.39 & 92.59 & 286.18 & 81 & 3.53309 & 0 & 1011.10 \\
\hline 2 & 10.68 & 29.78 & 96.98 & 1.81 & 54 & 0.03352 & V & 0.06 \\
\hline 3 & 11.34 & 30.42 & 96.61 & -10.61 & 162 & -0.06549 & $\overline{\mathrm{V}^{2}}$ & 0.69 \\
\hline 4 & 10.26 & 26.03 & -1.10 & 8.47 & 54 & 0.15685 & Tyo & 1.33 \\
\hline 5 & 10.52 & 38.25 & 1.86 & -3.06 & 36 & -0.08500 & $\mathrm{VTp}$ & 0.26 \\
\hline 6 & 9.00 & 32.70 & 1.05 & -0.08 & 108 & -0.00074 & $\mathrm{~V}^{2} \mathrm{Tp}$ & 0.00 \\
\hline 7 & 9.87 & 31.18 & -5.48 & -9.35 & 162 & -0.05772 & $\mathrm{Tp}^{2}$ & 0.54 \\
\hline 8 & 11.49 & 30.48 & -2.20 & 6.94 & 108 & 0.06426 & $V T p^{2}$ & 0.45 \\
\hline 9 & 9.06 & 34.95 & -2.93 & -6.44 & 324 & -0.01988 & $\mathrm{~V}^{2} \mathrm{Tp}^{2}$ & 0.13 \\
\hline 10 & 7.29 & 0.97 & -1.97 & 4.02 & 54 & 0.07444 & $\mathrm{P}$ & 0.30 \\
\hline 11 & 9.75 & -1.26 & 6.67 & 2.15 & 36 & 0.05972 & $\mathrm{VP}$ & 0.13 \\
\hline 12 & 8.99 & -0.81 & 3.77 & 2.55 & 108 & 0.02361 & $\mathrm{~V}^{2} \mathrm{P}$ & 0.06 \\
\hline 13 & 12.12 & 1.70 & -1.78 & 5.74 & 36 & 0.15944 & ToP & 0.92 \\
\hline 14 & 12.04 & 1.97 & -3.51 & 4.01 & 24 & 0.16708 & Vhas & 0.67 \\
\hline 15 & 14.09 & -1.81 & 2.23 & 6.61 & 72 & 0.09181 & $\mathrm{~V}^{2} \mathrm{TpP}$ & 0.61 \\
\hline 16 & 11.62 & 0.62 & -4.40 & 1.92 & 108 & 0.01778 & $\mathrm{Tp}^{2} \mathrm{P}$ & 0.03 \\
\hline 17 & 11.27 & -2.42 & 2.11 & 5.63 & 72 & 0.07819 & $V T p^{2} P$ & 0.44 \\
\hline 18 & 9.81 & 2.85 & 2.21 & 2.43 & 216 & 0.01125 & $\mathrm{~V}^{2} \mathrm{Tp}^{2} \mathrm{P}$ & 0.03 \\
\hline 19 & 9.80 & 0.35 & 3.25 & -4.76 & 162 & -0.02938 & $\mathrm{P}^{2}$ & 0.14 \\
\hline 20 & 10.96 & -1.78 & -17.77 & -3.77 & 108 & -0.03491 & $\mathrm{VP}^{2}$ & 0.13 \\
\hline 21 & 10.42 & -4.05 & 5.17 & -4.01 & 324 & -0.01238 & $\mathrm{~V}^{2} \mathrm{P}^{2}$ & 0.05 \\
\hline 22 & 11.08 & -3.22 & 2.68 & -11.54 & 108 & -0.10685 & $T p P^{2}$ & 1.23 \\
\hline 23 & 10.74 & 2.13 & -4.05 & 7.47 & 72 & 0.10375 & $\mathrm{VTpP}^{2}$ & 0.78 \\
\hline 24 & 8.66 & -1.11 & 8.31 & -6.41 & 216 & -0.02968 & $\mathrm{~V}^{2} \mathrm{TpP} \mathrm{P}^{2}$ & 0.19 \\
\hline 25 & 10.31 & -1.70 & -0.14 & 43.96 & 324 & 0.13568 & $\pi p^{2} P^{2}$ & 5.96 \\
\hline 26 & 11.48 & -1.74 & -8.59 & 19.09 & 216 & 0.08838 & $V T p^{2} P^{2}$ & 1.69 \\
\hline 27 & 13.16 & 0.51 & 2.29 & 19.33 & 648 & 0.02983 & $\mathrm{~V}^{2} T \mathrm{p}^{2} \mathrm{P}^{2}$ & 0.58 \\
\hline
\end{tabular}




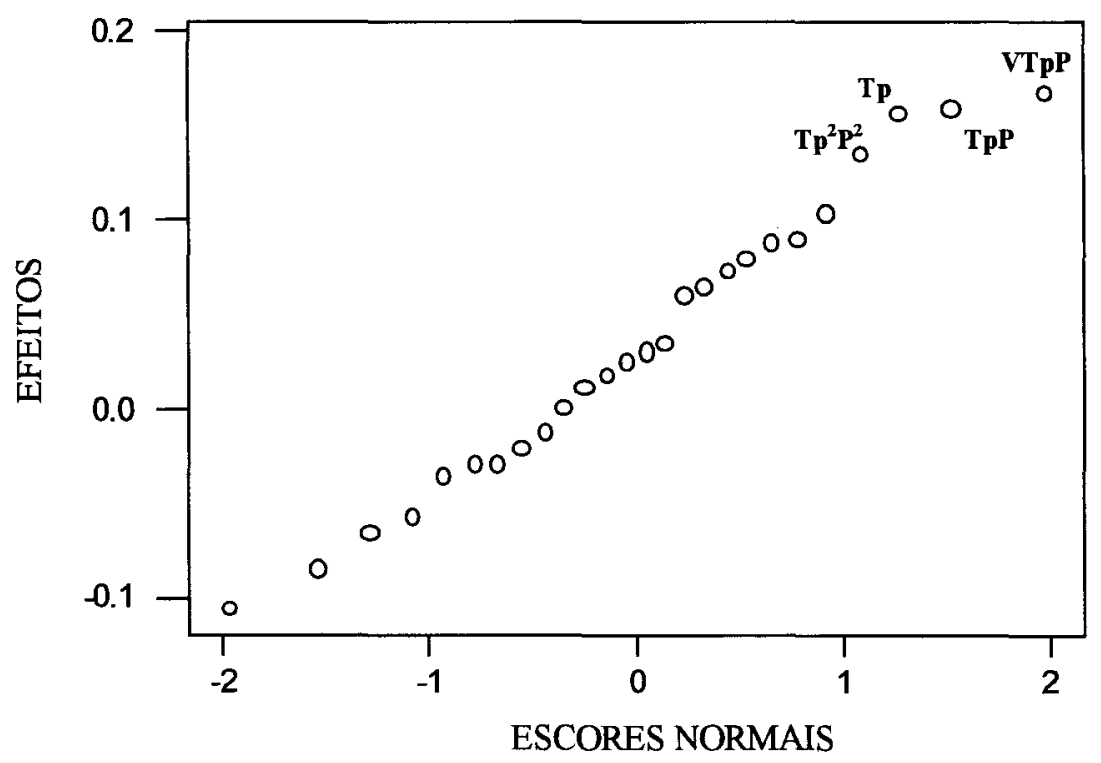

FIGURA 36- Efeitos $x$ Escores normais- Tração normal - Pinus caribea hondurensis.

TABELA 10 - Intervalo de confiança a 95\%- Tração normal - Pimus caribea hondurensis.

\begin{tabular}{|c|c|c|c|c|}
\hline Row & C26 & c20 & C27 & Efeito \\
\hline 2 & -0.052198 & 0.033518 & 0.119235 & $\mathrm{~V}$ \\
\hline 3 & -0.151210 & -0.065494 & 0.020223 & $\mathrm{~V}^{2}$ \\
\hline 4 & 0.071135 & 0.156852 & 0.242569 & To \\
\hline 5 & -0.170717 & -0.085000 & 0.000717 & VTp \\
\hline 6 & -0.086457 & -0.000741 & 0.084976 & $\mathrm{~V}^{2} \mathrm{Tp}$ \\
\hline 7 & -0.143433 & -0.057716 & 0.028001 & $T p^{2}$ \\
\hline 8 & -0.021457 & 0.064259 & 0.149976 & $V_{T p}^{2}$ \\
\hline 9 & -0.105593 & -0.019877 & 0.065840 & $\mathrm{~V}^{2} \mathrm{Tp}^{2}$ \\
\hline 10 & -0.011272 & 0.074445 & 0.160161 & $\mathrm{P}$ \\
\hline 11 & -0.025994 & 0.059722 & 0.145439 & $\mathrm{VP}$ \\
\hline 12 & -0.062106 & 0.023611 & 0.109328 & $\mathrm{~V}^{2} \mathrm{P}$ \\
\hline 13 & 0.073728 & 0.159444 & 0.245161 & TpP \\
\hline 14 & 0.081367 & 0.167083 & 0.252800 & $\mathrm{VmpP}_{\mathrm{P}}$ \\
\hline 15 & 0.006089 & 0.091806 & 0.177522 & $\mathrm{~V}^{2} \mathrm{TpP}$ \\
\hline 16 & -0.067939 & 0.017778 & 0.103494 & $\mathrm{Tp}^{2} \mathrm{P}$ \\
\hline 17 & -0.007522 & 0.078194 & 0.163911 & $V T p^{2} p$ \\
\hline 18 & -0.074467 & 0.011250 & 0.096967 & $\mathrm{~V}^{2} \mathrm{Tp}^{2} \mathrm{P}$ \\
\hline 19 & -0.115099 & -0.029383 & 0.056334 & $\mathrm{P}^{2}$ \\
\hline 20 & -0.120624 & -0.034907 & 0.050809 & $\mathrm{VP}^{2}$ \\
\hline 21 & -0.098093 & -0.012377 & 0.073340 & $\mathrm{~V}^{2} \mathrm{P}^{2}$ \\
\hline 22 & -0.192568 & -0.106852 & -0.021135 & $\mathrm{TpP}^{2}$ \\
\hline 23 & 0.018033 & 0.103750 & 0.189467 & $V T p P^{2}$ \\
\hline 24 & -0.115393 & -0.029676 & 0.056041 & $\mathrm{~V}^{2} \mathrm{Tp} \mathrm{P}^{2}$ \\
\hline 25 & 0.049962 & 0.135679 & 0.221396 & $T p^{2} P^{2}$ \\
\hline 26 & 0.002663 & 0.088380 & 0.174096 & $V T p^{2} P^{2}$ \\
\hline 27 & -0.055886 & 0.029830 & 0.115547 & $\mathrm{~V}^{2} \mathrm{Tp}^{2} \mathrm{P}^{2}$ \\
\hline
\end{tabular}




\subsubsection{Resistência da emenda dentada colada (finger joint) à tração paralela às fibras $\left(f_{g t, 0}\right)$}

Na tabela 11 são apresentados os resultados dos ensaios de tração paralela, por combinação de parâmetros e níveis. Na figura 37 estão plotados os valores médios dos resultados das combinações e o valor médio dos corpos-de-prova maciços utilizados como controle.

TABELA 11 - Resistência à tração paralela (finger joint)- Pinus caribea hondurensis.

\begin{tabular}{|c|c|c|c|c|c|c|}
\hline \multirow[b]{2}{*}{ ENSAIOS } & \multicolumn{2}{|c|}{ VARIÁVEIS INDEPENDENTES } & \multicolumn{4}{|c|}{ VARIAVEL RESPOSTA (MPa) } \\
\hline & $\begin{array}{l}\text { VSCOSIDADE } \\
\text { (min.) }\end{array}$ & $\begin{array}{l}\text { PRESSĀO } \\
\text { (MPa) }\end{array}$ & $Y_{1}$ & $Y_{2}$ & $Y_{3}$ & $\bar{Y}$ \\
\hline 1 & 0 & 7,0 & 35,62 & 47,55 & 42,76 & 41,98 \\
\hline 2 & 3 & 7,0 & 35,74 & 44,36 & 51,35 & 43,82 \\
\hline 3 & 6 & 7,0 & 43,95 & 43,26 & 45,41 & 44,21 \\
\hline 4 & 0 & 8,0 & 42,78 & 45,09 & 47,53 & 45,13 \\
\hline 5 & 3 & 8,0 & 49,00 & 34,46 & 34,97 & 39,48 \\
\hline 6 & 6 & 8,0 & 51,71 & 46,60 & 52,50 & 50,27 \\
\hline 7 & 0 & 9,0 & 58,15 & 58,47 & 48,42 & 55,01 \\
\hline 8 & 3 & 9,0 & 50,95 & 49,68 & 50,96 & 50,53 \\
\hline 9 & 6 & 9,0 & 48,15 & 55,87 & 50,68 & 51,57 \\
\hline
\end{tabular}

Obs: $\mathrm{Y}_{1}, \mathrm{Y}_{2}, \mathrm{Y}_{3}$ e $\overline{\mathrm{Y}}$ são as réplicas e a média da variável resposta, respectivamente.

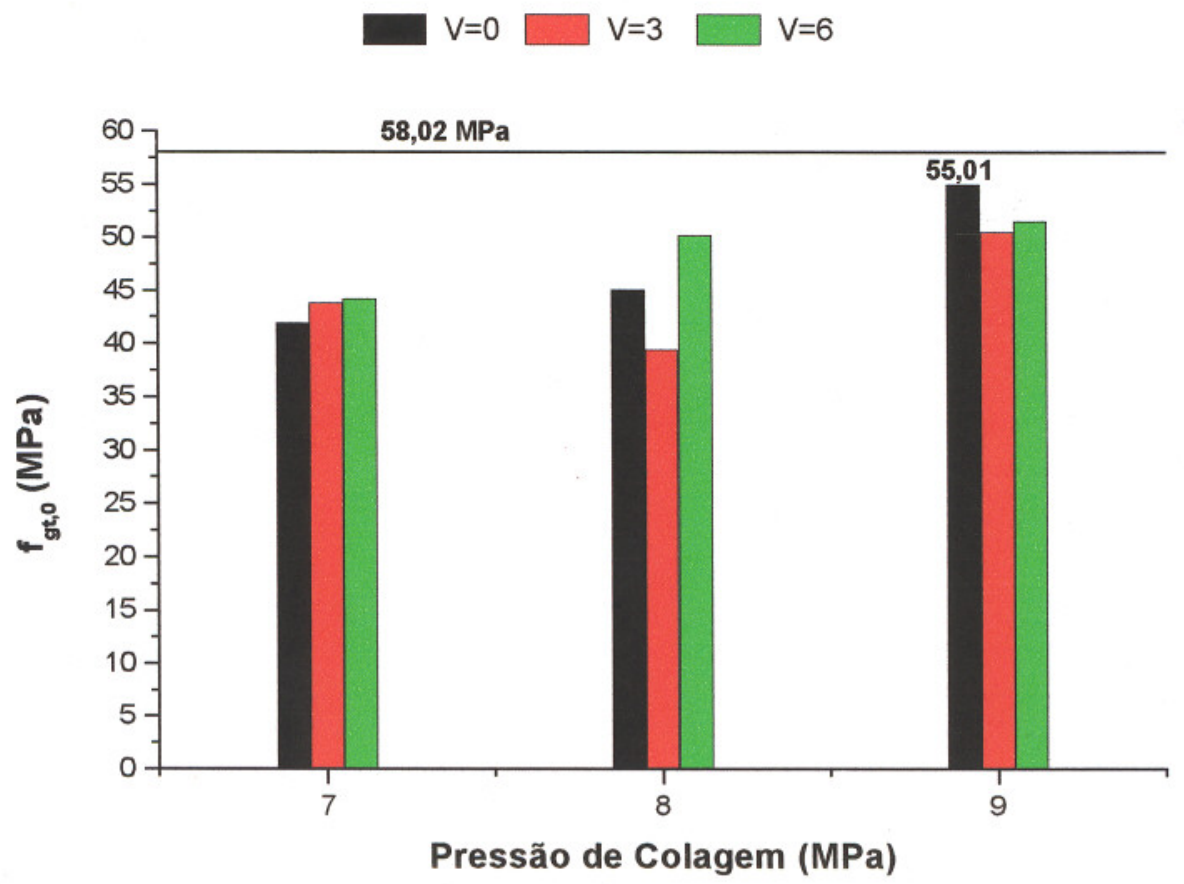

FIGURA 37- Tração paralela - Valores médios dos resultados das combinações e dos corpos-de-prova maciços de controle- Pinus caribea hondurensis. 
O melhor resultado da combinação, em destaque, foi obtido para a viscosidade $\mathrm{V}=0$ ' e a pressão $\mathrm{P}=9,0 \mathrm{MPa}$ com o valor da resistência média à tração paralela de $\mathrm{f}_{\mathrm{gt}, 0}=55,01 \mathrm{MPa}$.

\section{- Forma de ruptura}

Os corpos-de-prova foram avaliados quanto a forma de ruptura, figura 38, e as respectivas porcentagens de cada intervalo de ruptura apresentadas na tabela 12 .

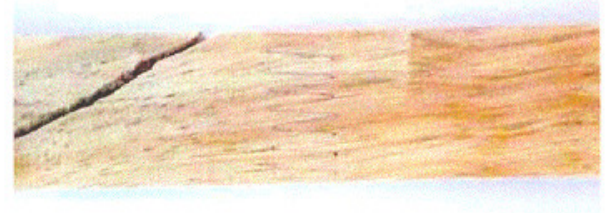

Região fora da emenda (A).

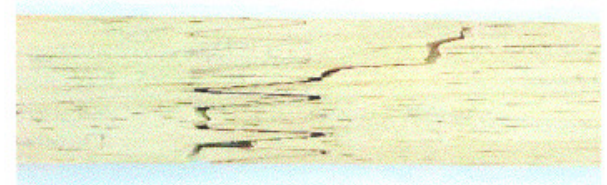

Região fora da emenda e região da emenda na madeira e na interface madeira adesivo $\left(\mathrm{B}_{2}\right)$.

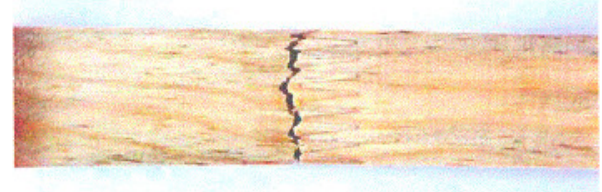

Região da emenda na madeira $\left(\mathrm{C}_{1}\right)$.

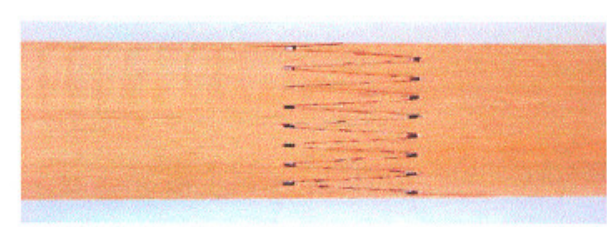

Região da emenda na interface madeira adesivo $\left(\mathrm{C}_{3}\right)$.

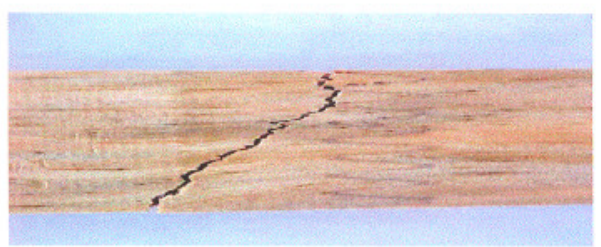

Região fora da emenda e região da emenda na madeira $\left(\mathrm{B}_{1}\right)$

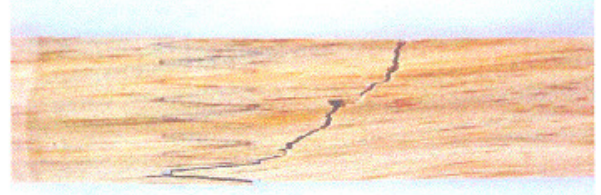

Região fora da emenda e região da emenda na interface madeira adesivo $\left(\mathrm{B}_{3}\right)$.

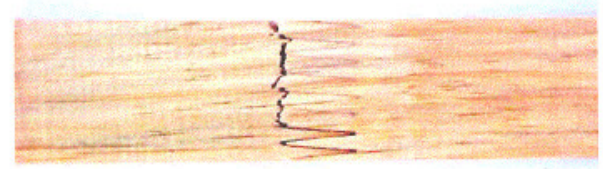

Região da emenda na madeira e na interface madeira adesivo $\left(\mathrm{C}_{2}\right)$.

FIGURA 38- Formas de ruptura- Tração paralela 
TABELA 12 - Forma de ruptura - Tração paralela - Pinus caribea hondurensis.

\begin{tabular}{|c|c|c|c|c|c|c|c|c|}
\hline \multirow{3}{*}{ (\%)de ruptura } & \multicolumn{7}{|c|}{ Regiōes de ocorrência de ruptura } & \multirow{3}{*}{$\begin{array}{l}\text { Total } \\
(\%)\end{array}$} \\
\hline & \multirow{2}{*}{$\mathbf{A}$} & \multicolumn{3}{|c|}{$\mathbf{B}$} & \multicolumn{3}{|c|}{$\mathbf{C}$} & \\
\hline & & 1 & 2 & 3 & 1 & 2 & 3 & \\
\hline Regiões $\mathbf{A}+\mathbf{B}+\mathbf{C}$ & 37 & 14,8 & 7,4 & 11,1 & 22,3 & 7,4 & 0 & 100 \\
\hline Regiōes $A+B_{1}+C_{1}$ & 37 & 14,8 & & & 22,3 & & & 74,1 \\
\hline
\end{tabular}

OBS: Regiōes de ruptura
A- Região fora da emenda
B-Região fora da emenda e região da emenda $\left(B_{1}, B_{2}\right.$ e $\left.B_{3}\right)$
C- Regiāo dă emenda $\left(C_{1}, C_{2}\right.$ e $\left.C_{3}\right)$
1- Madeira
2- Madeira/ interface madeira- adesivo
3- Interface madeira- adesivo

\section{- Análise dos resultados}

As análises dos valores encontrados nas tabelas 13 e 14, e na figura 39, permitiram definir os efeitos mais significativos das variáveis e suas iterações apresentados em destaque a seguir:

P- Efeito linear da variável "pressão".

TABELA 13 - Efeitos significativos das variáveis e suas iterações- Tração paralelaPinus caribea hondurensis.

\begin{tabular}{rrrrrrrrr}
\hline ROW & RESPOSTA & $\mathbf{( 1 )}$ & (2) & DIVISOR & ORTOGONA & NOMEEFE & SQ & RAIZ(SQ) \\
\hline 1 & 125.93 & 390.000 & 1265.97 & 27 & 46.8878 & 0 & $\mathbf{5 9 3 5 8 . 5}$ & 243.636 \\
2 & 131.45 & 404.640 & 11.76 & 18 & 0.6533 & $\mathrm{~V}$ & 7.7 & 2.772 \\
3 & 132.62 & 471.330 & 61.56 & 54 & 1.1400 & $\mathrm{~V}^{2}$ & $\mathbf{7 0 . 2}$ & $\mathbf{8} .377$ \\
$\mathbf{4}$ & $\mathbf{1 3 5 . 4 0}$ & $\mathbf{6 . 6 9 0}$ & $\mathbf{8 1 . 3 3}$ & $\mathbf{1 8}$ & $\mathbf{4 . 5 1 8 3}$ & $\mathbf{P}$ & $\mathbf{3 6 7 . 5}$ & $\mathbf{1 9 . 1 7 0}$ \\
5 & 118.43 & 15.410 & -17.03 & 12 & -1.4192 & $\mathrm{VP}$ & 24.2 & 4.916 \\
6 & 150.81 & -10.340 & 20.91 & 36 & 0.5808 & $\mathrm{~V}^{2} \mathrm{P}$ & 12.1 & 3.485 \\
7 & 165.04 & -4.350 & 52.05 & 54 & 0.9639 & $\mathrm{P}^{2}$ & 50.2 & 7.083 \\
8 & 151.59 & 49.350 & -34.47 & 36 & -0.9575 & $\mathrm{VP}^{2}$ & 33.0 & 5.745 \\
9 & 154.70 & 16.560 & -86.49 & 108 & -0.8008 & $\mathrm{~V}^{2} \mathrm{P}^{2}$ & 69.3 & 8.323 \\
\hline
\end{tabular}




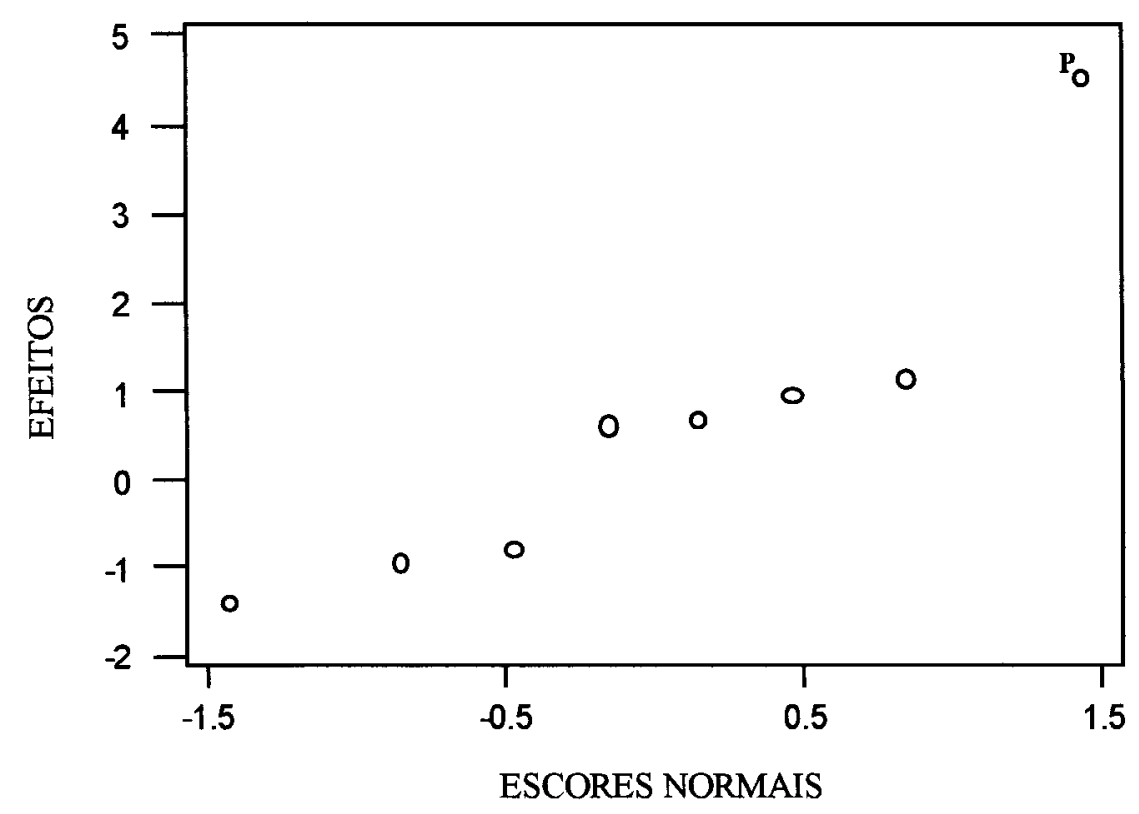

FIGURA 39- Efeitos $x$ Escores normais- Tração paralela- Pinus caribea hondurensis.

TABELA 14- Intervalo de confiança a 95\% - Tração paralela- Pimus caribea hondurensis.

\begin{tabular}{rrrrr}
\hline Row & C26 & ORTOGONA & C27 & Efeito \\
\hline 1 & 44.9767 & 46.8878 & 48.7989 & 0 \\
2 & -1.2578 & 0.6533 & 2.5645 & $\mathrm{~V}$ \\
3 & -0.7711 & 1.1400 & 3.0511 & $\mathrm{~V}^{2}$ \\
$\mathbf{4}$ & $\mathbf{2 . 6 0 7 2}$ & $\mathbf{4 . 5 1 8 3}$ & $\mathbf{6 . 4 2 9 5}$ & $\mathbf{P}$ \\
5 & -3.3303 & -1.4192 & 0.4920 & $\mathrm{VP}$ \\
6 & -1.3303 & 0.5808 & 2.4920 & $\mathrm{~V}^{2} \mathrm{P}$ \\
7 & -0.9472 & 0.9639 & 2.8750 & $\mathrm{P}^{2}$ \\
8 & -2.8686 & -0.9575 & 0.9536 & $\mathrm{VP}^{2}$ \\
9 & -2.7120 & -0.8008 & 1.1103 & $\mathrm{~V}^{2} \mathrm{P}^{2}$ \\
\hline
\end{tabular}

\subsubsection{Tempo de cura}

As tabelas 15,16 e 17 e a figura 40 apresentam os tempos de cura em função da resistência dos ensaios de cisalhamento, tração normal e paralela relativos às melhores combinações da viscosidade, tempo de pressão e pressão definidas nos ensaios anteriores. 
TABELA 15 - Tempo de cura - Cisalhamento - Pinus caribea hondurensis.

(Combinação: $3 ; 4 ; 0,4$ )

\begin{tabular}{crrrr}
\hline TEMPO & \multicolumn{4}{c}{ VARIAVEL RESPOSTA (MPa) } \\
\cline { 2 - 5 } (dias) & $Y_{1}$ & $Y_{2}$ & $Y_{3}$ & $\bar{\gamma}$ \\
\hline 4 & 9,26 & 12,06 & 10,80 & 10,71 \\
8 & 11,39 & 11,47 & 11,94 & 11,60 \\
12 & 12,64 & 12,15 & 11,67 & 12,15 \\
16 & 9,02 & 11,22 & 12,65 & 10,96 \\
20 & 8,82 & 9,53 & 12,79 & 10,38 \\
\hline
\end{tabular}

Obs: $Y_{1}, Y_{2}, Y_{3}$ e $\bar{Y}$ são as réplicas e a média da variável resposta, respectivamente.

TABELA 16 - Tempo de cura - Tração normal - Pinus caribea hondurensis.

(Combinação: 6; 6; 0,6)

\begin{tabular}{ccccc}
\hline TEMPO & \multicolumn{4}{c}{ VARIAVEL RESPOSTA (MPa) } \\
\cline { 2 - 5 } (dias) & $Y_{1}$ & $Y_{2}$ & $Y_{3}$ & $\bar{Y}$ \\
\hline 4 & 2,59 & 2,14 & 2,59 & 2,44 \\
$\mathbf{8}$ & $\mathbf{3 , 3 3}$ & $\mathbf{3 , 1 2}$ & $\mathbf{3 , 0 4}$ & $\mathbf{3 , 1 6}$ \\
12 & 2,85 & 2,15 & 3,58 & 2,95 \\
16 & 2,73 & 2,85 & 2,46 & 2,68 \\
20 & 3,79 & 2,94 & 2,29 & 3,01 \\
\hline
\end{tabular}

Obs: $\mathrm{Y}_{1}, \mathrm{Y}_{2}, \mathrm{Y}_{3}$ e $\overline{\mathrm{Y}}$ são as réplicas e a média da variável resposta, respectivamente.

TABELA 17 - Tempo de cura - Tração paralela - Pinus caribea hondurensis.

(Combinação: $0 ; 9,0$ )

\begin{tabular}{ccccr}
\hline \multirow{2}{*}{$\begin{array}{c}\text { TEMPO } \\
\text { (dias) }\end{array}$} & \multicolumn{4}{c}{ VARIAVEL RESPOSTA (MPa) } \\
\cline { 2 - 5 }$Y_{1}$ & $Y_{2}$ & $Y_{3}$ & $\bar{Y}$ \\
\hline 4 & 55,18 & 54,11 & 56,22 & 55,17 \\
8 & $\mathbf{7 0 , 8 3}$ & $\mathbf{6 0 , 6 2}$ & $\mathbf{6 0 , 1 6}$ & $\mathbf{6 3 , 8 7}$ \\
12 & 69,48 & 59,68 & 55,50 & 61,55 \\
16 & 46,90 & 45,04 & 58,92 & 50,29 \\
20 & 55,98 & 52,54 & 53,63 & 54,05 \\
\hline
\end{tabular}

Obs: $Y_{1}, Y_{2}, Y_{3}$ e $\bar{Y}$ são as réplicas e a média da variável resposta, respectivamente. 


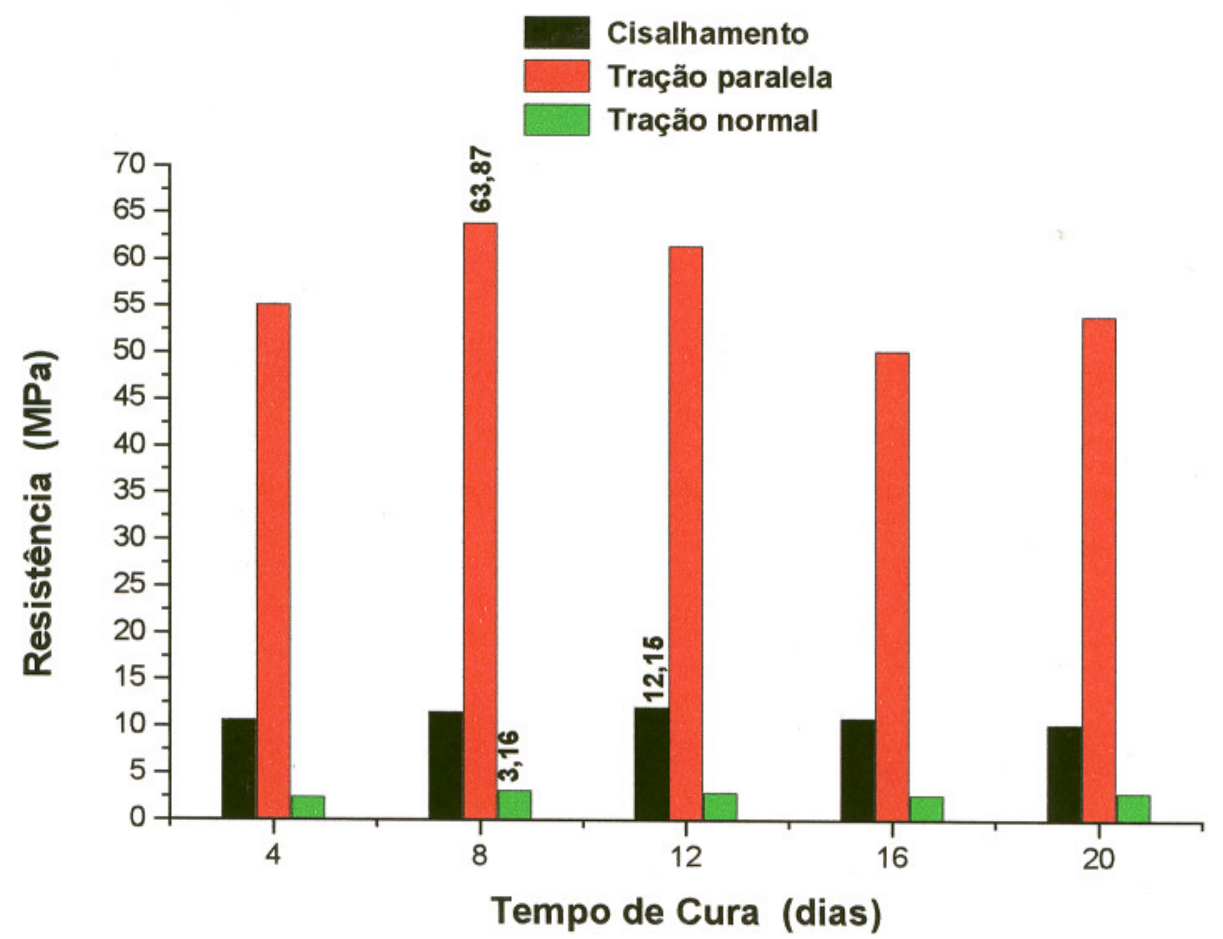

FIGURA 40 - Tempo de cura - Valores médios dos resultados dos ensaios- Pinus caribea hondurensis.

O tempo de cura apresentado em destaque para os ensaios de cisalhamento e de tração normal foi de 8 dias e para o ensaio de tração paralela de 12 dias.

\subsection{Eucaliptus grandis}

A madeira empregada apresentava densidade aparente $\rho=0,600 \mathrm{~g} / \mathrm{cm}^{3}$, umidade $U=12,61 \%$ e foi classificada na classe C40 dicotiledôneas (NBR 7190/97), segundo sua resistência à compressão paralela às fibras.

\subsubsection{Resistência ao cisalhamento na lâmina de cola paralela às fibras da madeira $\left(f_{g v, 0}\right)$}

Na tabela 18 são apresentados os resultados dos ensaios de cisalhamento por 
combinação de parâmetros e níveis. Na figura 41 estão plotados os valores médios dos resultados das combinações e o valor médio dos corpos-de-prova maciços utilizados como controle.

Pode-se observar, em destaque, que o melhor resultado da combinação entre a viscosidade V (minutos), o tempo de pressão Tp (horas) e a pressão P (MPa) ocorreu para $\mathrm{V}=0, \mathrm{Tp}=4, \mathrm{P}=0,6$ quando foi registrada a tensão média $\mathrm{f}_{\mathrm{gv}, 0}=17,70 \mathrm{MPa}$.

TABELA 18- Resistência ao cisalhamento - Eucaliptus grandis.

\begin{tabular}{|c|c|c|c|c|c|c|c|}
\hline \multirow[b]{2}{*}{ ENSAIOS } & \multicolumn{3}{|c|}{ VARIÁVEIS INDEPENDENTES } & \multicolumn{4}{|c|}{ VARIAVEL RESPOSTA (MPa) } \\
\hline & $\begin{array}{l}\text { VSCOSIDADE } \\
\text { (min.) }\end{array}$ & $\begin{array}{c}\text { TEMPO DE } \\
\text { PRESSÃO (h) }\end{array}$ & $\begin{array}{l}\text { PRESSĀO } \\
\text { (MPa) }\end{array}$ & $Y_{1}$ & $Y_{2}$ & $\mathbf{Y}_{\mathbf{3}}$ & $\bar{\gamma}$ \\
\hline 1 & 0 & 4 & 0,4 & 10,86 & 8,34 & 10,31 & 9,84 \\
\hline 2 & 3 & 4 & 0,4 & 9,20 & 10,37 & 8,04 & 9,20 \\
\hline 3 & 6 & 4 & 0,4 & 9,08 & 10,31 & 9,29 & 9,56 \\
\hline 4 & 0 & 6 & 0,4 & 16,98 & 15,51 & 16,14 & 16,21 \\
\hline 5 & 3 & 6 & 0,4 & 18,29 & 17,10 & 17,56 & 17,65 \\
\hline 6 & 6 & 6 & 0,4 & 16,65 & 16,60 & 14,28 & 15,84 \\
\hline 7 & 0 & 8 & 0,4 & 9,35 & 11,21 & 11,59 & 10,72 \\
\hline 8 & 3 & 8 & 0,4 & 13,83 & 14,30 & 13,28 & 13,80 \\
\hline 9 & 6 & 8 & 0,4 & 14,93 & 13,10 & 11,82 & 13,28 \\
\hline 10 & 0 & 4 & 0,6 & 16,76 & 18,55 & 17,79 & 17,70 \\
\hline 11 & 3 & 4 & 0,6 & 12,61 & 12,36 & 14,12 & 13,03 \\
\hline 12 & 6 & 4 & 0,6 & 14,35 & 16,82 & 12,81 & 14,66 \\
\hline 13 & 0 & 6 & 0,6 & 15,66 & 14,26 & 15,83 & 15,25 \\
\hline 14 & 3 & 6 & 0,6 & 13,10 & 13,41 & 12,60 & 13,04 \\
\hline 15 & 6 & 6 & 0,6 & 15,15 & 13,98 & 15,11 & 14,75 \\
\hline 16 & 0 & 8 & 0,6 & 10,95 & 10,80 & 12,51 & 11,42 \\
\hline 17 & 3 & 8 & 0,6 & 15,19 & 12,90 & 11,38 & 13,16 \\
\hline 18 & 6 & 8 & 0,6 & 13,32 & 11,26 & 10,99 & 11,86 \\
\hline 19 & 0 & 4 & 0,8 & 17,65 & 18,00 & 17,12 & 17,59 \\
\hline 20 & 3 & 4 & 0,8 & 13,37 & 12,82 & 14,94 & 13,71 \\
\hline 21 & 6 & 4 & 0,8 & 12,49 & 15,13 & 13,41 & 13,68 \\
\hline 22 & 0 & 6 & 0,8 & 10,50 & 10,70 & 12,68 & 11,29 \\
\hline 23 & 3 & 6 & 0,8 & 15,34 & 10,62 & 11,67 & 12,54 \\
\hline 24 & 6 & 6 & 0,8 & 10,64 & 8,36 & 9,00 & 9,33 \\
\hline 25 & 0 & 8 & 0,8 & 10,25 & 13,02 & 11,85 & 11,71 \\
\hline 26 & 3 & 8 & 0,8 & 11,80 & 11,78 & 13,57 & 12,38 \\
\hline 27 & 6 & 8 & 0,8 & 9,20 & 8,59 & 10,76 & 9,52 \\
\hline
\end{tabular}

Obs: $\mathrm{Y}_{1}, \mathrm{Y}_{2}, \mathrm{Y}_{3}$ e $\overline{\mathrm{Y}}$ são as réplicas e a média da variável resposta, respectivamente. 


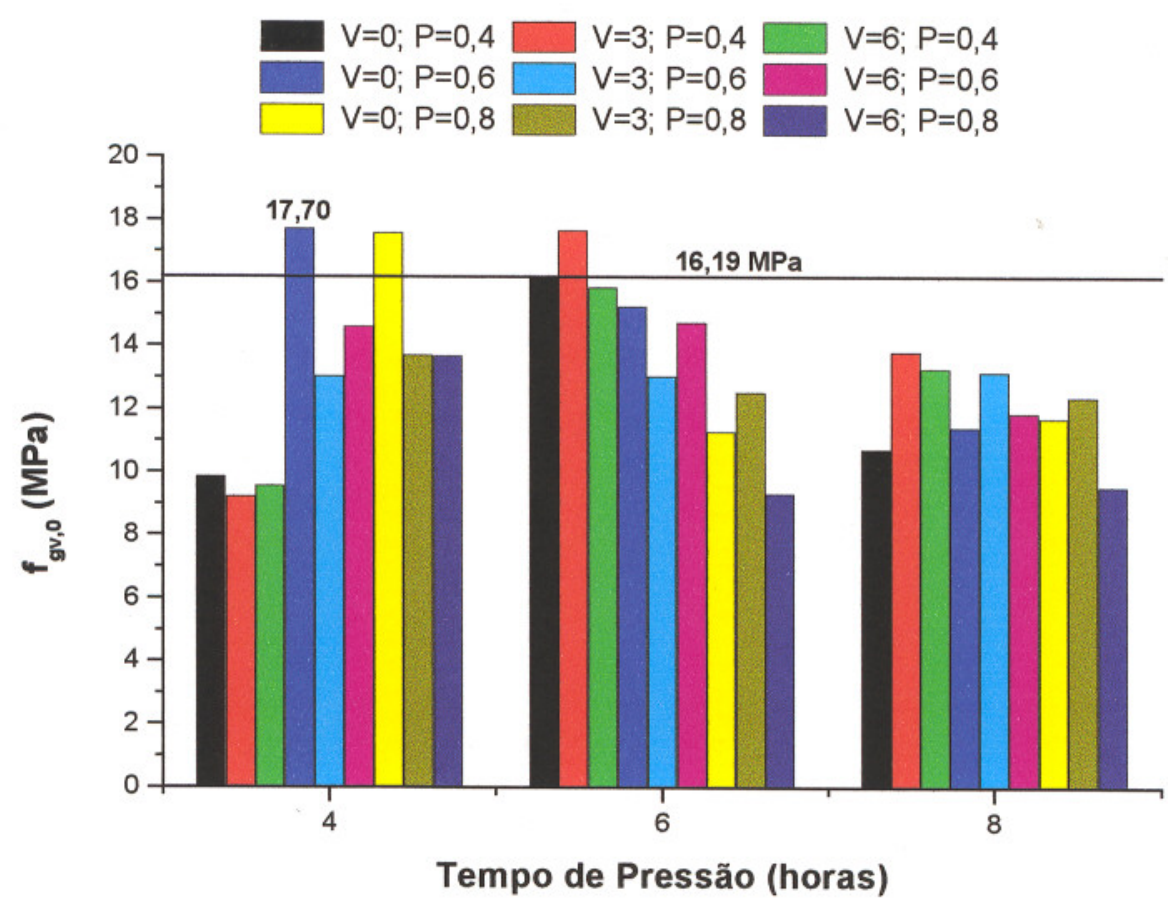

FIGURA 41- Cisalhamento - Valores médios dos resultados das combinações e dos corpos-de-prova maciços de controle - Eucaliptus grandis.

\section{- Forma de ruptura}

Os corpos-de-prova foram avaliados quanto a forma de ruptura e as respectivas porcentagens de cada intervalo de ruptura apresentadas na figura 42 .

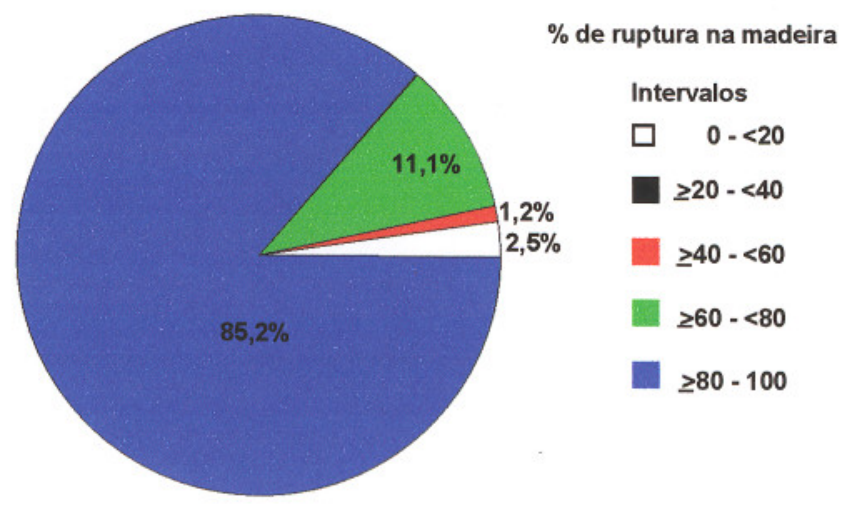

FIGURA 42 - Forma de ruptura - Cisalhamento- Eucaliptus grandis.

\section{- Análise dos resultados}

As análises dos valores encontrados nas tabelas 19 e 20, e na figura 43, permitiram definir os efeitos mais significativos das variáveis e suas iterações 
apresentados em destaque a seguir:

VTp- Iteração entre os efeitos lineares das variáveis "viscosidade" e "tempo de pressão".

VP- Iteração entre os efeitos lineares das variáveis "viscosidade" e "pressão".

TpP- Iteração entre os efeitos lineares das variáveis, "tempo de pressão" e "pressão".

$\mathbf{T p}^{2} \mathbf{P}$ Iteração entre o efeito de $2^{a}$ ordem da variável "tempo de pressão" e o efeito linear da variável "pressão".

TpP 2 Iteração entre o efeito linear da variável "tempo de pressão" e o efeito de 2 a ordem da variável "pressão".

TABELA 19- Efeitos significativos das variáveis e suas iterações- CisalhamentoEucaliptus grandis.

\begin{tabular}{|c|c|c|c|c|c|c|c|c|}
\hline Row & RESPOSTA & (1) & (2) & (3) & DIVISOR & ORTOGONA & Nomeefe & MS \\
\hline 1 & 29.51 & 85.80 & 347.77 & 1057.54 & 81 & 13.0561 & 0 & 13807.3 \\
\hline 2 & 27.61 & 149.11 & 374.57 & -28.49 & 54 & -0.5276 & $\mathrm{~V}$ & 15.0 \\
\hline 3 & 28.68 & 112.86 & 335.20 & -8.93 & 162 & -0.0551 & $\mathrm{~V}^{2}$ & 0.5 \\
\hline 4 & 48.63 & 136.17 & 5.02 & -33.98 & 54 & -0.6293 & $\mathrm{Tp}$ & 21.4 \\
\hline 5 & 52.95 & 129.10 & -9.32 & 23.38 & 36 & 0.6494 & vap & 15.2 \\
\hline 6 & 47.53 & 109.30 & -24.19 & -64.40 & 108 & -0.5963 & $\mathrm{~V}^{2} \mathrm{Tp}$ & 38.4 \\
\hline 7 & 32.25 & 134.93 & -18.14 & -75.62 & 162 & -0.4668 & $T p^{2}$ & 35.3 \\
\hline 8 & 41.41 & 99.51 & 21.56 & -3.02 & 108 & -0.0280 & $\mathrm{VTp}^{2}$ & 0.1 \\
\hline 9 & 39.20 & 100.76 & -12.35 & 25.12 & 324 & 0.0775 & $\mathrm{~V}^{2} \mathrm{Tp} \mathrm{p}^{2}$ & 1.9 \\
\hline 10 & 53.10 & -0.83 & 27.06 & -12.57 & 54 & -0.2328 & $\mathrm{P}$ & 2.9 \\
\hline 11 & 39.09 & -1.10 & -26.87 & -29.21 & 36 & -0.8114 & $\boldsymbol{D P}$ & 23.7 \\
\hline 12 & 43.98 & 6.95 & -34.17 & 5.79 & 108 & 0.0536 & $\mathrm{~V}^{2} \mathrm{P}$ & 0.3 \\
\hline 13 & 45.75 & $-9,12$ & 7.78 & -61.23 & 36 & -1.7008 & Dop? & 104.1 \\
\hline 14 & 39.11 & -1.51 & 10.43 & -2.61 & 24 & -0.1087 & VTpP & 0.3 \\
\hline 15 & 44.24 & 1.31 & 5.17 & -7.71 & 72 & -0.1071 & $\mathrm{~V}^{2} \mathrm{TpP}$ & 0.8 \\
\hline 16 & 34.26 & -11.74 & -14.34 & 136.23 & 108 & 1.2614 & $7^{2} p$ & 171.8 \\
\hline 17 & 39.47 & -5.88 & -28.01 & -14.87 & 72 & -0.2065 & $V T p^{2} P$ & 3.1 \\
\hline 18 & 35.57 & -6.57 & -22.05 & 16.71 & 216 & 0.0774 & $\mathrm{~V}^{2} \mathrm{Tp}^{2} \mathrm{P}$ & 1.3 \\
\hline 19 & 52.77 & 2.97 & -99.56 & -66.17 & 162 & -0.4085 & $\mathrm{P}^{2}$ & 27.0 \\
\hline 20 & 41.13 & -9.74 & -12.73 & -0.53 & 108 & -0.0049 & $\mathrm{VP}^{2}$ & 0.0 \\
\hline 21 & 41.03 & -11.37 & 36.67 & -73.61 & 324 & -0.2272 & $\mathrm{~V}^{2} \mathrm{P}^{2}$ & 16.7 \\
\hline 22 & 33.88 & 18.90 & 8.32 & 46.63 & 108 & 0.4318 & $\mathbf{t a p}^{2}$ & 20.1 \\
\hline 23 & 37.63 & 11.77 & -4.79 & -7.91 & 72 & -0.1099 & $\mathrm{VTpP}^{2}$ & 0.9 \\
\hline 24 & 28.00 & -9.11 & -6.55 & 19.63 & 216 & 0.0909 & $\mathrm{~V}^{2} \mathrm{TpP}^{2}$ & 1.8 \\
\hline 25 & 35.12 & 11.54 & 11.08 & -37.43 & 324 & -0.1155 & $T p^{2} P^{2}$ & 4.3 \\
\hline 26 & 37.09 & -13.38 & -13.75 & 11.35 & 216 & 0.0525 & $V T p^{2} P^{2}$ & 0.6 \\
\hline 27 & 28.55 & -10.51 & 27.79 & 66.37 & 648 & 0.1024 & $\mathrm{~V}^{2} \mathrm{Tp^{2 }} \mathrm{P}^{2}$ & 6.8 \\
\hline
\end{tabular}




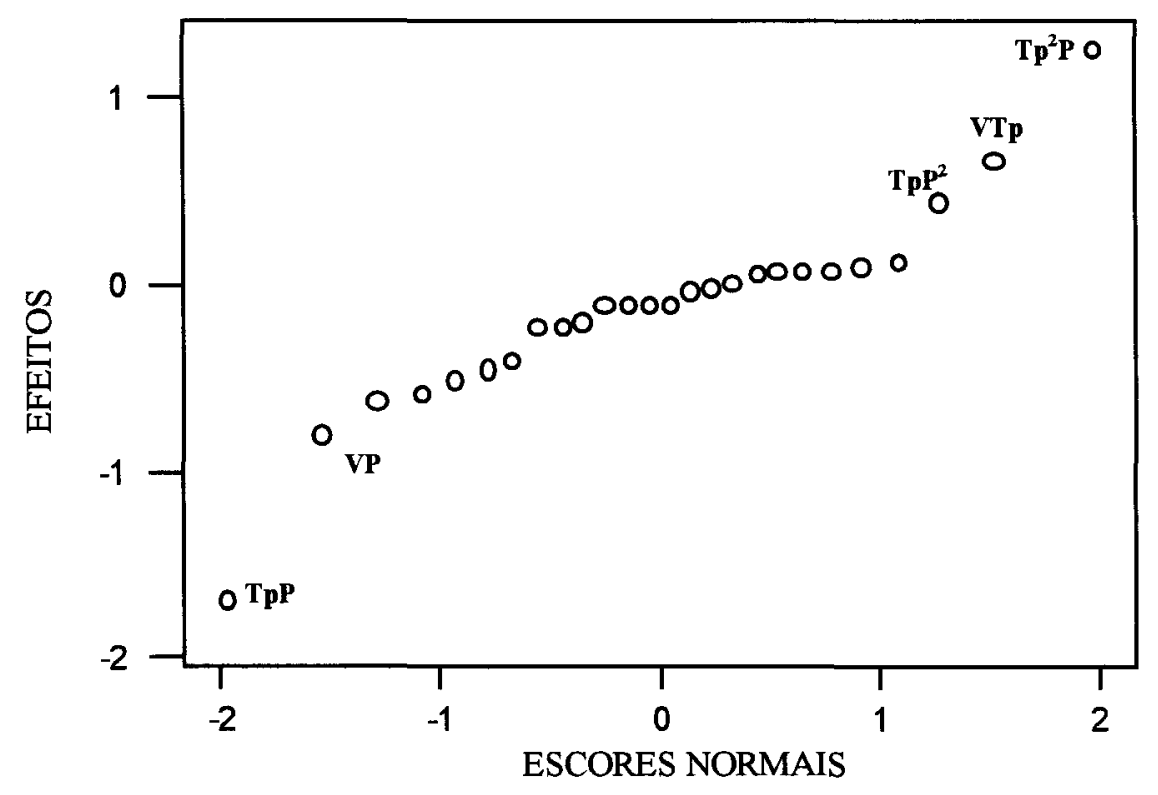

FIGURA 43 - Efeitos $x$ Escores normais-Cisalhamento-Eucaliptus grandis.

TABELA 20- Intervalo de confiança a 95\%-Cisalhamento- Eucaliptus grandis.

\begin{tabular}{|c|c|c|c|c|}
\hline Row & C26 & $\mathrm{C} 20$ & C27 & Efeito \\
\hline 2 & -0.79018 & -0.52759 & -0.26500 & $\mathrm{~V}$ \\
\hline 3 & -0.31771 & -0.05512 & 0.20747 & $\mathrm{~V}^{2}$ \\
\hline 4 & -0.89185 & -0.62926 & -0.36667 & $\mathrm{Tp}$ \\
\hline 5 & 0.38686 & 0.64944 & 0.91203 & $\mathrm{vmp}_{\mathrm{p}}$ \\
\hline 6 & -0.85889 & -0.59630 & -0.33371 & $\mathrm{~V}^{2} \mathrm{Tp}$ \\
\hline 7 & -0.72938 & -0.46679 & -0.20420 & $T p^{2}$ \\
\hline 8 & -0.29055 & -0.02796 & 0.23463 & $V T p^{2}$ \\
\hline 9 & -0.18506 & 0.07753 & 0.34012 & $\mathrm{~V}^{2} \mathrm{Tp} \mathrm{p}^{2}$ \\
\hline 10 & -0.49537 & -0.23278 & 0.02981 & $P$ \\
\hline 11 & -1.07398 & -0.81139 & -0.54880 & $\mathbf{n}$ \\
\hline 12 & -0.20898 & 0.05361 & 0.31620 & $V^{2} P$ \\
\hline 13 & -1.96342 & -1.70083 & -1.43824 & $I_{\mathbf{P} P}$ \\
\hline 14 & -0.37134 & -0.10875 & 0.15384 & VTpP \\
\hline 15 & -0.36967 & -0.10708 & 0.15551 & $\mathrm{~V}^{2} \mathrm{Tp} P$ \\
\hline 16 & 0.99880 & 1.26139 & 1.52998 & $\mathbf{T p}^{2} \mathrm{P}$ \\
\hline 17 & -0.46912 & -0.20653 & 0.05606 & $V T p^{2} P$ \\
\hline 18 & -0.18523 & 0.07736 & 0.33995 & $V^{2} T p^{2} P$ \\
\hline 19 & -0.67105 & -0.40846 & -0.14587 & $\mathrm{P}^{2}$ \\
\hline 20 & -0.26750 & -0.00491 & 0.25768 & $V P^{2}$ \\
\hline 21 & -0.48978 & -0.22719 & 0.03540 & $\mathrm{~V}^{2} \mathrm{P}^{2}$ \\
\hline 22 & 0.16917 & 0.43176 & 0.69435 & $\mathrm{TPP}^{2}$ \\
\hline 23 & -0.37245 & -0.10986 & 0.15273 & $V T p P^{2}$ \\
\hline 24 & -0.17171 & 0.09088 & 0.35347 & $\mathrm{~V}^{2} \mathrm{Tp} \mathrm{P}^{2}$ \\
\hline 25 & -0.37811 & -0.11552 & 0.14706 & $T p^{2} P^{2}$ \\
\hline 26 & -0.21004 & 0.05255 & 0.31514 & $V T p^{2} P^{2}$ \\
\hline 27 & -0.16017 & 0.10242 & 0.36501 & $\mathrm{~V}^{2} \mathrm{Tp}^{2} \mathrm{P}^{2}$ \\
\hline
\end{tabular}




\subsection{2- Resistência da lâmina de cola à tração normal $\left(f_{g t, 90)}\right.$}

$\mathrm{Na}$ tabela 21 são apresentados os resultados dos ensaios de tração normal por combinação de parâmetros e níveis. Na figura 44 estão plotados os valores médios dos resultados das combinações e o valor médio dos corpos-de-prova maciços utilizados como controle.

Pode-se observar em destaque que o melhor resultado da combinação entre a viscosidade V (minutos), o tempo de pressão Tp (horas) e a pressão P (MPa) ocorreu para $V=3, T p=4$ e $P=0,6$ quando foi registrada a tensão média $f_{\mathrm{gt}, 90}=6,42 \mathrm{MPa}$.

TABELA 21 - Resistência à tração normal- Eucaliptus grandis.

\begin{tabular}{|c|c|c|c|c|c|c|c|}
\hline \multirow[b]{2}{*}{ ENSAIOS } & \multicolumn{3}{|c|}{ VARIÁVEIS INDEPENDENTES } & \multicolumn{4}{|c|}{ VARIAVEL RESPOSTA (MPa) } \\
\hline & $\begin{array}{l}\text { VSCOSIDADE } \\
\text { (min.) }\end{array}$ & $\begin{array}{c}\text { TEMPO DE } \\
\text { PRESSĀO (h.) }\end{array}$ & $\begin{array}{c}\text { PRESSÃO } \\
\text { (MPa) }\end{array}$ & $Y_{1}$ & $Y_{2}$ & $\mathbf{Y}_{3}$ & $\bar{\gamma}$ \\
\hline 1 & 0 & 4 & 0,4 & 5,20 & 5,24 & 6,03 & $5, \overline{49}$ \\
\hline 2 & 3 & 4 & 0,4 & 4,25 & 4,60 & 6,13 & 5,00 \\
\hline 3 & 6 & 4 & 0,4 & 4,35 & 3,22 & 5,94 & 4,50 \\
\hline 4 & 0 & 6 & 0,4 & 5,19 & 4,35 & 5,36 & 4,97 \\
\hline 5 & 3 & 6 & 0,4 & 5,21 & 4,12 & 5,19 & 4,84 \\
\hline 6 & 6 & 6 & 0,4 & 6,73 & 5,95 & 5,21 & 5,96 \\
\hline 7 & 0 & 8 & 0,4 & 3,49 & 3,11 & 5,41 & 4,00 \\
\hline 8 & 3 & 8 & 0,4 & 3,32 & 3,00 & 5,72 & 4,01 \\
\hline 9 & 6 & 8 & 0,4 & 6,42 & 3,59 & 3,66 & 4,56 \\
\hline 10 & 0 & 4 & 0,6 & 5,98 & 6,51 & 4,60 & 5,70 \\
\hline 11 & 3 & 4 & 0,6 & 7,02 & 6,46 & 5,76 & 6,42 \\
\hline 12 & 6 & 4 & 0,6 & 6,78 & 6,41 & 4,67 & 5,95 \\
\hline 13 & 0 & 6 & 0,6 & 4,43 & 5,82 & 4,84 & 5,03 \\
\hline 14 & 3 & 6 & 0,6 & 5,10 & 4,23 & 4,45 & 4,59 \\
\hline 15 & 6 & 6 & 0,6 & 4,71 & 4,44 & 3,41 & 4,19 \\
\hline 16 & 0 & 8 & 0,6 & 5,36 & 4,91 & 4,83 & 5,03 \\
\hline 17 & 3 & 8 & 0,6 & 5,78 & 5,26 & 6,89 & 5,98 \\
\hline 18 & 6 & 8 & 0,6 & 5,85 & 3,85 & 4,12 & 4,61 \\
\hline 19 & 0 & 4 & 0,8 & 4,10 & 2,95 & 3,77 & 3,61 \\
\hline 20 & 3 & 4 & 0,8 & 5,08 & 3,84 & 3,92 & 4,28 \\
\hline 21 & 6 & 4 & 0,8 & 5,28 & 4,49 & 5,93 & 5,23 \\
\hline 22 & 0 & 6 & 0,8 & 6,46 & 5,31 & 4,88 & 5,55 \\
\hline 23 & 3 & 6 & 0,8 & 6,16 & 4,60 & 5,21 & 5,32 \\
\hline 24 & 6 & 6 & 0,8 & 3,94 & 4,42 & 4,84 & 4,40 \\
\hline 25 & 0 & 8 & 0,8 & 4,15 & 6,69 & 6,46 & 5,77 \\
\hline 26 & 3 & 8 & 0,8 & 5,95 & 4,51 & 6,31 & 5,59 \\
\hline 27 & 6 & 8 & 0,8 & 5,68 & 5,98 & 4,32 & 5,33 \\
\hline
\end{tabular}

Obs: $\mathrm{Y}_{1}, \mathrm{Y}_{2}, \mathrm{Y}_{3}$ e $\overline{\mathrm{Y}}$ são as réplicas e a média da variável resposta, respectivamente. 


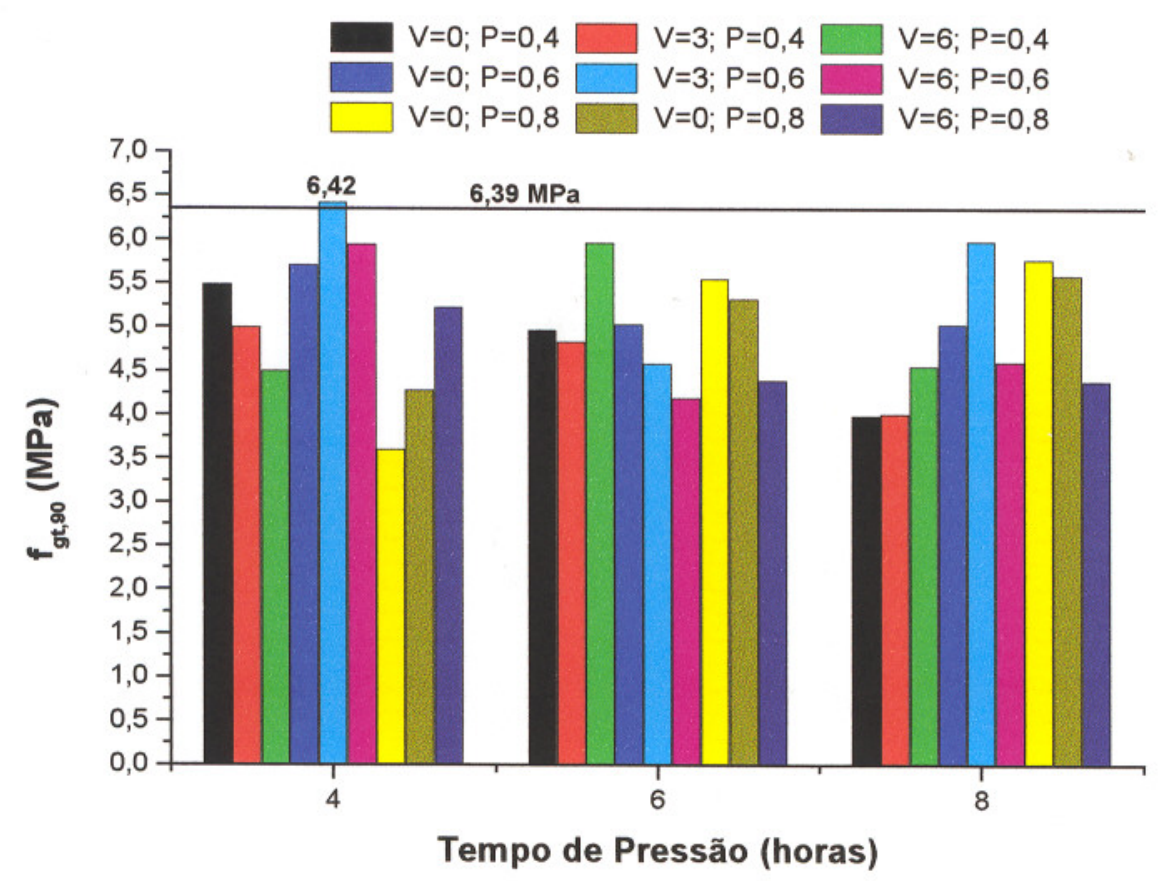

FIGURA 44 - Tração normal - Valores médios dos resultados das combinações e dos corpos-de-prova maciços de controle - Eucaliptus grandis.

\section{- Forma de ruptura}

Os corpos-de-prova foram avaliados quanto a forma de ruptura e as respectivas porcentagens de cada intervalo de ruptura apresentadas na figura 45 .

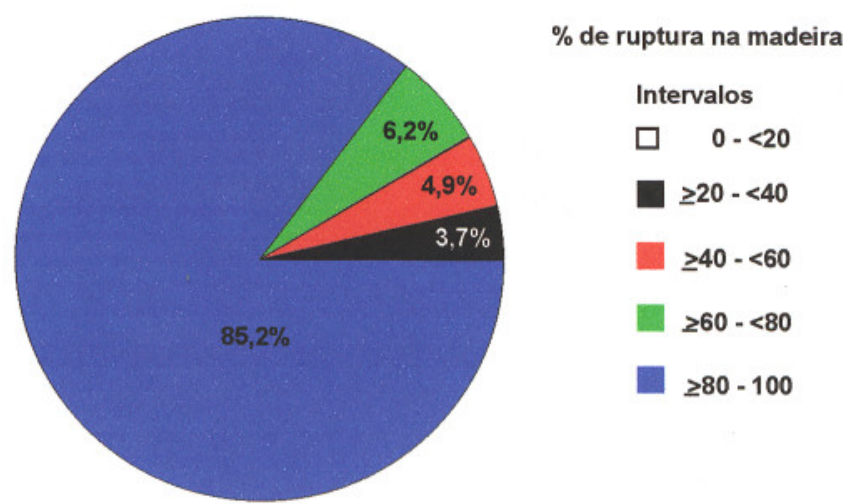

FIGURA 45 - Forma de ruptura - Tração normal- Eucaliptus grandis. 


\section{- Análise dos resultados}

As análises dos valores encontrados nas tabelas 22 e 23 , e na figura 46, permitiram definir os efeitos mais significativos das variáveis e suas iterações apresentados em destaque a seguir:

TpP- Iteração entre os efeitos lineares das variáveis "tempo de pressão" e "pressão".

VTpP- Iteração entre os efeitos lineares das variáveis, "viscosidade", "tempo de pressão" e "pressão".

VTp ${ }^{2} \mathbf{P}$ Iteração entre o efeito linear da variável "viscosidade", o efeito de $2^{\mathrm{a}}$ ordem da variável "tempo de pressão" e o efeito linear da variável "pressão".

TABELA 22- Efeitos significativos das variáveis e suas iterações- Tração normalEucaliptus grandis.

\begin{tabular}{|c|c|c|c|c|c|c|c|c|}
\hline Row & RESPOSTA & (1) & (2) & (3) & DIVISOR & ORTOGONA & nomeefe & MS \\
\hline 1 & 16.47 & 44.96 & 129.99 & 407.71 & 81 & 5.03346 & 0 & 2052.19 \\
\hline 2 & 14.98 & 47.31 & 142.49 & -1.24 & 54 & -0.02296 & $\overrightarrow{\mathrm{V}}$ & 0.03 \\
\hline 3 & 13.51 & 37.72 & 135.23 & -6.56 & 162 & -0.04049 & $\mathrm{v}^{2}$ & 0.27 \\
\hline 4 & 14.90 & 54.21 & 1.69 & -3.91 & 54 & -0.07241 & $\mathrm{Tp}$ & 0.28 \\
\hline 5 & 14.52 & 41.43 & -3.04 & -3.63 & 36 & -0.10083 & VTp & 0.37 \\
\hline 6 & 17.89 & 46.85 & 0.11 & -2.89 & 108 & -0.02676 & $\mathrm{~V}^{2} \mathrm{Tp}$ & 0.08 \\
\hline 7 & 12.01 & 39.36 & 5.37 & 4.03 & 162 & 0.02488 & $T p^{2}$ & 0.10 \\
\hline 8 & 12.04 & 45.82 & -10.42 & 7.73 & 108 & 0.07157 & $V T p^{2}$ & 0.55 \\
\hline 9 & 13.67 & 50.05 & -1.51 & -11.81 & 324 & -0.03645 & $\mathrm{~V}^{2} \mathrm{Tp^{2 }}$ & 0.43 \\
\hline 10 & 17.09 & -2.96 & -7.24 & 5.24 & 54 & 0.09704 & $\mathrm{P}$ & 0.51 \\
\hline 11 & 19.26 & 2.99 & -7.36 & -1.58 & 36 & -0.04389 & $\mathrm{VP}$ & 0.07 \\
\hline 12 & 17.86 & 1.66 & 10.69 & -6.88 & 108 & -0.06370 & $\mathrm{~V}^{2} \mathrm{P}$ & 0.44 \\
\hline 13 & 15.09 & 0.77 & 4.62 & 17.93 & 36 & 0.49806 & $\mathrm{TPP}$ & 8.93 \\
\hline$\overline{14}$ & 13.78 & -2.53 & -2.05 & -10.82 & 24 & -0.45083 & Vrop & 4.80 \\
\hline 15 & 12.56 & -1.28 & -6.20 & -2.68 & 72 & -0.03722 & $\mathrm{~V}^{2} \mathrm{TpP}$ & 0.10 \\
\hline 16 & 15.10 & 4.88 & 1.58 & 9.71 & 108 & 0.08991 & $\mathrm{Tp}^{2} \mathrm{P}$ & 0.87 \\
\hline 17 & 17.93 & -3.45 & -3.37 & 17.74 & 72 & 0.24639 & $\operatorname{lop}^{2} \mathrm{P}$ & 0.37 \\
\hline 18 & 13.82 & -1.32 & -1.10 & 10.64 & 216 & 0.04926 & $\mathrm{~V}^{2} \mathrm{Tp}^{2} \mathrm{P}$ & 0.52 \\
\hline 19 & 10.82 & 0.02 & -11.94 & -19.76 & 162 & -0.12198 & $\mathrm{P}^{2}$ & 2.41 \\
\hline 20 & 12.84 & 3.75 & 18.20 & 7.88 & 108 & 0.07296 & $\mathrm{VP}^{2}$ & 0.57 \\
\hline 21 & 15.70 & 1.60 & -2.23 & 24.70 & 324 & 0.07623 & $\mathrm{~V}^{2} \mathrm{P}^{2}$ & 1.88 \\
\hline 22 & 16.65 & -3.57 & -7.28 & 18.17 & 108 & 0.16824 & $\mathrm{TpP}^{2}$ & 3.06 \\
\hline 23 & 15.97 & 0.09 & 4.55 & 2.52 & 72 & 0.03500 & $\mathrm{VTpP} \mathrm{P}^{2}$ & 0.09 \\
\hline 24 & 13.20 & -6.94 & 10.46 & 7.22 & 216 & 0.03343 & $\mathrm{~V}^{2} \mathrm{Tp} \mathrm{P}^{2}$ & 0.24 \\
\hline 25 & 17.30 & 0.84 & -5.88 & -50.57 & 324 & -0.15608 & $T p^{2} p^{2}$ & 7.89 \\
\hline 26 & 16.77 & -2.09 & -10.69 & -5.92 & 216 & -0.02741 & $V T p^{2} p^{2}$ & 0.16 \\
\hline 27 & 15.98 & -0.26 & 4.76 & 20.26 & 648 & 0.03127 & $\mathrm{~V}^{2} \mathrm{Tp}^{2} \mathrm{P}^{2}$ & 0.63 \\
\hline
\end{tabular}




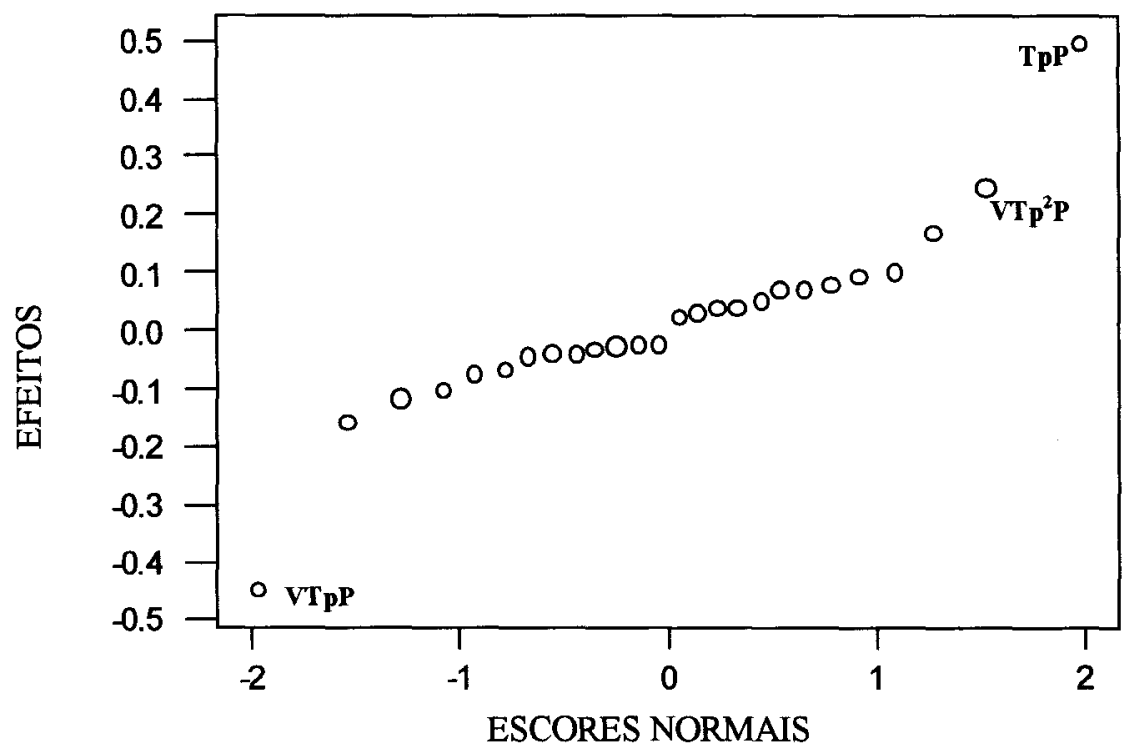

FIGURA 46 - Efeitos $x$ Escores normais- Tração normal- Eucaliptus grandis.

TABELA 23 - Intervalo de confiança a 95\% - Tração normal - Eucaliptus grandis.

\begin{tabular}{|c|c|c|c|c|}
\hline Row & C26 & $\mathrm{C2O}$ & $\mathrm{C27}$ & Efeito \\
\hline 2 & -0.223741 & -0.022963 & 0.177815 & $\mathrm{~V}$ \\
\hline 3 & -0.241272 & -0.040494 & 0.160284 & $\mathrm{~V}^{2}$ \\
\hline 4 & -0.273185 & -0.072407 & 0.128370 & $\mathrm{Tp}$ \\
\hline 5 & -0.301611 & -0.100833 & 0.099944 & VTp \\
\hline 6 & -0.227537 & -0.026759 & 0.174019 & $\mathrm{~V}^{2} \mathrm{Tp}$ \\
\hline 7 & -0.175901 & 0.024877 & 0.225654 & $\mathrm{Tp}^{2}$ \\
\hline 8 & -0.129204 & 0.071574 & 0.272352 & $\mathrm{VTp}^{2}$ \\
\hline 9 & -0.237228 & -0.036451 & 0.164327 & $\mathrm{~V}^{2} \mathrm{Tp} \mathrm{p}^{2}$ \\
\hline 10 & -0.103740 & 0.097037 & 0.297815 & $\mathrm{P}$ \\
\hline 11 & -0.244667 & -0.043889 & 0.156889 & VP \\
\hline 12 & -0.264482 & -0.063704 & 0.137074 & $\mathrm{~V}^{2} \mathrm{P}$ \\
\hline 13 & 0.297270 & 0.490055 & 0.690833 & 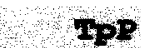 \\
\hline 14 & -0.651611 & -0.450833 & -0.250055 & $\mathrm{mipl}$ \\
\hline 15 & -0.238000 & -0.037222 & 0.163556 & $\mathrm{~V}^{2} \mathrm{TpP}$ \\
\hline 16 & -0.110871 & 0.089907 & 0.290685 & $T p^{2} P$ \\
\hline 17 & 0.045611 & 0.246389 & 0.447167 & $\operatorname{tap}^{2} P$ \\
\hline 18 & -0.151519 & 0.049259 & 0.250037 & $\mathrm{~V}^{2} \mathrm{Tp} \mathrm{p}^{2} \mathrm{P}$ \\
\hline 19 & -0.322753 & -0.121975 & 0.078803 & $\mathrm{P}^{2}$ \\
\hline 20 & -0.127815 & 0.072963 & 0.273741 & $\mathrm{VP}^{2}$ \\
\hline 21 & -0.124543 & 0.076235 & 0.277012 & $\mathrm{~V}^{2} \mathrm{P}^{2}$ \\
\hline 22 & -0.032537 & 0.168241 & 0.369019 & $\mathrm{Tp} \mathrm{P}^{2}$ \\
\hline 23 & -0.165778 & 0.035000 & 0.235778 & $V T p P^{2}$ \\
\hline 24 & -0.167352 & 0.033426 & 0.234204 & $\mathrm{~V}^{2} \mathrm{TpP}^{2}$ \\
\hline 25 & -0.356858 & -0.156080 & 0.044698 & $\mathrm{Tp}^{2} \mathrm{P}^{2}$ \\
\hline 26 & -0.228185 & -0.027407 & 0.173370 & $V T p^{2} P^{2}$ \\
\hline 27 & -0.169512 & 0.031265 & 0.232043 & $V^{2} T p^{2} P^{2}$ \\
\hline
\end{tabular}




\subsection{3- Resistência da emenda dentada colada (finger joint) à tração paralela às fibras $\left(f_{g t, 0}\right)$}

Na tabela 24 são apresentados os resultados dos ensaios de tração paralela, por combinação de parâmetros e níveis. Na figura 47 estão plotados os valores médios dos resultados das combinações e o valor médio dos corpos-de-prova maciços utilizados como controle.

TABELA 24 - Resistência à tração paralela (finger joint)- Eucaliptus grandis.

\begin{tabular}{|c|c|c|c|c|c|c|}
\hline \multirow[b]{2}{*}{ ENSAIOS } & \multicolumn{2}{|c|}{ VARIÁVEIS INDEPENDENTES } & \multicolumn{4}{|c|}{ VARIAVEL RESPOSTA (MPa) } \\
\hline & $\begin{array}{l}\text { VSCOSIDADE } \\
\text { (min.) }\end{array}$ & $\begin{array}{l}\text { PRESSĀO } \\
\text { (MPa) }\end{array}$ & $Y_{1}$ & $Y_{2}$ & $Y_{3}$ & $\bar{Y}$ \\
\hline 1 & 0 & 8,0 & 55,60 & 50,00 & 35,60 & 47,10 \\
\hline 2 & 3 & 8,0 & 32,20 & 46,60 & 53,50 & 44,10 \\
\hline 3 & 6 & 8,0 & 65,80 & 35,90 & 42,00 & 47,90 \\
\hline 4 & 0 & 10,0 & 52,50 & 44,40 & 67,20 & 54,70 \\
\hline 5 & 3 & 10,0 & 52,20 & 67,70 & 45,20 & 55,03 \\
\hline 6 & 6 & 10,0 & 65,60 & 74,20 & 87,20 & 75,67 \\
\hline 7 & 0 & 12,0 & 59,10 & 59,40 & 64,30 & 60,93 \\
\hline 8 & 3 & 12,0 & 53,30 & 48,50 & 43,70 & 48,50 \\
\hline 9 & 6 & 12,0 & 62,30 & 65,60 & 77,10 & 68,33 \\
\hline
\end{tabular}

Obs: $\mathrm{Y}_{1}, \mathrm{Y}_{2}, \mathrm{Y}_{3}$ e $\overline{\mathrm{Y}}$ são as réplicas e a média da variável resposta, respectivamente.

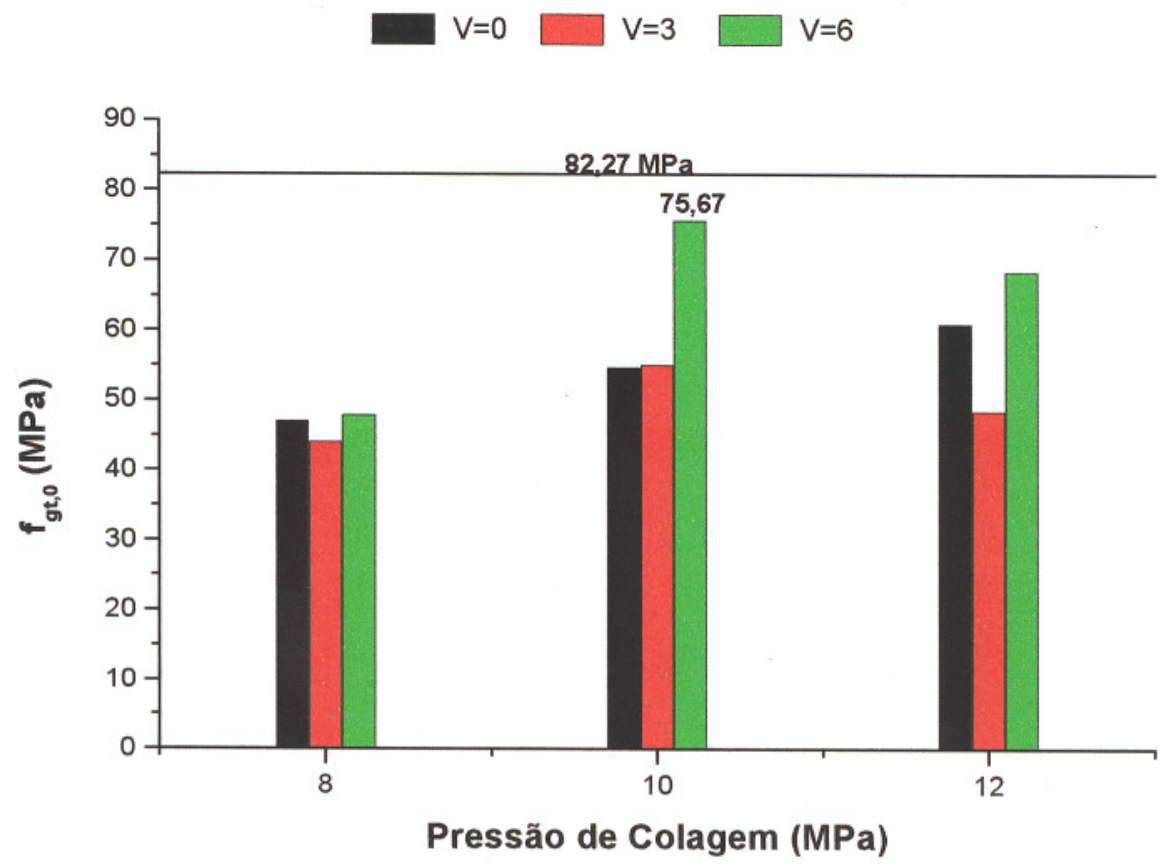

FIGURA 47 - Tração paralela - Valores médios dos resultados das combinações e dos corpos-de-prova maciços de controle- Eucaliptus grandis. 
O melhor resultado da combinação em destaque foi obtida para a viscosidade $\mathrm{V}=6$ ' e a pressão $\mathrm{P}=10,0 \mathrm{MPa}$ com o valor da resistência média à tração paralela de $\mathrm{f}_{\mathrm{gt}, 0}=75,67 \mathrm{MPa}$.

\section{- Forma de ruptura}

Os corpos-de-prova foram avaliados quanto a forma de ruptura figura 48 e as respectivas porcentagens de cada intervalo de ruptura apresentadas na tabela 25 .

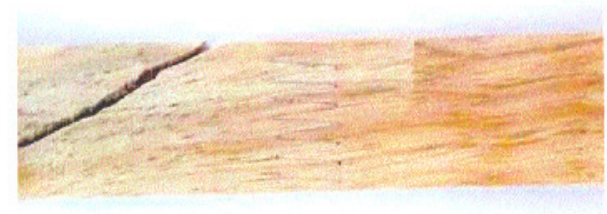

Região fora da emenda (A).

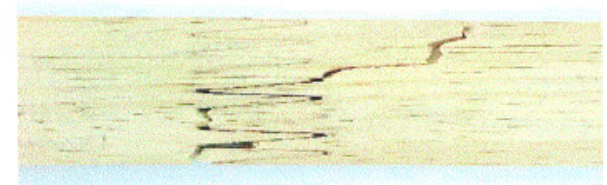

Região fora da emenda e região da emenda na madeira e na interface madeira adesivo $\left(\mathrm{B}_{2}\right)$.

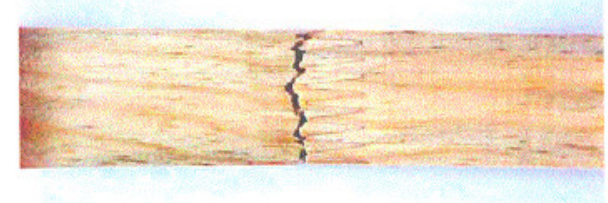

Região da emenda na madeira $\left(\mathrm{C}_{1}\right)$.

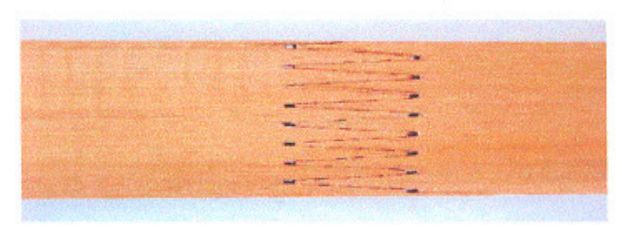

Região da emenda na interface madeira adesivo $\left(\mathrm{C}_{3}\right)$.

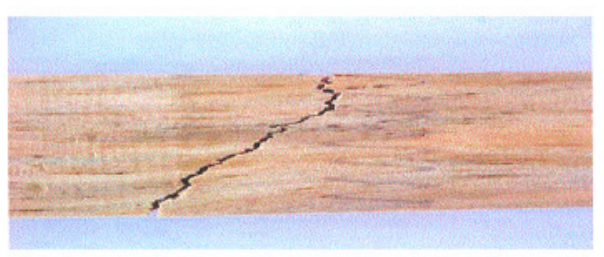

Região fora da emenda e região da emenda na madeira $\left(\mathrm{B}_{1}\right)$

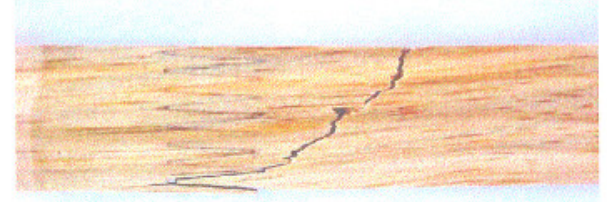

Região fora da emenda e região da emenda na interface madeira adesivo $\left(B_{3}\right)$.

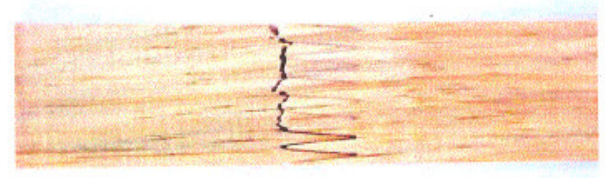

Região da emenda na madeira e na interface madeira adesivo $\left(\mathrm{C}_{2}\right)$.

FIGURA 48- Formas de ruptura- Tração paralela 
TABELA 25 - Forma de ruptura - Tração paralela - Eucaliptus grandis.

\begin{tabular}{|c|c|c|c|c|c|c|c|c|}
\hline \multirow{3}{*}{ (\%) de ruptura } & \multicolumn{7}{|c|}{ Regiōes de ocorrência de ruptura } & \multirow{3}{*}{$\begin{array}{l}\text { Total } \\
(\%)\end{array}$} \\
\hline & \multirow{2}{*}{$\mathbf{A}$} & \multicolumn{3}{|c|}{$\mathbf{B}$} & \multicolumn{3}{|c|}{$\mathbf{C}$} & \\
\hline & & 1 & 2 & 3 & 1 & 2 & 3 & \\
\hline Regiões $\mathbf{A}+\mathbf{B}+\mathbf{C}$ & 29,6 & 7,4 & 0 & 22,3 & 0 & 7,4 & 33,3 & 100 \\
\hline Regiões $A+B_{1}+C_{1}$ & 29,6 & 7,4 & & & 0 & & & 37 \\
\hline \multicolumn{9}{|c|}{$\begin{array}{l}\text { OBS: Regiōes de ruptura } \\
\text { A- Região fora da emenda } \\
\text { B- Região fora da emenda e reglão da emenda }\left(B_{1}, B_{2} \in B_{3}\right) \\
\text { C- Região da emenda }\left(C_{1}, C_{2} \text { e } C_{3}\right) \\
\text { 1- Madeira } \\
\text { 2- Madeira/ interface madeira- adesivo } \\
\text { 3- Interface madeira- adesivo }\end{array}$} \\
\hline
\end{tabular}

\section{- Análise dos resultados}

As análises dos valores encontrados nas tabelas 26 e 27 , e na figura 49, permitiram definir os efeitos mais significativos das variáveis e suas iterações apresentados em destaque a seguir:

V- Efeito linear da variável "viscosidade".

P- Efeitos linear da variável, "pressão".

TABELA 26 - Efeitos significativos das variáveis e suas iterações - Tração paralelaEucaliptus grandis.

\begin{tabular}{rrrrrrrrrr}
\hline ROW & RESPOSTA & (1) & (2) & DIVISOR & ORTOGONA & NOMEEFE & SQ & RAIZ (SQ) \\
\hline 1 & 141.2 & 417.2 & 1506.7 & 27 & 55.8037 & 0 & 84079.4 & 289.965 \\
$\mathbf{2}$ & $\mathbf{1 3 2 . 3}$ & $\mathbf{5 5 6 . 2}$ & $\mathbf{8 7 . 6}$ & $\mathbf{1 8}$ & $\mathbf{4 . 0 6 6 7}$ & $\mathbf{V}$ & $\mathbf{4 2 6 . 3}$ & $\mathbf{2 0 . 6 4 8}$ \\
3 & 143.7 & 533.3 & 178.0 & 54 & 3.2963 & $\mathrm{~V}^{2}$ & $\mathbf{5 8 6 . 7}$ & $\mathbf{2 4 . 2 2 3}$ \\
$\mathbf{4}$ & $\mathbf{1 6 4 . 1}$ & $\mathbf{2 . 5}$ & $\mathbf{1 1 6 . 1}$ & $\mathbf{1 6}$ & $\mathbf{6 . 4 5 0 0}$ & $\mathbf{P}$ & $\mathbf{7 4 8 . 8}$ & $\mathbf{2 7 . 3 6 5}$ \\
5 & 165.1 & 62.9 & 19.7 & 12 & 1.6417 & $\mathrm{VP}$ & $\mathbf{3 2 . 3}$ & 5.687 \\
6 & 227.0 & 22.2 & 76.5 & 36 & 2.1250 & $\mathrm{~V}^{2} \mathrm{P}$ & 162.6 & 12.750 \\
7 & 182.8 & 20.3 & -161.9 & 54 & -2.9981 & $\mathrm{P}^{2}$ & 485.4 & 22.032 \\
8 & 145.5 & 60.9 & -101.1 & 36 & -2.8083 & $\mathrm{VP}^{2}$ & 283.9 & 16.850 \\
9 & 205.0 & 96.8 & -4.7 & 108 & -0.0435 & $\mathrm{~V}^{2} \mathrm{P}^{2}$ & 0.2 & 0.452 \\
\hline
\end{tabular}




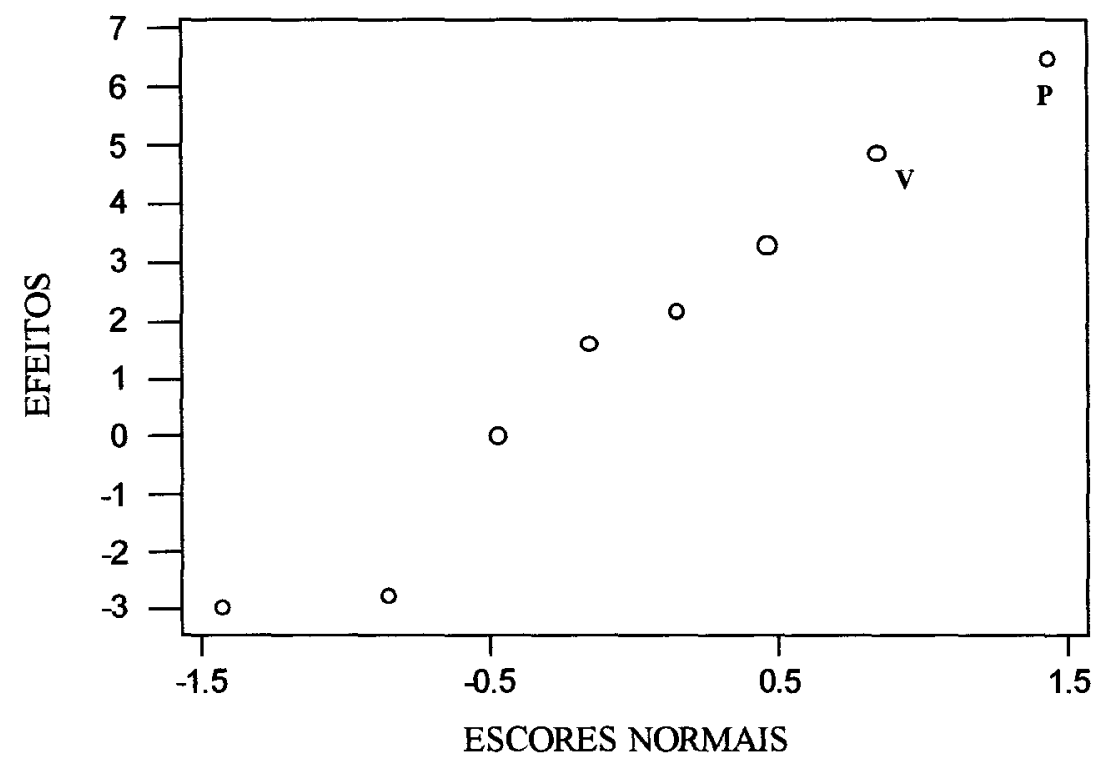

FIGURA 49 - Efeitos $x$ Escores normais- Tração paralela - Eucaliptus grandis.

TABELA 27 - Intervalo de confiança a 95\% - Tração paralela- Eucaliptus grandis.

\begin{tabular}{crrrrr}
\hline Row & C26 & ORTOGONA & C27 & Efeito \\
\hline 1 & 51.9272 & 55.8037 & 59.6802 & 0 \\
$\mathbf{2}$ & $\mathbf{0 . 9 9 0 2}$ & $\mathbf{4 . 8 6 6 7}$ & $\mathbf{8 . 7 4 3 1}$ & $\mathbf{V}$ \\
3 & -0.5802 & 3.2963 & 7.1728 & $\mathrm{~V}^{2}$ \\
$\mathbf{4}$ & $\mathbf{2 . 5 7 3 5}$ & $\mathbf{6 . 4 5 0 0}$ & $\mathbf{1 0 . 3 2 6 5}$ & $\mathbf{P}$ \\
5 & -2.2348 & 1.6417 & 5.5181 & $\mathrm{VP}$ \\
6 & -1.7515 & 2.1250 & 6.0015 & $\mathrm{~V}^{2} \mathrm{P}$ \\
7 & -6.8746 & -2.9981 & 0.8783 & $\mathrm{P}^{2}$ \\
8 & -6.6848 & -2.8083 & 1.0681 & $\mathrm{VP}^{2}$ \\
9 & -3.9200 & -0.0435 & 3.8329 & $\mathrm{~V}^{2} \mathrm{P}^{2}$ \\
\hline
\end{tabular}

\subsection{4- Tempo de cura}

As tabelas 28,29 e 30 e a figura 50 apresentam os tempos de cura em função da resistência dos ensaios de cisalhamento, tração normal e paralela relativos às melhores combinações da viscosidade, tempo de pressão e pressão definidas nos ensaios anteriores. 
TABELA 28 -- Tempo de cura - Cisalhamento - Eucaliptus grandis.

(Combinação: $0 ; 4 ; 0,6$ )

\begin{tabular}{crrrr}
\hline TEMPO & \multicolumn{4}{c}{ VARIAVEL RESPOSTA (MPa) } \\
\cline { 2 - 5 } (dias) & $Y_{1}$ & $Y_{2}$ & $Y_{3}$ & $\bar{Y}$ \\
\hline 4 & 11,41 & 11,94 & 12,44 & 11,93 \\
$\mathbf{8}$ & $\mathbf{1 3 , 1 2}$ & $\mathbf{1 2 , 7 5}$ & $\mathbf{1 4 , 4 4}$ & $\mathbf{1 3 , 4 4}$ \\
12 & 9,87 & 10,10 & $\mathbf{8 , 9 6}$ & 9,64 \\
16 & 14,15 & 13,37 & 12,38 & 13,30 \\
20 & 12,76 & 10,11 & 10,05 & 10,97 \\
\hline
\end{tabular}

Obs: $\mathrm{Y}_{1}, \mathrm{Y}_{2}, \mathrm{Y}_{3} \mathrm{e} \overline{\mathrm{Y}}$ são as réplicas e a média da variável resposta, respectivamente.

TABELA 29 - Tempo de cura - Tração normal - Eucaliptus grandis. (Combinação: $3 ; 4 ; 0,6$ )

\begin{tabular}{crrrr}
\hline TEMPO & \multicolumn{4}{c}{ VARIAVEL RESPOSTA (MPa) } \\
\cline { 2 - 5 } (dias) & $Y_{1}$ & $Y_{2}$ & $Y_{3}$ & $\bar{Y}$ \\
\hline 4 & 3,13 & 3,53 & 3,71 & 3,46 \\
8 & 2,42 & 2,93 & 3,66 & 3.00 \\
12 & 3,04 & 3,09 & $\mathbf{4 , 3 7}$ & 3,50 \\
16 & $\mathbf{4 , 5 9}$ & $\mathbf{4 , 4 8}$ & $\mathbf{4 , 8 7}$ & $\mathbf{4 , 6 5}$ \\
20 & $\mathbf{4 , 5 6}$ & $\mathbf{4 , 2 2}$ & $\mathbf{4 , 8 8}$ & $\mathbf{4 , 5 5}$ \\
\hline
\end{tabular}

Obs: $Y_{1}, Y_{2}, Y_{3}$ e $\bar{Y}$ são as réplicas e a média da variável resposta, respectivamente.

TABELA 30 - Tempo de cura - Tração paralela - Eucaliptus grandis.

(Combinação: 6; 10,0)

\begin{tabular}{crrrr}
\hline \multirow{2}{*}{$\begin{array}{c}\text { TEMPO } \\
\text { (dias) }\end{array}$} & \multicolumn{4}{c}{ VARIAVEL RESPOSTA (MPa) } \\
\cline { 2 - 5 } & $Y_{1}$ & $Y_{2}$ & $Y_{3}$ & $\bar{Y}$ \\
\hline 4 & 97,27 & 99,84 & $\mathbf{8 7 , 0 1}$ & $\mathbf{9 4 , 7 1}$ \\
$\mathbf{8}$ & $\mathbf{1 0 1 , 1 0}$ & $\mathbf{1 0 2 , 4 3}$ & $\mathbf{9 8 , 7 4}$ & $\mathbf{1 0 0 , 7 6}$ \\
12 & 94,51 & 100,34 & $\mathbf{8 8 , 6 5}$ & $\mathbf{9 4 , 5 0}$ \\
16 & 97,70 & 90,92 & 93,23 & 93,95 \\
20 & $\mathbf{8 9 , 5 6}$ & 71,61 & $\mathbf{8 0 , 6 0}$ & $\mathbf{8 0 , 5 9}$ \\
\hline
\end{tabular}

Obs: $\mathrm{Y}_{1}, \mathrm{Y}_{2}, \mathrm{Y}_{3}$ e $\overline{\mathrm{Y}}$ são as réplicas e a média da variável resposta, respectivamente.

O tempo de cura apresentado em destaque para os ensaios de cisalhamento e de tração paralela foi de 8 dias e para o ensaio de tração normal de 16 dias. 


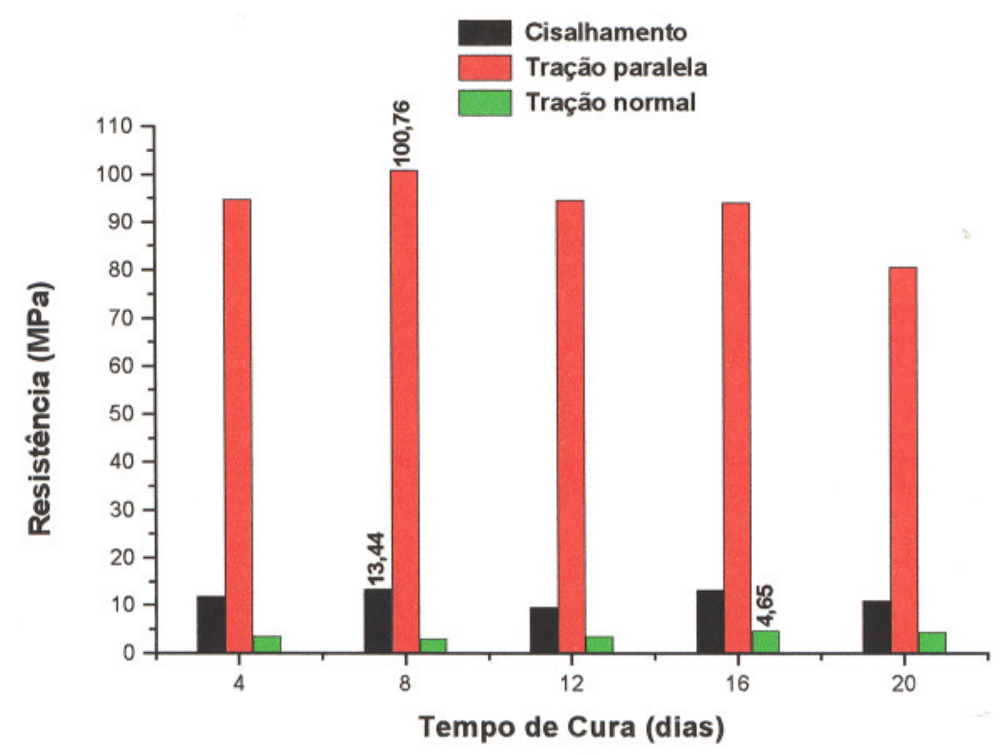

FIGURA 50 - Tempo de cura - Valores médios dos resultados dos ensaios Eucaliptus grandis.

\subsection{Análise dos coeficientes de variação}

As tabelas 31, 32, 33 e 34 apresentam os valores das médias $(\overline{\mathrm{x}})$, dos desvios padrão (sd) e dos coeficientes de variação (cv), referentes às variáveis viscosidade (V), tempo de pressão (Tp) e pressão de colagem (P)e seus níveis, por ensaio e por espácies.

\section{- Pinus caribea hondurensis}

TABELA 31- Coeficientes de variação- Cisalhamento e tração normal- Pinus caribea hondurensis.

\begin{tabular}{rcccccc}
\hline \multirow{2}{*}{ VARIÁVEL } & \multicolumn{3}{c}{ Cisalhamento } & \multicolumn{3}{c}{ Tração normal } \\
\cline { 2 - 7 } & $\overline{\mathbf{x}}$ & $\mathbf{s d}$ & $\mathbf{c v}$ & $\overline{\mathbf{x}}$ & $\mathbf{s d}$ & $\mathbf{C v}$ \\
\hline $\mathrm{V}=0$ & 9,60 & 1,025 & 9,37 & 3,43 & 0,557 & 6,16 \\
$\mathrm{~V}=3$ & 9,44 & 1,259 & 7,50 & 3,66 & 0,368 & 9,95 \\
$\mathrm{~V}=6$ & 9,22 & 1,170 & 7,88 & 3,50 & 0,718 & 4,88 \\
\hline $\mathrm{T}=4$ & 9,77 & 0,983 & 9,94 & 3,32 & 0,484 & 6,86 \\
$\mathrm{~T}=4=6$ & 9,66 & 0,922 & 10,48 & 3,65 & 0,643 & 5,68 \\
$\mathrm{~T} p=8$ & 8,79 & 1,269 & 6,93 & 3,63 & 0,521 & 6,97 \\
\hline $\mathrm{P}=0,4$ & 10,26 & 0,689 & 14,89 & 3,43 & 0,432 & 7,94 \\
$\mathrm{P}=0,6$ & 9,06 & 1,204 & 7,53 & 3,59 & 0,743 & 4,83 \\
$\mathrm{P}=0,8$ & 8,91 & 0,985 & 9,05 & 3,58 & 0,484 & 7,40 \\
\hline TOTAL & $\mathbf{9 , 4 1}$ & $\mathbf{1 , 1 4 5}$ & $\mathbf{8 , 2 2}$ & $\mathbf{3 , 5 3}$ & $\mathbf{0 , 5 6 7}$ & $\mathbf{6 , 2 3}$ \\
\hline
\end{tabular}


TABELA 32- Coeficientes de variação- Tração paralela- Pinus caribea hondurensis.

\begin{tabular}{cccc}
\hline \multirow{2}{*}{ VARIÁVEL } & \multicolumn{3}{c}{ Tração paralela (MPa) } \\
\cline { 2 - 4 } & $\overline{\mathbf{x}}$ & $\mathbf{s d}$ & $\mathbf{c V}$ \\
\hline $\mathrm{V}=0$ & 47,37 & 7,30 & 6,49 \\
$\mathrm{~V}=3$ & 44,61 & 7,46 & 5,98 \\
$\mathrm{~V}=6$ & 48,68 & 4,28 & 11,37 \\
\hline $\mathrm{P}=7,0$ & 43,33 & 5,07 & 8,55 \\
$\mathrm{P}=8,0$ & 44,96 & 6,55 & 6,86 \\
$\mathrm{P}=9,0$ & 52,37 & 4,04 & $\mathbf{1 2 , 9 6}$ \\
\hline TOTAL & $\mathbf{4 6 , 8 9}$ & $\mathbf{6 , 4 9}$ & $\mathbf{7 , 2 3}$ \\
\hline
\end{tabular}

\section{- Eucaliptus grandis}

TABELA 33- Coeficientes de variação- Cisalhamento e tração normal- Eucaliptus grandis

\begin{tabular}{ccccccc}
\hline \multirow{2}{*}{ VARIÁVEL } & \multicolumn{3}{c}{ Cisalhamento (MPa) } & \multicolumn{3}{c}{ Tração normal (MPa) } \\
\cline { 2 - 7 } & $\overline{\mathbf{x}}$ & $\mathbf{s d}$ & $\mathbf{c V}(\%)$ & $\overline{\mathbf{x}}$ & $\mathbf{s d}$ & $\mathbf{c v}(\%)$ \\
\hline $\mathrm{V}=0$ & $\mathbf{1 3 , 5 3}$ & 3,129 & 4,32 & 5,02 & 1,016 & 4,94 \\
$\mathrm{~V}=\mathbf{3}$ & 13,17 & 2,345 & 5,62 & 5,11 & 1,051 & 4,86 \\
$\mathrm{~V}=6$ & 12,50 & 2,655 & 4,71 & 4,97 & 1,070 & 4,65 \\
\hline $\mathrm{Tp}=4$ & 13,22 & 3,242 & 4,08 & 5,13 & 1,125 & 4,56 \\
$\mathrm{Tp}=6$ & 13,99 & 2,730 & 5,13 & 4,98 & 0,772 & 6,45 \\
$\mathrm{Tp}=8$ & 11,98 & 1,677 & 7,14 & 4,99 & 1,190 & 4,19 \\
\hline $\mathrm{P}=0,4$ & 12,90 & $\mathbf{3 , 2 0 6}$ & $\mathbf{4 , 0 2}$ & 4,81 & $\mathbf{1 , 0 9 6}$ & 4,39 \\
$\mathrm{P}=0,6$ & 13,87 & 2,117 & 6,55 & 5,28 & 0,990 & 5,33 \\
$\mathrm{P}=0,8$ & 12,42 & 2,646 & 4,69 & 5,01 & 1,000 & 5,01 \\
\hline TOTAL & $\mathbf{1 3 , 0 6}$ & $\mathbf{2 , 7 2 8}$ & $\mathbf{4 , 7 9}$ & $\mathbf{5 , 0 3}$ & $\mathbf{1 , 0 3 5}$ & $\mathbf{4 , 8 6}$ \\
\hline
\end{tabular}

TABELA 34- Coeficientes de variação- Tração paralela- Eucaliptus grandis

\begin{tabular}{cccc}
\hline \multirow{2}{*}{ VARIÁVEL } & \multicolumn{3}{c}{ Tração paralela (MPa) } \\
\cline { 2 - 4 } & $\overline{\mathbf{x}}$ & $\mathbf{s d}$ & $\mathbf{c V ~ ( \% )}$ \\
\hline $\mathrm{V}=0$ & 54,23 & 9,916 & 5,47 \\
$\mathrm{~V}=\mathbf{3}$ & 49,21 & 9,546 & 5,16 \\
$\mathrm{~V}=6$ & 63,97 & 16,197 & $\mathbf{3 , 9 5}$ \\
\hline $\mathrm{P}=8,0$ & 46,36 & 11,024 & 4,21 \\
$\mathrm{P}=10,0$ & 61,80 & 14,293 & 4,32 \\
$\mathrm{P}=12,0$ & 59,26 & 9,916 & 5,98 \\
\hline TOTAL & $\mathbf{5 5 , 8 0}$ & $\mathbf{1 3 , 3 4 1}$ & $\mathbf{4 , 1 8}$ \\
\hline
\end{tabular}




\section{CONCLUSÕES}

Após a análise e discussão dos resultados são aqui apresentadas as principais conclusões do trabalho, com ênfase na análise da influência de cada parâmetro.

\section{- Parâmetros de colagem}

\section{Viscosidade, Tempo de Pressão e Pressão de colagem}

A tabela 35 apresenta os parâmetros finais de colagem, viscosidade (V), tempo de pressão (Tp) e pressão de colagem (P) por ensaio, para as duas espécies empregadas.

TABELA 35- Parâmetros de colagem - viscosidade, tempo de pressão e pressão.

\begin{tabular}{ccccc}
\hline ESPECIES & ENSAIOS/ PARAMETROS & V (min.) & Tp (h) & P (MPa) \\
\hline CISALHAMENTO & 3 & 4 & 0,4 \\
& TRAÇÃO NORMAL & 6 & 6 & 0,6 \\
& TRAÇÃO PARALELA & 0 & - & 9,0 \\
\hline & CISALHAMENTO & 0 & 4 & 0,6 \\
\hline
\end{tabular}


A tabela 36 relaciona os valores médios das resistências encontrados para o pinus e para o eucalitptus nos ensaios de cisalhamento, tração normal e tração paralela.

Com exceção dos ensaios de tração paralela para ambas as espécies, todos os outros ensaios apresentaram valores superiores aos valores médios dos corpos-deprova maciços de controle. Isto indica que o polímero à base de mamona penetrou nas estruturas micro e macro anatômicas da madeira, reforçando a madeira, e levando a ruptura da madeira ocorrer em uma região mais interna à interface madeira adesivo. Esta penetração é verificada também pelos resultados dos ensaios de tração paralela. Considerando-se apenas a geometria da emenda dentada, esta reduz a área líquida dos corpos-de-prova (RANKES, 1980), previsto em normas ( CEN, 1995), como a DIN 68140 (1971) que recomenda uma redução de 16\%. Assim a porcentagem da resistência em relação aos corpos-de-prova de controle ficaria em $84 \%$ levando-se em consideração apenas este aspecto. Outro fator a ser considerado na redução da resistência é a alta concentração de esforços na região dos "dentes" da emenda (MACEDO,1998). Assim os valores percentuais apresentados na tabela 36 indicam uma ação positiva do polímero também sobre os resultados dos ensaios de tração paralela.

TABELA 36- Relação percentual entre as resistências dos corpos-de-prova colados e dos corpos-de-prova de controle.

\begin{tabular}{ccccc}
\hline ESPÉCIES & ENSAIOS & $\begin{array}{c}\text { A } \\
(\mathbf{M P a})\end{array}$ & $\begin{array}{c}\text { B } \\
(\mathbf{M P a})\end{array}$ & $\begin{array}{c}\text { C } \\
(\%)\end{array}$ \\
\hline CISALHAMENTO & 10,94 & 10,74 & 101,86 \\
& TRAÇÃo NORMAL & 4,70 & 3,92 & 119,90 \\
& TRAÇÃo PARALELA & 55,01 & 58,02 & 94,81 \\
\hline & CISALHAMENTO & 17,70 & 16,19 & 109,33 \\
& TRAÇÃO NORMAL & 6,42 & 6,39 & 100,47 \\
& TRAÇÃO PARALELA & 75,67 & 82,27 & 91,20
\end{tabular}

OBS: A - Resistência dos corpos-de-prova colados.

B - Resistência dos corpos-de-prova maciços de controle.

C - Porcentagem de A em relação a B. 


\section{Tempo de cura}

As tabelas e gráficos referentes aos tempos de cura indicam pequena variabilidade da resistência em relação a este parâmetro.

A tabela 37 resume os tempos de cura por ensaio e por espécie e compara as resistências relativas a esses tempos, com aquelas desenvolvidas para o tempo de cura de 4 dias. Pode-se observar pelos, percentuais indicados, que a resistência desenvolvida aos 4 dias é adequada para o emprego em estruturas de MLC. Isto pode ser reforçado pelo fato de que o tempo decorrido entre a produção da estrutura na indústria, o seu transporte, a montagem e entrega da obra, com a posterior solicitação total da carga prevista no projeto, é superior aos tempos de cura encontrados originalmente para cada ensaio.

TABELA 37- Tempo de cura.

\begin{tabular}{|c|c|c|c|c|c|}
\hline \multirow{2}{*}{ ESPÉCIES } & \multirow{2}{*}{ ENSAIOS } & \multicolumn{2}{|c|}{$\mathbf{A}$} & \multirow{2}{*}{$\frac{\text { B }}{(\mathrm{MPa})}$} & \multirow{2}{*}{$\frac{C}{(\%)}$} \\
\hline & & $\begin{array}{l}\text { TEMPO DE } \\
\text { CURA (dias) }\end{array}$ & (MPa). & & \\
\hline \multirow{3}{*}{ 촐 } & CISALHAMENTO & 12 & 12,15 & 10,71 & 88,2 \\
\hline & TRAÇÃO NORMAL & 8 & 3.16 & 2,44 & 77,2 \\
\hline & TRAÇĀO PARALELA & 8 & 63,87 & 55,17 & 86,4 \\
\hline \multirow{3}{*}{ 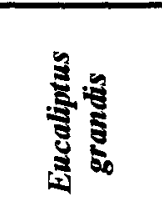 } & CISALHAMENTO & 8 & 13,44 & 11,93 & $\overline{88,8}$ \\
\hline & TRAÇĀO NORMAL & 16 & 4,65 & 3,46 & 74,4 \\
\hline & TRAÇÃO PARALELA & 8 & 100,76 & 94,71 & 94,0 \\
\hline
\end{tabular}

\section{Coeficientes de variação (cv)}

Os valores dos coeficientes de variação obtidos para as diversas variáveis em estudo permitem avaliar esta variabilidade. Os fatores internos, intrínsecos à madeira e ao adesivo e os fatores externos relativos ao processo de produção, colagem e ensaios podem ser qualificados pela avaliação da variabilidade da viscosidade, tempo 
de pressão e pressão.

Pesquisas desenvolvidas por SALES (1996), ROCCO LAHR (1990) e FREITAS (1978), mostraram que os valores dos coeficientes de variação para as propriedades da madeira são da ordem de $18 \%$, com a madeira com o teor de umidade de $12 \%$.

Nas tabelas 31, 32, 33 e 34 observa-se que todos os coeficientes de variação são inferiores ao coeficiente de variação acima. Assim, conclui-se que tanto os procedimentos de: produção, colagem dos corpos-de-prova e os de ensaios, foram bem conduzidos.

\section{- Forma de ruptura}

\section{Cisalhamento}

Os resultados obtidos para o Pinus caribea hondurensis, figura 32, indicam que mais da metade $(50,7 \%)$ dos corpos-de-prova ensaiados tiveram ruptura no intervalo de 80 a 100\% na madeira. Os ensaios do Eucaliptus grandis, figura 42, para o mesmo intervalo de ruptura, apresentaram $85,2 \%$. Esta diferença entre as espécies empregadas pode ser explicada pela presença de resinas, característica das essências florestais do tipo pinus, que interferem negativamente no processo de adesão.

\section{Tração normal}

Os resultados encontrados indicam alta porcentagem de ruptura no intervalo de 80 a 100\% na madeira. Para o Pinus caribea hondurensis, figura 35, essa porcentagem foi de $93,8 \%$ e para o Eucaliptus grandis, figura 45, de 85,2\%.

\section{Tração paralela}

Os resultados observados para o Pinus caribea hondurensis, para este tipo de ensaio, tabela 12 e figura 38, mostram que o somatório das porcentagens de ruptura na madeira - região fora da emenda (A), região fora da emenda e região da emenda 
na madeira $\left(B_{1}\right)$ e região da emenda na madeira $\left(C_{1}\right)$ - totalizou $74,1 \%$. Não foi registrada nenhuma ruptura na região da emenda na interface madeira adesivo $\left(C_{3}\right)$. O Eucaliptus grandis, tabela 25 e figura 48, nas mesmas regiões acima, apresentou as porcentagens $37 \%$ e $33 \%$, respectivamente. A madeira tem seu maior poder de absorção de líquidos, na direção axial às fibras. Dessa forma o pinus, que é uma espécie cuja absorção é maior do que a do eucaliptus, absorve mais o polímero, o que aumenta a resistência da interface madeira adesivo, explicando assim as diferenças dos resultados.

\section{- Efeitos mais significativos das variáveis e suas iterações}

Os efeitos de $1^{\text {a }}$ ordem foram significativamente superiores aos de $2^{\mathrm{a}}$ ordem em todas as espécies e propriedades avaliadas. $O$ único efeito de $2^{a}$ ordem expressivo considerado nesta análise foi registrado para o ensaio de cisalhamento do eucaliptus. Em função destas considerações e através da tabela 38, é possível tecer alguns comentários a respeito da influência exercida pelas variáveis e suas iterações em estudo no âmbito da pesquisa.

TABELA 38- Efeitos mais significativos das variáveis e suas iterações.

\begin{tabular}{|c|c|c|c|c|}
\hline ESPÉCIES & EFEITOS/ ENSAIOS & $\mathbf{f}_{\mathrm{gv}, 0}(\mathrm{MPa})$ & $\mathrm{f}_{\mathrm{gt}, 90}(\mathrm{MPa})$ & $\mathbf{f}_{\mathrm{gt}, 0}(\mathbf{M P a})$ \\
\hline 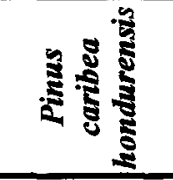 & $\begin{array}{r}\mathbf{T p} \\
\mathbf{P} \\
\mathbf{T p} \mathbf{P} \\
\mathbf{V} \mathbf{T p} \mathbf{P} \\
\end{array}$ & $\begin{array}{c}-0,50 \downarrow \\
-0,68 \downarrow \\
-0- \\
-0-\end{array}$ & $\begin{array}{c}+0,16 \uparrow \\
-0- \\
+0,16 \uparrow \\
+0,17 \uparrow\end{array}$ & $\begin{array}{c}-0- \\
+4,52 \uparrow \\
-0- \\
-0-\end{array}$ \\
\hline 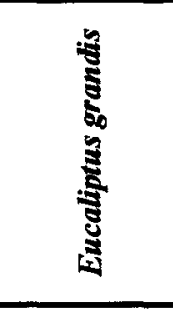 & $\begin{array}{r}T_{p^{2}} \mathbf{P} \\
\mathbf{V} \mathbf{T p} \\
\mathbf{V P} \\
\mathbf{T p} \mathbf{P} \\
\mathbf{V} \mathbf{T p} \mathbf{P} \\
\mathbf{P} \\
\mathbf{V}\end{array}$ & $\begin{array}{c}+1,26 \uparrow \\
+0,65 \uparrow \\
-0,81 \downarrow \\
-1,70 \downarrow \\
-0- \\
-0- \\
-0- \\
\end{array}$ & $\begin{array}{c}-0- \\
-0- \\
-0- \\
+0,50 \uparrow \\
-0,45 \downarrow \\
-0- \\
-0- \\
\end{array}$ & $\begin{array}{c}-0- \\
-0- \\
-0- \\
-0- \\
-0- \\
+6,45 \uparrow \\
+4,87 \uparrow \\
\end{array}$ \\
\hline
\end{tabular}

\section{Cisalhamento}

Da tabela 38 observa-se que a resposta do ensaio de cisalhamento para o pinus foi influenciada negativamente pelos efeitos lineares das variáveis tempo de 
pressão e pressão. Para o eucaliptus houve influência negativa sobre a variável resposta da iteração entre o efeito linear da variável viscosidade com o efeito linear da variável pressão e da iteração entre o efeito linear da variável tempo de pressão com o efeito linear da variável pressão. A iteração entre o efeito linear da variável viscosidade com o efeito linear da variável tempo de pressão influencia positivamente a variável resposta. A iteração entre o efeito de $2^{\mathrm{a}}$ ordem da variável tempo de pressão com o efeito linear da variável pressão influenciou positivamente a variável resposta. Constata-se que o efeito da variável viscosidade ocorreu apenas para os ensaios de cisalhamento com o eucaliptus. Isto pode ser explicado pela baixo poder de absorção desta madeira se comparado, por exemplo, com o pinus.

A ocorrência de efeitos de $2^{\mathrm{a}}$ ordem só foi verificada para o ensaio com o eucaliptus. Isto pode ser explicado pois as dicotiledôneas quando submetidas à esforços de cisalhamento, em geral, apresentam ruptura do tipo elastofrágil, o que ocasionou a ocorrência do efeito de segunda ordem $\mathrm{Tp}^{2} \mathrm{P}$. Somente os efeitos lineares e suas iterações não foram suficientes para explicar esse comportamento. Já nas coníferas, caso do pinus, o tipo de ruptura é elastoplástica. Quando submetidas à esforços da mesma magnitude dos aplicados às dicotiledôneas, acomodam uma maior deformação antes da ruptura, o que foi detectado pelos efeitos lineares e suas iterações (BODIG \& JAYNE, 1982).

\section{Tração normal}

Neste ensaio para o pinus, a resposta foi influenciada positivamente pelo efeito linear da variável tempo de pressão, pela iteração entre o efeito da variável tempo de pressão com o efeito linear da variável pressão e pela iteração entre os efeitos lineares das variáveis viscosidade, tempo de pressão e pressão. Para o eucaliptus a resposta foi influenciada positivamente pela iteração entre o efeito linear da variável tempo de pressão com o efeito linear da variável pressão e, negativamente pela iteração do efeito linear das variáveis viscosidade, tempo de pressão e pressão. Constata-se que para este tipo de solicitação a variável viscosidade influenciou ambas as espécies e que o efeito linear da variável tempo de pressão só afeta o pinus. 


\section{Tração paralela}

A resposta deste ensaio para o pinus é influenciada positivamente apenas pelo efeito linear da variável pressão. Para o eucaliptus a resposta é influenciada pelos efeitos lineares das variáveis pressão e viscosidade.

Constata-se que a o efeito da variável viscosidade ocorreu apenas para os ensaios com o eucaliptus. Isto pode ser explicado pelo baixo poder de absorção desta madeira se comparado, por exemplo, com o pinus.

\section{- Recomendações para o emprego do adesivo poliuretano à base de mamona}

Para a utilização do adesivo poliuretano à base de mamona, com base no amplo estudo teórico e experimental realizado, recomenda-se:

\section{Processamento dos corpos-de-prova e condução dos ensaios}

Atenção especial deve ser dada ao preparo da madeira e a confecção dos corpos-de-prova colados. As imperfeições nos cortes podem gerar superfícies imperfeitas o que concorre para uma colagem de má qualidade. Além desse aspecto, em espécies como o eucaliptus, podem surgir "tensões internas de secagem" durante um processo de secagem mau conduzido. Estas tensões serão liberadas quando do processamento da madeira ocasionando o defeito conhecido por "empenamento longitudinal encurvado". Isto provoca uma união imperfeita entre as superficies coladas, enfraquecendo-as.

Após o processo de colagem são obtidos os corpos-de-prova colados que seguem geometria definida por norma. O processamento das peças coladas, transformando-as nos corpos-de-prova para os ensaios, deve ser cuidadoso, feito com ferramentas perfeitamente afiadas e sem defeitos. Se esta recomendação não for observada os corpos-de-prova podem ser submetidos a esforços que, atingindo as estruturas micro e macro anatômicas da madeira, poderão interferir nos resultados dos ensaios para os quais foram confeccionados. As superficies devem ser 
perfeitamente planas e perpendiculares entre si, e o posicionamento do corpo-deprova na máquina de ensaios deve ser rigoroso para que as solicitações sejam aplicadas da forma prevista na norma.

Todas essas recomendações são de fundamental importância para os ensaios de corpos-de-prova colados.

\section{Parâmetros finais de colagem}

Empregando-se a proporção em peso de uma parte de poliol B1640 e uma parte do prepolímero A249, para obter-se o adesivo à base de mamona e com o consumo de adesivo de $350 \mathrm{~g} / \mathrm{m}^{2}$, são recomendados os seguintes parâmetros de colagem:

\section{Emendas dentadas coladas:}

Pinus caribea hondurensis

Viscosidade $=0$ minutos

Pressão de colagem $=9 \mathrm{MPa}$

Tempo de cura $=4$ dias

\section{Eucaliptus grandis}

Viscosidade $=6$ minutos

Pressão de colagem $=10 \mathrm{MPa}$

Tempo de cura $=4$ dias

\section{Vigas:}

\section{Pinus caribea hondurensis}

Viscosidade $=3$ minutos

Tempo de pressão $=4$ horas

Pressão de colagem $=0,4 \mathrm{MPa}$

Tempo de cura $=4$ dias 


\section{Eucaliptus grandis}

Viscosidade $=0$ minutos

Tempo de pressão $=4$ horas

Pressão de colagem $=0,6 \mathrm{MPa}$

Tempo de cura $=4$ dias

Finalmente, o comportamento do adesivo poliuretano à base de mamona para emprego em estruturas de madeira laminada colada mostrou-se perfeitamente adequado, tornando-se alternativa tecnicamente viável. O custo atual deste adesivo, em escala ainda não industrial, é da mesma ordem do adesivo comercial, atualmente em utilização pela indústria da MLC.

\section{- Recomendações para outras pesquisas:}

Estudo de peças estruturais de MLC coladas com o adesivo à base de mamona, que em ensaios preliminares tiveram comportamento satisfatório;

Estudo da influência da umidade da madeira em peças coladas com o adesivo à base de mamona;

Estudo do comportamento do adesivo à base de mamona em madeiras impregnadas com preservativos contra fungos e insetos;

Estudo da influência do intemperismo em peças de madeiras coladas com o adesivo à base de mamona que em ensaios preliminares tiveram comportamento satisfatório. 


\section{REFERÊNCIAS BIBLIOGRÁFICAS}

ALBA QUÍMICA (1998). Cascophen RS- 216-M. Boletim Técnico. S. Paulo, 5p.

ARAÚJO, L.C.R. (1992). Caracterização química, térmica e mecânica de poliuretanas elastoméricas baseadas em materiais oleoquímicos. São Carlos. 105p. Dissertação (Mestrado).Instituto de Física e Química de São Carlos. Universidade de São Paulo.

ASSOCIAÇÃO BRASILEIRA DE NORMAS TÉCNICAS (1997). NBR 7190. Projeto de estruturas de madeira. 107p. Rio de Janeiro.

BODIG, J.; JAYNE, B.A. (1982). Mechanics of wood and wood composites. New York, Van Nostrand Reynold Company Inc.

BOX, G.E.P.; DRAPER, N.R. (1987). Empirical model- building and response surfaces. New York, John Wiley \& Sons, inc.

BROTERO, F.A. (1946). Dados para a indústria de contraplacados. São Paulo, IPT, Boletim Técnico n $33,54 p$. 
BURGUER, L.M.; RICHTER, H. G. (1991). Anatomia da madeira. São Paulo Livraria Nobel S.A.

CLARO NETO, S. (1997) Caracterizações físico-química de um poliuretano derivado de óleo de mamona utilizada para implantes ósseos. São Carlos. 127p. Tese (Doutorado). Instituto de Química de São Carlos. Universidade de São Paulo.

D'ALMEIDA, M. L. O. (1988). Composição química dos materiais lignocelulósicos. In: CELULOSE E PAPEL, v1. Tecnologia de fabricação da pasta celulósica. São Paulo. SENAI, cap.III, 2ed, p.45- 106.

DIN 68140 (1971). Keilzinkenverbindung Von Holz. Berlim Alemanha. 3p.

DINWOODIE, J. M. (1981). Timber, its nature and behavior. 101p. New York, Van Nostrand Reynold Company Inc.

EUROPEAN COMITTEE FOR STANDARDIZATION. (1995). Finger jointed structural timber CEN-EN 385- Performance requirements and minimum production requirements. Bruxelas. $17 \mathrm{p}$.

FENGEL, D.; WEGENER, G. (1984). Wood: Chemistry, ultraestructure, reactions. Berlin, Walter de Gruyter.

FERREIRA, C.E.M.; CARRASCO, E.V.; HELMEISTER, J.C. (1988). Tecnologia de adesivos poliuretanos propriedades e aplicações em madeira. In: III ENCONTRO BRASILEIRO EM MADEIRAS E EM ESTRUTURAS DE MADEIRA Anais, São Carlos, SP, v.6, p.39-74.

FREITAS, A. R. (1978). Probabilistic approach in the design of wood structures in Brazil based on the variability of 23 species. São Paulo. IPT/ Divisão de Madeiras, IPT- Publicações 1198, 34p. 
GALAZ, V. A. (1979). Manual de Madera Laminada. Departamento Construcciones en Madera. Instituto Forestal, (Manual $\mathrm{n}^{0} 11$ ), 228p. Santiago, Chile.

HOEKSTRA, J.; FRITZIUS, U.W. (1951). Reology of adhesives: in adhesion and adhesives. New York, Elsevier Publishing Company.

HOUWINK, R; SALOMON, G. (1965). Adhesion and adhesives.2ed. New York, Elsevier Publishing Company.

KOCH, G. S.; KLAREICH, F.; EXSTRUM, B. (1987). Adhesives for the composite wood panel industry. New Jersey, Noyes Data Corporation.

KNIGHT, R.A.G. (1952). Adhesives for wood. London, Chapman \& Hall.

KOGA, M.E.T. (1988). Matérias primas fibrosas. In: CELULOSE E PAPEL. v1. Tecnologia de fabricação da pasta celulósica. São Paulo. SENAI cap.I, 2ed, p. 15-44.

KOLLMANN, F.F.P.; KUENZI, E.W.: STAMM, A.J. (1975). Principles of wood science and technology. v.2. New York, Springer-Verlag.

LAURIE, A.C. (1910). Materials of the painters craft. London.

MACÊDO, A.N. (1996). Estudo de emendas dentadas em madeira laminada colada: calibração de método de ensaio. São Carlos. 113p. Dissertação (Mestrado). Escola de Engenharia de São Carlos, Universidade de São Paulo. . (1998). Fadiga em emendas dentadas em madeira laminada colada. São Carlos. 31p. Exame de Qualificação (Doutorado). Escola de Engenharia de São Carlos, Universidade de São Paulo. 
MANTILLA CARRASCO, E.V. (1984). Ligações estruturais de madeira por adesivos. São Carlos. 221p. 2v. Dissertação (Mestrado). Escola de Engenharia de São Carlos. Universidade de São Paulo.

(1989). Resistência, elasticidade e distribuição de tensões nas vigas retas de Madeira Laminada Colada (MLC). São Carlos 348p. Tese (Doutorado). Escola de Engenharia de São Carlos, Universidade de São Paulo.

MINITAB. (1991). Reference manual, pc version. Release 8.0. Rosmont, PA.

MYERS, G. E. (1988). New Technologies and Materials for Bonding Wood Products. Adhesive Age, NY. 6p

NEIVA, G. S.; HELLMEISTER, J. C. (1988). Estudo de resinas sintéticas como adesivos para madeira. São Carlos, Escola de Engenharia de São Carlos, Universidade de São Paulo (Relatórios de Iniciação Científica LaMEM- USP, 2-4 Orientador Prof. Dr. João César Hellmeister.

OLIVEIRA, J.T.; FREITAS, A.R. (1995). Painéis à base de madeira. São Paulo, Boletim Técnico BT/PCC/149, Escola Politécnica da USP. Departamento de Engenharia de Construção Civil, EPUSP.

PANSHIN, A. J.; DE ZEEUW, C. (1980). Textbook of wood technology. 4ed. New York, McGrow-Hill Company.

PARHAM, R. A.; GRAY, R. L. (1984). Formation and Structure of wood. In: THE CHEMISTRY OF SOLID WOOD.. American Chemical Society, Washington DC. p. 3- 56.

PETTERSEN. (1984). The Chemical Composition of Wood. In: THE CHEMISTRY OF SOLID WOOD. American Chemical Society, Washington DC. p. 57- 126. 
PETERSON, R.W. (1964). Wood adhesives. Otawa, Forest Products Research Branch, $\mathrm{n}^{0} 1055$.

PRESTON, R. D.(1964). Structural and mechanical aspects of plant cell wall. In: THE FORMATION OF WOOD IN FOREST TREES. H. M. Zimmermann (Ed.) Academic Press New York.

RANKES, E. (1980). The influence of production conditions on the strength of finger-joints. In: SEMINAR ON THE PRODUCTION MARKETING AND USE OF FINGER-JOINTED SAWNWOOD, Hamar, Norway.

REINHART, F.W.; CALLOMON, I.G. (1959). Survey of adhesion and adhesives. Wade technical report 58-540.

ROCCO LAHR, F. A. (1990). Considerações a respeito da variabilidade de propriedades de resistência e elasticidade da madeira. São Carlos, p. 5-104. Tese ( Livre Docência). Escola de Engenharia de São Carlos, Universidade de São Paulo.

ROWELL, R. M. (1990). Chemical modification of wood- its application to composite wood products. In: PROCEEDINGS OF THE COMPOSITE WOOD PRODUCTS SYMPOSIUM. Rotura, New Zeland. FRI Bulletin n 153, pag. 5767.

SALES, A. (1996). Proposição de classes de resistência para madeira. São Carlos. 223p. Tese ( Doutorado). Escola de Engenharia de São Carlos, Universidade de São Paulo.

SAMLAIC, J. (1983). Os atuais problemas e as possibilidades dos adesivos para madeira. Revista da Madeira $\mathrm{N}^{0} 374$, p.7-10. 
SELBO, M. L. (1975). Adhesives bonding of wood. Was., DC. FPL-FS-USDA, 128p. Technical Bulletin $\mathrm{N}^{0} 1512$. 128p.

SKEIST, I. (1962). Handbook of adhesives. New York, Reinhold Publishing.

SJÖSTRÖM, E. (1981). Wood Chemistry: Fundamentals and Applications. Orlando Flórida, London. Academic Press, inc.

STAMM, A.J. (1964). Wood and cellulose science. New York. The Ronald Press Company.

STRICKLER, M. D. (1967). Impression finger jointing of lumber. Research Report $n^{0} 62 / 15-104$ Institute of Technology, Washington State University.

SUBRAMANIAN. (1984). Chemical of Adhesion. In: THE CHEMISTRY OF SOLID WOOD. American Chemical Society, Washington DC. p. 323- 348.

TOMAZELLO FILHO, M. (1996). Formação e anatomia da madeira. Exercicios práticos. Apostila, 74p. S. Paulo.

TSOUMIS, G. (1991). Science and technology of wood- Structure, properties, utilization. 3ed. New York. Van Nostrand Reinhold.

WATAI, L.T. (1987). Painéis derivados da madeira. São Paulo. Boletim ABPM $\mathrm{n}^{0} 52.17 \mathrm{p}$.

WINANDY, J. E.; ROWELL, R. M. (1984). The Chemistry of Wood Strength. In: THE CHEMISTRY OF SOLID WOOD. American Chemical Society, Washington DC. p. 211- 55. 


\section{BIBLIOGRAFIA COMPLEMENTAR}

BONO, C. T.; MACÊDO, A. N. (1995). Madeira Laminada Colada (MLC) no Brasil: o estado da arte. In: V ENCONTRO BRASILEIRO EM MADEIRAS E EM ESTRUTURAS DE MADEIRAS, Anais, Belo Horizonte MG, v.1, p.587-611.

FOREST PRODUCTS LABORATORY (1974). Wood Handbook. Washington DC. USDA. Handbook $\mathrm{n}^{0} 72.456 \mathrm{p}$.

GILLESPIE, R.H; COUNTRYMAN, D.; BLONQUIST, R. F. (1978). Wood Handbook: adhesives in building construction. Mad., Wis., FS- USDA Agriculture Handbook, $n^{0} 516,165 \mathrm{p}$.

KOLlMANN, F.P.; COTE JR, W. A., (1968). Principles of wood science technology.vol.1, 560p. Solid wood. Germany, Spring- Verlag, Berlin Heildberg.

KOLLMANN, F.P.; KUENZI, W. E.; STAMM, A. J. (1975). Principles of wood science and technology. vol.2, 717p. Wood based materials. New York, SpringVerlag Berlin - Heildelberg. 
KOLLMANN, F.P. (1959). Tecnologia de la madera y sus aplicacciones. Trad. 2 ed. Madri, v. 1 Instituto Forestal de Investigaciones y Experiencias y Servicio de la Madera.

MANO, E. B. (1991). Polímeros como Materiais de Engenharia. S. Paulo, Ed. Edgard Blücher Ltda.

MAYER, J. A. (1984). Wood- Polymer Materials. In: THE CHEMISTRY OF SOLID WOOD. American Chemical Society, Washington DC. p. 257-89.

METTEN, C. J. (1986). Stuctural timber and Technology: Stuctural Adhesives. Great Britain, cap. 5, p. 129- 47.

ROWELL, R. M. (1984). Penetration and Reactivity of Cell Wall Components. In: THE CHEMISTRY OF SOLID WOOD. American Chemical Society, Washington DC. p. 175- 210.

SIAU, J. F. (1971). Flow in wood. Syracuse, NY. Syracuse University Press.

SKAAR, A. J. (1972). Water in wood. Syracuse wood series, Syracuse, NY. Syracuse University Press. 217p.

(1984). Wood- water Relationships. In: THE CHEMISTRY OF SOLID WOOD. American Chemical Society, Washington DC. p. 127- 72.

STAMM, A. J. (1967). Movement of fluids in wood. Part 2: Difusion. Wood Science and Tecnhology NY. p. 205-30.

TIEMANN, H. D. (1951). Wood Tecnhology Constrution, Properties and Uses. 3 ed. London. London Pitman, 396p. 
ZAKARIAN, R. V. (1984). Activation of Wood Surface and Nonconventional Bonding. In: THE CHEMISTRY OF SOLID WOOD. American Chemical Society, Washington DC. p. 349- 400. 